\author{
Mon ograph \\ urn:lsid:zoobank.org:pub:E836E138-D6E2-4F62-B4B3-CE2E073F2B24
}

\title{
A revision of the spider genus Raveniola (Araneae, Nemesiidae). I. Species from Western Asia
}

\author{
Sergei ZONSTEIN ${ }^{1, *}$, Kadir B. KUNT ${ }^{2} \&$ Ersen A. YAĞMUR ${ }^{3}$ \\ ${ }^{1}$ Department of Zoology, Steinhardt Museum of Natural History, \\ Tel-Aviv University, 69978 Tel-Aviv, Israel. \\ ${ }^{2}$ Department of Biology, Faculty of Science, Anadolu University, TR- 26470, Eskişehir, Turkey. \\ ${ }^{3}$ Celal Bayar University, Alaşehir Vocational School, TR-45600, Alaşehir, Manisa, Turkey. \\ ${ }^{*}$ Corresponding author: znn@post.tau.ac.il \\ ${ }^{2}$ Email: chaetopelma@gmail.com \\ ${ }^{3}$ Email: ersen.yagmur@gmail.com \\ ${ }^{1}$ urn:1sid:zoobank.org:author:BD9F97A7-CADB-4DD2-9082-1689952DDF38
${ }^{2}$ urn:1sid:zoobank.org:author:13EEAB4A-F696-41D7-A323-2333410BF5D7
${ }^{3}$ urn:1sid:zoobank.org:author:8DB0B243-5B2F-4428-B457-035A8274500C
}

\section{Table of contents}

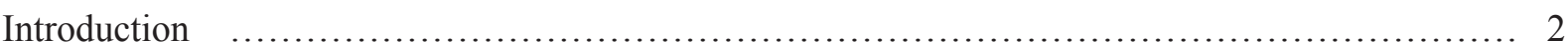

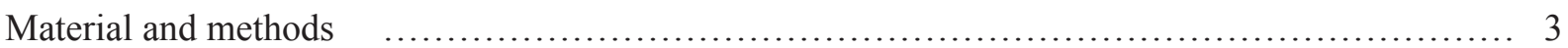

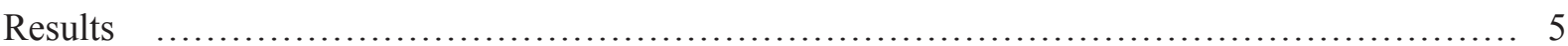

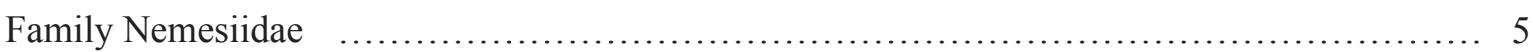

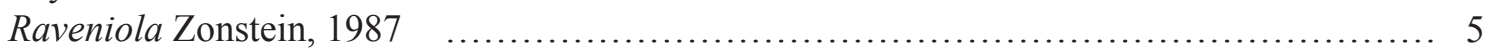

Key to Western Asian species groups of Raveniola $\quad$..................................... 6

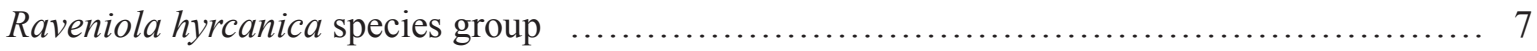

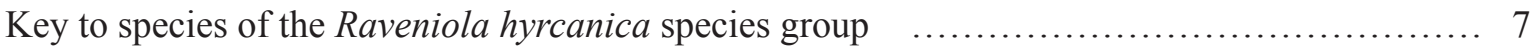

Raveniola adjarica sp. nov. ......................................................... 8

Raveniola dunini sp. nov. ....................................................... 10

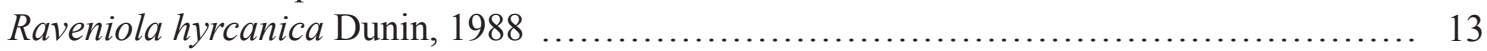

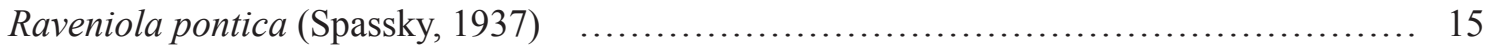

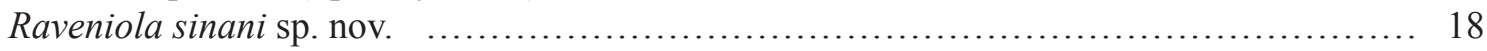

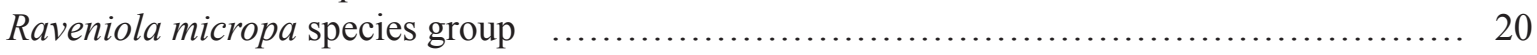

Key to species of the Raveniola micropa species group .................................. 20

Raveniola birecikensis sp. nov. ................................................... 21

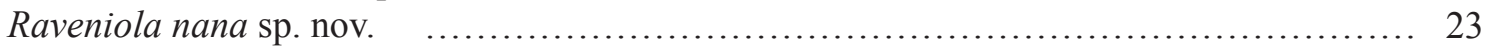

Raveniola anadolu sp. nov. …............................................... 24

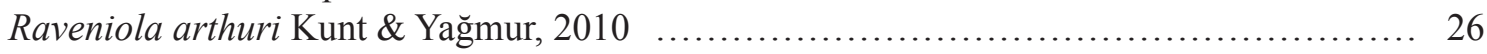

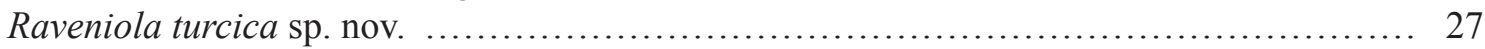

Raveniola micropa (Ausserer, 1871) ................................................. 29

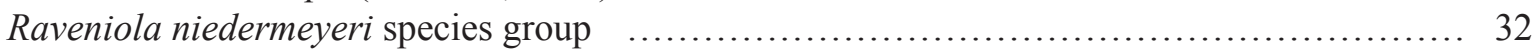


Key to species of the Raveniola niedermeyeri species group .............................. 32

Raveniola mazandaranica Marusik, Zamani \& Mirshamsi, 2014 ......................... 32

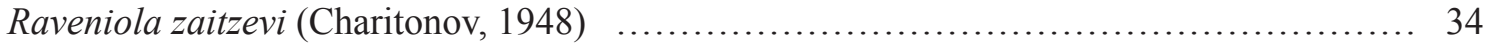

Raveniola marusiki sp. nov. …................................................. 37

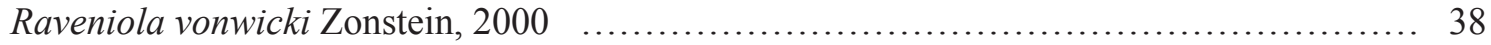

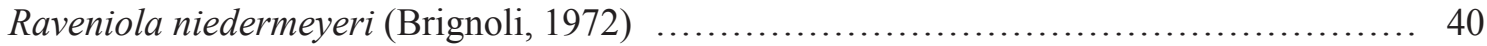

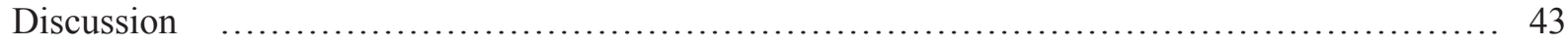

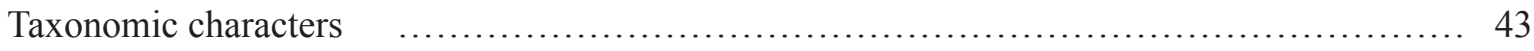

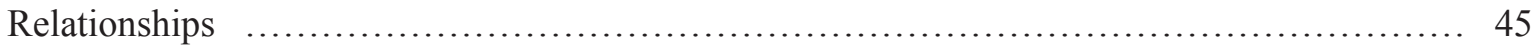

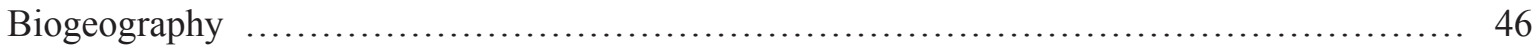

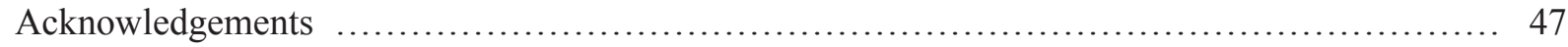

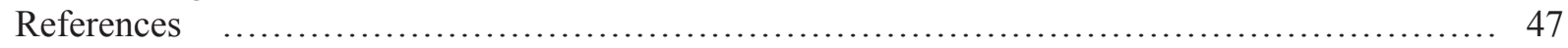

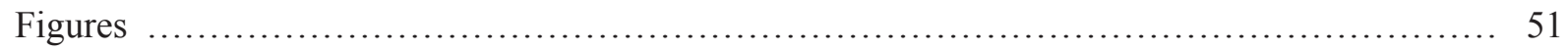

Abstract. The genus Raveniola Zonstein, 1987 is found to be represented in Western Asia by 16 species: $\hat{\jmath} 0$ R . adjarica sp. nov. (Georgia), $\hat{\jmath} R$. anadolu sp. nov. (Turkey), $\hat{O} R$. arthuri Kunt \& Yağmur, 2010 (Turkey), $\widehat{\delta} R$. birecikensis sp. nov. (Turkey), 수 $R$. dunini sp. nov. (Armenia, Azerbaijan,

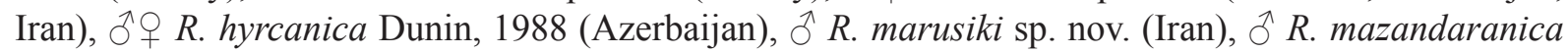
Marusik, Zamani \& Mirshamsi, 2014 (Iran), ôo $R$. micropa (Ausserer, 1871) (Turkey), ㅇ R. nana

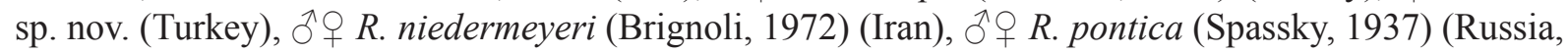

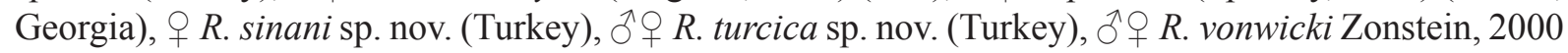
(Iran) and $\widehat{\jmath}+$ P $R$. zaitzevi (Charitonov, 1948) (Azerbaijan, Georgia) $=q$ Brachythele recki Mcheidze, 1983, syn. nov. Eight species are described as new; others are redescribed from types and/or conspecific material. Males of R. micropa and R. zaitzevi, hitherto unknown, are described for the first time. Data on the variability, relationships, distribution and ecology of all considered species are also provided.

Key words. Taxonomy, Mygalomorphae, new species, new records, Palearctic Region.

Zonstein S., Kunt K.B. \& Yağmur E.A. 2018. A revision of the spider genus Raveniola (Araneae, Nemesiidae). I. Species from Western Asia. European Journal of Taxonomy 399: 1-93. https://doi.org/10.5852/ejt.2018.399

\section{Introduction}

The spider family Nemesiidae is represented in Asia by only 52 species. Worldwide about 400 nemesiid species are currently known (World Spider Catalog 2017). It should also be noted that a majority (31) of these Asian nemesiids, as well as three of the seven recognized nemesiid genera (i.e., Raveniola Zonstein, 1987, Sinopesa Raven \& Schwendinger, 1995 and Damarchilus Siliwal, Molur \& Raven, 2015) were described within the last three decades. Many collection samples from Asia contain nemesiid specimens that cannot be assigned to the already known species (see Zonstein \& Marusik 2012). This suggests that most of the Asian regions, suitable for the presence of the Nemesiidae, remain poorly investigated in this respect. This also holds true for the nemesiid fauna of sub-Mediterranean western Asia, which is the topic of this study.

Ausserer (1871) described the first mygalomorph species from the Ponto-Caspian region and placed it in the concurrently described genus Brachythele Ausserer, 1871. Spassky (1937), Charitonov (1948), Brignoli (1972), and Mcheidze (1983) followed him in the taxonomic placement of a few extraMediterranean "diplurids" that they described. All these species were assigned to the same genus, Brachythele. However, the genus, rediagnosed by Raven (1985) as a member of the Nemesiidae, was at the same time delimited and shown to include only a few East-Mediterranean species distributed from the Balkans to Anatolia. 
The Caucasian and Iranian species of Brachythele known at that time were almost simultaneously grouped to form a separate subgroup within the virgata species group (Zonstein 1985). Soon afterwards, these species, together with their close relatives from other Asian regions, were transferred to the new genus Raveniola (Zonstein 1987), which was specially established for them. Four further members of Raveniola occurring within the Caspian region and eastern Anatolia were described later (Dunin 1988; Zonstein 2000; Kunt \& Yağmur 2010; Marusik et al. 2014).

In this study, we examine all available material from the studied region belonging to Raveniola (338 specimens), revealing a total of 16 species. Eight of them are described as new, while males of two other species, hitherto unknown, are described for the first time. The goal of this work is to diagnose and revise the regional congeners, and to study the taxonomy, distribution and relationships of these species. Keys to the species and species groups, as well as data on ecology, are provided.

\section{Material and methods}

\section{Depositories}

Specimens from the following institutions were studied:

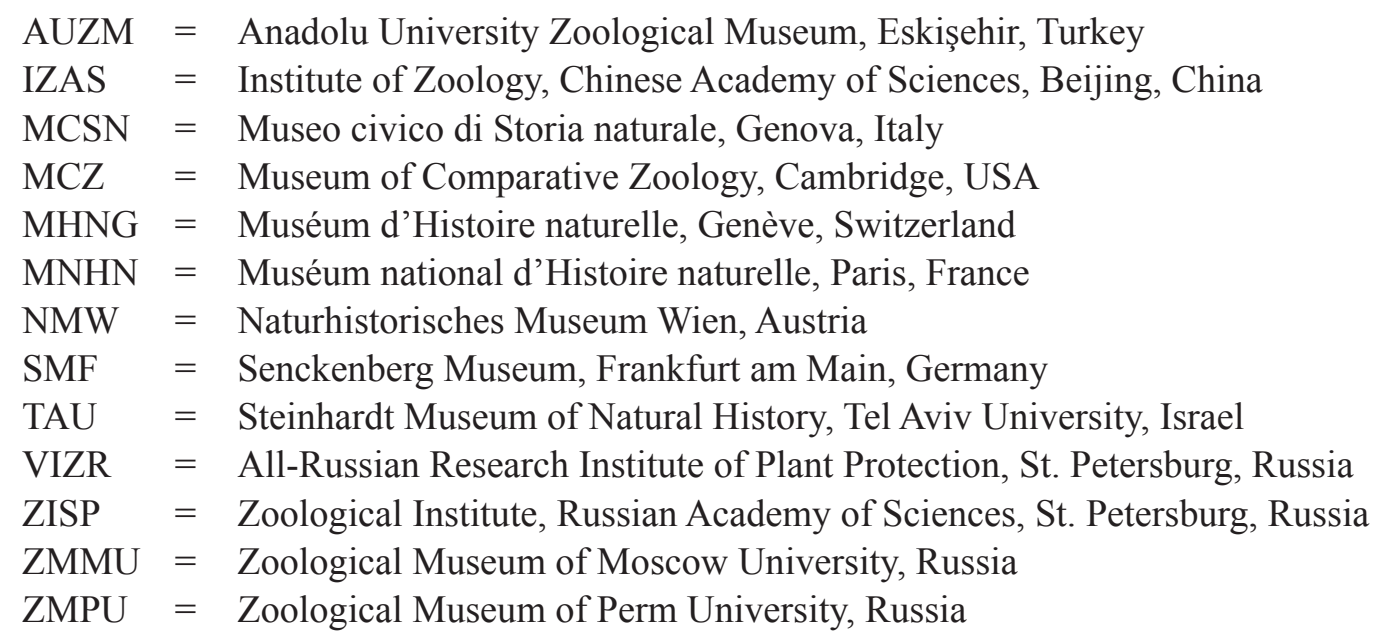

\section{Comparative material examined}

In addition to the Western Asian nemesiids assigned to Raveniola, the following Nemesiidae were examined:

Raveniola Zonstein, 1987 (Central and Eastern Asian congeners): over 30 described and undescribed species (the latter deposited mostly in TAU), including the types of $R$. caudata Zonstein, 2009 (TAU), R. chayi Li \& Zonstein, 2015 (SMF), R. concolor Zonstein, 2000 (MCSN A.R. 17), Brachythele fedotovi Charitonov, 1946 (ZMPU), Brachythele ferghanensis Zonstein, 1984 (ZISP), Sinopesa guangxi Raven \& Schwendinger, 1995 (MCZ), Brachythele kopetdaghensis Fet, 1984 (ZISP), R. montana Zonstein \& Marusik, 2012 (IZAS), Brachythele redikorzevi Spassky, 1937 (ZISP), R. shangrila Zonstein \& Marusik, 2012 (IZAS), R. songi Zonstein \& Marusik, 2012 (IZAS), R. yunnanensis Zonstein \& Marusik, 2012 (IZAS), Brachythele virgata Simon, 1891 (MNHN 6506).

Sinopesa Raven \& Schwendinger, 1995: S. chinensis (Kulczyński, 1901), 1 đ, 1 q (NMW nr. 51) collected from Pingshiang, China; S. kumensis Shimojana \& Haupt, 2000, $\widehat{\jmath}$, holotype and 1 , , paratype (MNHN AR10680); S. maculata Raven \& Schwendinger, 1995, 2 §ิ ô, 2 우우 (MNHG), collected from Chiang Mai, Thailand. 


\section{Structure}

Structure, sectioning and headers follow Schwendinger (2009), Schwendinger \& Zonstein (2011) and Zonstein \& Marusik (2016). To enable better identification, the 16 species are listed according to their similarity, rather than alphabetically. To maintain uniformity in the species descriptions, males are described first, even in cases where the holotypes are females.

\section{Terminology}

Apart from a few exceptions, terminology and descriptive format follow Raven $(1980,1985)$. The term "megaspines", first introduced by Raven (1980), refers to the modified (enlarged and curved) and often movable spines on the anterior tibiae of male mygalomorphs which differ from other spines in their larger size. They are used during copulation to lock females in the mating position. The terms "intercheliceral tumescence" and "preening combs" are explained as follows: the former is a softened pallid area occurring in some male mygalomorphs and confined mostly to the lower basal interface of the chelicerae; the latter is a distal comb of a few stiff ventral bristles set on a common base and located on the metatarsi of some mygalomorphs (see Raven 1984, 1985).

\section{Illustrations}

Photographs were taken using either a digital camera (Canon 350D, Canon 500D) coupled with $100 \mathrm{~mm}$ Canon macro lenses or with a Zeiss Discovery V20 stereo microscope provided with a Canon PowerShot G9 digital camera. Some were then used to prepare the background for line drawings. Scanning electron micrographs (Figs 1-42) were made using a JEOL JSM-5200 scanning microscope at the Zoological Museum, University of Turku, Finland. Photographs and other figures were processed, grouped, and arranged using ${ }^{\circledR}$ Adobe Photoshop SC5. Line drawings were made using ${ }^{\circledR}$ Adobe Illustrator CS5. To draw and reproduce spine and hair images, shading, etc., the corresponding types of art brushes were created on the base of the standard AI imagery.

\section{Measurements}

Measurements were taken with a Leica MZ12 stereo microscope to an accuracy of $0.025 \mathrm{~mm}$ (approximated up to the nearest centesimal) and with a Zeiss Discovery V20 stereo microscope with an accuracy of $0.01 \mathrm{~mm}$. All measurements are given in millimeters. The total body length includes the chelicerae, but not the spinnerets. The sternum length was measured along a straight line between the posterior tip of the sternum and the hindmost part of the labium (if the full length of the sternum is also shown, it then follows within brackets). Lengths of leg and palp segments were measured on the dorsal side, and lengths of spinneret segments on the ventral side, from midpoint of anterior margin to midpoint of posterior margin. The diameter of the AME is usually given as the diameter of a sharply edged AME circle (the "pupil"). When the AME cornea was well-separated and elevated, and its diameter could be measured, the corresponding data follow between brackets. Any eye interdistances counting this parameter are also given between brackets.
Abbreviations
$\mathrm{ALE}=$ anterior lateral eyes
$\mathrm{AME}=$ anterior median eyes
$\mathrm{b}=$ bristle
$\mathrm{CL}=$ carapace length
$\mathrm{CW}=$ carapace width
$\mathrm{LL}=$ labium length
$\mathrm{LW}=$ labium width
$\mathrm{m}=$ megaspine
$\mathrm{p}=$ prolateral 


$$
\begin{aligned}
\mathrm{pd} & =\text { prodorsal } \\
\mathrm{PLE} & =\text { posterior lateral eyes } \\
\mathrm{PLS} & =\text { posterior lateral spinnerets } \\
\mathrm{PME} & =\text { posterior median eyes } \\
\mathrm{PMS} & =\text { posterior median spinnerets } \\
\mathrm{pv} & =\text { proventral } \\
\mathrm{SL} & =\text { sternum length } \\
\mathrm{SW} & =\text { sternum width } \\
\mathrm{r} & =\text { retrolateral } \\
\mathrm{rd} & =\text { retrodorsal } \\
\mathrm{rv} & =\text { retroventral } \\
\mathrm{TBL} & =\text { total body length } \\
\mathrm{v} & =\text { ventral }
\end{aligned}
$$

\section{Results}

Class Arachnida Cuvier, 1812

Order Araneae Clerck, 1757

Family Nemesiidae Simon, 1889

Raveniola Zonstein, 1987

Raveniola Zonstein, 1987: 1014.

Raveniola - Zonstein \& Marusik 2012: 74. — Li \& Zonstein 2015: 3.

\section{Type species}

Brachythele virgata Simon, 1891, by original designation.

\section{Emended diagnosis}

Raveniola and Sinopesa share two (sometimes three) retroventral megaspines located sequentially on tibia I in males (the unique position among male nemesiids) and the paired spermathecae in females, each carrying two individual receptacular heads; within these taxa the PMS are reduced in size (lost entirely in some species) and the maxillary serrula and preening combs are absent. Raveniola is currently known to differ from Sinopesa by a noticeably longer and denser leg scopula (vs a short and rare scopula in Sinopesa), and by a developed leg and carapace setation. The male palpal organ is moderate in size in Raveniola but appears to be enlarged (with respect to the entire male palp) in Sinopesa.

\section{Morphological peculiarities of Western Asian congeners}

HaBitus (Figs 43-58). The studied spiders are mostly small or medium-sized nemesiids with a carapace length of $2-10 \mathrm{~mm}$.

Prosoma. Carapace broad-oval and hirsute, with cephalic part slightly to noticeably higher than thoracic part. Eye tubercle predominantly low in males and females (best developed in Raveniola hyrcanica). Cheliceral mound and rastellum absent (see Fig. 1). In males chelicerae with a small, softened, pale area probably corresponding to a vestigial or poorly-developed intercheliceral male tumescence and located in the well-developed cavity on the ventral cheliceral surface (Figs 59-60). Sternal sigilla medium-sized to small, broad-oval, submarginal (see Figs 62-64). Maxillae with few to numerous maxillary cuspules confined to probasal edge. Serrula absent, but cuticle near the anterior maxillary edge has remnants of scales (Figs 2-3). 
Structures OF LEgs I-IV. Male tibia and metatarsus I as shown in Figs 129-144. Leg scopula varies from dense and moderately long to thin and short; distal on metatarsi I-II, generally entire on tarsus I, mostly divided on tarsus II; females also with entire scopula on palpal tarsus. Tarsal organ low, domed, with weak to sharp concentric ridges (Figs 7-12). Trichobothrial bases corrugiform (Figs 13-18). Female palp with tarsal claw dentate on promargin (Fig. 19). Paired tarsal claws of legs I-IV biserially dentate, unpaired claw always present, moderately small and bare (Figs 20-24).

Male palp. Tibia of moderate to short length, spinose. Cymbium moderately short, with or without spines (Figs 149-160). Male palpal bulb pyriform, inserted submedially. Embolus short to moderately long, tapering or spiraled, with or without keels and ridges (Figs 4, 171-197).

SpermatheCAe. Two wide or narrow spermathecae, each with two receptacles (Figs 198-212).

SPINNERETS. Two pairs of spinnerets (PMS always present). PMS small but with a few fully functional spigots confined to the apex (Figs 25-30). PLS with spigots confined to ventral surface of segments (Figs 33-36) and with apical segment triangular to digitiform (Figs 31-32, 65-67).

\section{Species included}

Raveniola currently comprises 37 species, including the new species described here; 16 of them occur in Western Asia: $R$. adjarica sp. nov., $R$. anadolu sp. nov., $R$. arthuri Kunt \& Yağmur, 2010, R. birecikensis sp. nov., $R$. dunini sp. nov., $R$. hyrcanica Dunin, 1988, $R$. marusiki sp. nov., $R$. mazandaranica Marusik, Zamani \& Mirshamsi, 2014, R. micropa (Ausserer, 1871), R. nana sp. nov., R. niedermeyeri (Brignoli, 1972), R. pontica (Spassky, 1937), R. sinani sp. nov., R. turcica sp. nov., $R$. vonwicki Zonstein, 2000 and R. zaitzevi (Charitonov, 1948).

\section{Species grouping}

To enhance identifications, the species treated here are assigned to three species groups. These assignments are preliminary, because males and females in some species are unknown, and they are not based on a phylogenetic grouping, though some of the groups may indeed reflect phylogenetic relationships. The similarity in external morphology in all females of Western Asian Raveniola necessitates their assignment both throughout the species and the species groups being entirely based on the structure of the spermathecae.

\section{Distribution and ecology}

Within Western Asia, representatives of Raveniola are distributed from the western part of Anatolia (Turkey: Bursa) through the Caucasus mountain region to the Alborz and Khorasan Mts, Iran. All species with known habitats were found in different types of piedmont and mountainous deciduous broad-leaved forests, and at least some of them may inhabit the higher coniferous forest belt ( $R$. adjarica sp. nov.) or even subalpine grasslands ( $R$. pontica); some species (like $R$. dunini sp. nov.) are also found in the open forest biotopes at low altitudes. In most species, females use cavities under rocks to build primitive burrow-like dwellings lacking any silk-lining. However, females of $R$. hyrcanica, unlike other congeners, dig very simple open burrows, also without silk-lining, in the forest floor.

\section{Key to the Western Asian species groups of Raveniola}

\section{Males}

1. Palpal tibia subcylindrical, without bare preapical area, low mound and sensilla (as in Figs 171188)

- Palpal tibia dilated subapically, bearing retrolateral hump and bare retroventral-distal area with low mound and sensilla (as in Figs 189-197) niedermeyeri group 
2. Embolus always keeled; embolic keel laterally directed (Figs 171-179) ........hyrcanica group

- Embolus with or without keel; embolic keel, if present, running parallel to embolus (Figs 180188) micropa group

\section{Females}

1. Bases of spermathecae relatively narrow or moderately wide (Figs 204-212)

- Bases of spermathecae very wide (Figs 198-203) hyrcanica group

2. Bases of spermathecae always moderately wide; median and lateral receptacles subequal in shape and size (Figs 204-207) micropa group

- Bases of spermathecae generally relatively narrow (Figs 210-212); median and lateral receptacles different in shape and size (Figs 208-209) niedermeyeri group

\section{Raveniola hyrcanica group}

\section{Diagnostic characters}

Male palpal tibia short to moderately short and subcylindrical, without subapical sensilla (Figs 149152). Embolus relatively short, more or less twisted, always with well-developed and horizontallyoriented keel (as in Figs 171-179). Spermathecae very wide (Figs 198-203).

\section{Species included}

Raveniola adjarica sp. nov., $R$. dunini sp. nov., $R$. hyrcanica Dunin, 1988, $R$. pontica (Spassky, 1937) and $R$. sinani sp. nov.

\section{Key to species of hyrcanica group}

\section{Males}

Male of Raveniola sinani sp. nov. unknown.

1. Proximal part of embolus short to very short, and more or less flattened; keel arising from basal or median part of embolus (Figs 171-177)

- Proximal part of embolus long, gradually tapering and curved; keel arising from subapical part of embolus (Figs 178-179) R. pontica (Spassky, 1937)

2. Distal part of embolus (following keel) noticeably shorter than preceding part; keel rounded or acute, but not forming paraembolic apophysis (Fig. 171-173, 176-177)

- Distal part of embolus (following keel) considerably longer than preceding part; keel extended into paraembolic apophysis (Figs 174-175) R. dunini sp. nov.

3. Larger body size: CL 7.25-8.57. Distal part of embolus relatively wide; embolic keel acute (Figs 176-177) R. hyrcanica Dunin, 1988

- Smaller body size: CL 5.15-5.38. Distal part of embolus narrower; embolic keel rounded (Figs 171-173) R. adjarica sp. nov.

\section{Females}

1. Bases of spermathecae 2-3 times as wide as long; median receptacles arise only slightly more anterior than laterals (Figs 200-202)

- Bases of spermathecae 1.2-1.6 times as wide as long; median receptacles arise considerably more anterior than laterals (Figs 198-199, 203) 
2. Median and lateral receptacles little more than their diameter apart (Fig. 202)

R. pontica (Spassky, 1937)

- Median and lateral receptacles several diameters apart (Figs 200-201) ...R. hyrcanica Dunin, 1988

3. Median and lateral receptacles arising laterally on spermathecae (Figs 198-199) .............4

- Median and lateral receptacles arising from ventral side of spermatecae (Fig. 203)

.R. sinani sp. nov.

4. Spermathecae asymmetrical; median receptacle heads noticeably longer than laterals (Fig. 198)

R. adjarica sp. nov.

- Spermathecae symmetrical; median and lateral receptacle heads subequal (Fig. 199)

R. dunini sp. nov.

\section{Raveniola adjarica sp. nov. \\ urn:1sid:zoobank.org:act:BCF871CB-E0C5-4A75-B376-EA83C72B04A5}

Figs 43-44, 84, 102, 117, 129, 149, 171-173, 198, 219

Brachythele pontica Spassky, 1937: 368 (, part; misidentified).

\section{Diagnosis}

Different from other species in the same group by having a relatively short embolus with a rounded submedian keel (Figs 171-173; cf. Figs 174-179) and long, asymmetrical spermathecae with median receptacles being considerably longer than laterals (Fig. 198, cf. Figs 199-203).

\section{Etymology}

The specific epithet, a Latinized adjective, is derived from Adjaria (also Adjara or Adzharia), the historical region and administrative province of Georgia where the species was found.

\section{Material examined}

\section{Holotype}

GEORGIA: ${ }^{\top}$, South slope of Meskheti Mts, Kintrishi Valley, $3 \mathrm{~km} \mathrm{NE}$ of Khino, $900-950 \mathrm{~m}, 41^{\circ} 43.8^{\prime} \mathrm{N}$, $42^{\circ} 03.5^{\prime}$ E, 7 Sep. 1989, S.L. Zonstein leg. (TAU).

\section{Paratypes $(1 \hat{O}, 3$ 우 $)$}

GEORGIA: 2 우, same collection data as for holotype, but 7-8 Sep. 1989 (TAU); 1 ô, 1 q, Kintrishi Valley, $0.5 \mathrm{~km}$ W of Zerabozeli, $450 \mathrm{~m}, 41^{\circ} 44.0^{\prime} \mathrm{N}, 41^{\circ} 59.2^{\prime} \mathrm{E}, 15$ Sep. 1989, S.L. Zonstein leg. (TAU).

Additional material ( $2+q, 1$ juv.)

GEORGIA: 1 , , Batumi, 1909, S.A. Spassky leg. (ZISP, paralectotype of Brachythele pontica); 1 , same locality, no other collecting data (MNHN 10338); 1 juv., surroundings of Batumi, Mt Feria, $250 \mathrm{~m}$, 9 Feb. 1982, D.V. Logunov leg. (TAU).

\section{Description}

Male (holotype)

Habitus. See Fig. 43.

Measurements. TBL 13.10, CL 5.43, CW 4.88, LL 0.47, LW 1.03, SL 2.52, SW 2.38.

CoLour. Carapace brownish rufous with slightly lighter yellowish rufous pattern covering foveal area and protruding into few weak radial rays on darker background; eye tubercle with central and two 
symmetrical lateral brownish black spots surrounding AMEs and lateral eyes respectively; chelicerae and first pair of legs reddish brown; palps and legs II-IV brownish rufous; sternum, labium and maxillae light yellowish rufous; abdomen dorsally light greyish brown, with weak and darker brownish pattern represented by median lanceolate patch fused and crossed with few transverse fasciae; spinnerets and ventral surface of abdomen light yellowish grey.

Prosoma. Carapace and chelicerae as shown in Fig. 66. Clypeus and eye group as in Fig. 102. Eye diameters and interdistances: AME 0.15(0.20), ALE 0.23, PLE 0.15, PME 0.13, AME-AME 0.11(0.06), ALE-AME 0.10(0.08), ALE-PLE 0.08, PLE-PME 0.04, PME-PME 0.40. Each cheliceral furrow with 10 promarginal teeth and 5 mesobasal denticles. Maxillae with 7-8 cuspules each.

Legs. Tibia and metatarsus I as in Fig. 129. Scopula: in distal 1/3 of metatarsi I-II, entire on tarsi III, vestigial and widely divided by setae on tarsus III, absent on tarsus IV. Trichobothria: 2 rows of 9-11 per row on tibiae, 10-15 on metatarsi, 10-12 on tarsi, 9 on cymbium. Paired claws of tarsi I-II: outer and inner margins with 7-8 teeth each; claws of tarsi III-IV: outer and inner margins with 8-10 teeth each.

SPination. Palp: femur d1-1-1-1(2), pd1, rd1; patella p1; tibia d1, p1-1-1, r1-1, v2-2-2; tarsus d4. Leg I: femur d1-1-1-1, pd1-1-1, rd1; tibia p1-1(0), pv1-1, rv1-1-m-m; metatarsus v0-0-3. Leg II: femur d1-1-1-1, pd1-1-1; patella p1; tibia p1-1-1, v2-2-3; metatarsus p1, v1-2-3. Leg III: femur d1-1-1-1, pd1-1(0)-1, rd1-1(0) -1; patella p1, r1; tibia d1-1, p1-1, r1-1-1, v2-2-3; metatarsus d1-1, p1-1-1, r1-1-1, v2-3-3. Leg IV: femur d1-1-1-1-1(0), pd1, rd1(0)-1; patella r1; tibia d1-1, p1-1, r1-1, v22-3; metatarsus d1-1, p1-1-1-1, r1-1(0)-2-1-2, v1-2-2-1-3-3. Patella I and tarsi I-IV (except right tarsus III carrying 1 retrolateral spine) aspinose.

PaLP. Tibia, cymbium and palpal organ as shown in Fig. 149. Wide and flattened basal part of embolus provided with subapical keel extends into twisted and narrow apical part of embolus (Figs 171-173).

SPINNERETS. PMS: length 0.75; diameter 0.28. PLS: maximal diameter 0.65; length of basal, medial and apical segments 1.22, 0.85, 1.23; total length 3.30; apical segment digitiform.

LEG MEASUREMENTS. $\hat{\jmath}($ ( $)$.

\begin{tabular}{lcccccc}
\hline & Femur & Patella & Tibia & Metatarsus & Tarsus & Total \\
\hline Palp & $2.95(3.07)$ & $1.67(1.95)$ & $2.35(2.20)$ & - & $1.02(2.12)$ & $7.99(9.34)$ \\
Leg I & $4.55(4.07)$ & $2.60(2.57)$ & $3.57(2.95)$ & $3.28(2.43)$ & $2.01(2.12)$ & $16.01(13.77)$ \\
Leg II & $4.02(3.55)$ & $2.25(2.23)$ & $3.03(2.72)$ & $2.85(2.40)$ & $1.78(1.73)$ & $14.23(12.63)$ \\
Leg III & $3.17(3.03)$ & $1.72(1.90)$ & $2.46(2.17)$ & $3.22(2.75)$ & $1.79(1.73)$ & $12.36(11.58)$ \\
Leg IV & $4.47(4.10)$ & $2.20(2.25)$ & $3.43(3.23)$ & $4.15(3.88)$ & $2.02(2.07)$ & $16.27(15.53)$ \\
\hline
\end{tabular}

Female (paratype, from Khino)

Habitus. See Fig. 44.

Measurements. TBL 15.90, CL 6.17, CW 4.48, LL 0.62, LW 1.33, SL 2.85, SW 2.60.

CoLour. As in male, but with lighter, quite indistinct radial pattern on carapace and with lighter (yellowish rufous) clypeus.

Prosoma. Carapace and chelicerae as shown in Fig. 84. Clypeus and eye group as in Fig. 117. Eye diameters and interdistances: AME 0.14(0.19), ALE 0.22, PLE 0.13, PME 0.13, AME-AME 0.14(0.08), 
ALE-AME 0.15(0.12), ALE-PLE 0.07, PLE-PME 0.07, PME-PME 0.51. Each cheliceral furrow with 10 promarginal teeth and 4-5 mesobasal denticles. Maxillae with 5-7 cuspules each.

LEGS. Scopula: distal on metatarsi I-II, entire on tarsus I and on palpal tarsus, narrowly divided by setae on tarsus II, elsewhere absent. Trichobothria: 2 rows of 11-14 each on tibiae, 11-14 on metatarsi, 10-12 on tarsi, 8 on palpal tarsus. Paired claws: outer and inner margins with $6-8$ teeth each, palpal claw with 4 teeth on promargin.

Spination. Palp: femur d1 $+2 b$, pd1; tibia v2 $-2-3$; tarsus v2-2-3. Leg I: femur d1+3b, pd1; tibia v2$2-2$; metatarsus v2 $-2-3$. Leg II: femur d1 +3 b, pd1; tibia p1-1, v2-2-3; metatarsus p1, v2-2-3. Leg III: femur d1+3(4)b, pd2b, rd1-1; patella r1; tibia p1-1, r1-1, v2-2-3; metatarsus p1-1, r1-1, v2-2-3. Leg IV: femur d1+3b, pd2b, rd1; patella r1; tibia p1-1, r1-1, v2-2-3; metatarsus p1(0)-1-1, r1-1-1, v2-1(0)-2-3. Patellae I-II, and palpal patella aspinose.

Spermathecae. Broad and asymmetrical, with widely spaced receptacles (Fig. 198).

SPINNERETS. PMS: length 0.36; diameter 0.26. PLS: maximal diameter 0.55; length of basal, medial and apical segments $0.70,0.37,0.65$; total length 1.72 ; apical segment shortly digitiform.

\section{Variation}

Carapace length in males varies from 5.15 to 5.38 , in females from 4.55 to 6.20 . No variation in the structure of the male palpal organ has been observed. Female vulvas look surprisingly uniform and similar to the described type, even that in the conspecific female MNHN 10338 from Batumi, the known locality that is farthest from the type locality.

\section{Ecology}

The spiders collected from the Kintrishi area were found hiding in soil cavities under stones in chestnut and spruce mountain forests dominated by Castanea sativa Mill. and Picea orientalis L. (Link.), respectively.

\section{Distribution}

Known from the western part of the Caucasus Minor (Georgia: Adzharia). See Fig. 219.

Raveniola dunini sp. nov. urn:1sid:zoobank.org:act:91C857A7-FBD3-4676-8F5C-5C7795232F57

Figs $45,69,85,103,118,130,150,174-175,199,220,222$

\section{Diagnosis}

Different from other members of the same group by having an embolus with its flagelliform apical part arising laterally from the basal part, carrying a short acute keel forming a paraembolic apophysis (Figs 174-175; cf. Figs 171-173, 176-179), and by possessing high-arched spermathecae with median and lateral receptacles, subequal in size and located close to each other (Fig. 199; cf. Figs 198, 200-203).

\section{Etymology}

The specific epithet is given in honour of Dr. Pyotr Dunin (1952-1998), a prominent Soviet and Russian arachnologist, for his immense contribution to the study of the Caucasian spider fauna. 


\section{Material examined}

Holotype

AZERBAIJAN: $\delta^{\lambda}$, foothills of Karabakh Mts, hills alongside right (south) bank of Kendelanchai River, 1 km WSW of Kadzhar (Qacar), 39³8.6' N, 4702.2' E, 650 m, 13 Sep. 1987, S.L. Zonstein leg. (TAU).

Paratypes $(1 \circlearrowleft, 5$ 우)

AZERBAIJAN: $1 \hat{\jmath}, 1$, same collection data as for holotype (TAU); 4 $q+$, from same locality but collected 11 Aug. 1986, P.M. Dunin leg. (ZMMU, TAU).

Additional material ( 2 + $\circ, 2$ juvs)

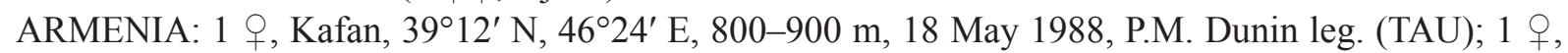
Kafan Distr., Shikahoh, 3906' N, 46² $28^{\prime}$ E, 1000-1200 m, 19 May 1988, P.M. Dunin leg. (TAU); 1 juv., Megri, 3854' N, 46²14' E, 700-800 m, 20 May 1988, P.M. Dunin leg. (TAU).

IRAN: 1 juv., East Azerbaijan Province, Arasbaran Reserve, Makīdī Valley, 1650-1800 m, 4-5 Jun. 1978, J. Martens and H. Pieper leg. (SMF).

\section{Description}

Male (holotype)

Habitus. See Fig. 45.

Measurements. TBL 13.20, CL 5.38, CW 4.67, LL 0.42, LW 1.05, SL 2.68, SW 2.43.

Colour. Carapace, palps and legs dorsally light reddish brown; eye tubercle with darker spots surrounding AMEs and lateral eyes; chelicerae cherry-red; sternum, labium, maxillae, palps and legs ventrally light brown; abdomen dorsally light brown, with darker brown dorsal pattern represented by weak and narrow median lanceolate spot and four pairs of inclined chevron-like fasciae located posteriorly, ventral abdominal surface and spinnerets pale yellowish grey.

Prosoma. Carapace and chelicerae as shown in Fig. 69. Clypeus and eye group as in Fig. 103. Eye diameters and interdistances: AME 0.14(0.17), ALE 0.18, PLE 0.13, PME: 0.10, AME-AME 0.12(0.09), ALE-AME 0.07(0.06), ALE-PLE 0.06, PLE-PME 0.03, PME-PME 0.38. Each cheliceral furrow with 9-11 promarginal teeth and 6-7 mesobasal denticles. Maxillae with 5-6 relatively long cuspules each.

Legs. Tibia and metatarsus I as shown in Fig. 130. Scopula: distal on metatarsi I-II, entire on tarsi III; few scopuliform hairs mixed with bristles on tarsi III-IV. Trichobothria: 2 rows of 9-11 each on tibiae, $11-13$ on metatarsi, 11-14 on tarsi, 9 on cymbium. Paired claws: inner margin with $6-8$ teeth; $7-8$ teeth on outer margin.

Spination. Palp: femur d1-1-1(0), pd1, rd1; tibia d1-1, p1-1-1(0), pv1-1-1, r1, v1-1; cymbium d4(5). Leg I: femur d1-1-1(0)-1(0), pd1-1; tibia p1-1, v2(3)-2(1)-2(1). Leg II: femur d1-1-1(0)-1(0), pd11; tibia p1-1-1, v1-2-1-3; metatarsus p1, v1-2-2. Leg III: femur d1-1-1(0)-1(0), pd1-1-1, rd1-1; patella p1, r1; tibia d1, p1-1-1, r1-1-1, v2-2-2; metatarsus pd1, rd1-1, p1-1-1, r1-1-1, v2-2-3. Leg IV: femur d1-1-1-1(0)-1(0), pd1, rd1; patella $\mathrm{p} 1(0)$, r1; tibia d1, p1-1, r1-1-1, v2-2-2; metatarsus pd1-1, rd1, p1-1-1, r1-1, v2-1(2)-3. Metatarsus I and patellae I-II aspinose.

PaLP. Tibia, cymbium and palpal organ as shown in Fig. 150. Palpal organ provided with moderately short sideward-arising lamellose embolus with keel forming short paraembolic apophysis (Figs 174175). 
SPINNERETS. PMS: length 0.47; diameter 0.20. PLS: maximal diameter 0.45; length of basal, medial and apical segments $0.93,0.70,0.82$; total length 2.45 ; apical segment shortly digitiform.

LEG MEASUREMENTS. $\widehat{\jmath}(+9)$.

\begin{tabular}{lcccccc}
\hline & Femur & Patella & Tibia & Metatarsus & Tarsus & Total \\
\hline Palp & $2.83(2.78)$ & $1.63(1.73)$ & $2.17(1.88)$ & - & $1.03(1.70)$ & $7.66(8.09)$ \\
Leg I & $4.37(3.65)$ & $2.65(2.40)$ & $3.53(2.77)$ & $3.55(2.10)$ & $2.03(1.58)$ & $16.13(12.50)$ \\
Leg II & $3.97(3.32)$ & $2.33(2.13)$ & $2.97(2.30)$ & $3.13(2.02)$ & $1.93(1.55)$ & $14.33(11.32)$ \\
Leg III & $3.20(2.93)$ & $1.77(1.83)$ & $2.47(1.85)$ & $3.25(2.75)$ & $1.93(1.62)$ & $12.62(10.61)$ \\
Leg IV & $4.35(3.80)$ & $2.17(2.25)$ & $3.45(2.82)$ & $4.37(3.55)$ & $2.27(1.87)$ & $16.61(14.29)$ \\
\hline
\end{tabular}

Female (paratype)

Measurements. TBL 13.65, CL 4.67, CW 4.50, LL 0.37, LW 0.97, SL 2.65, SW 2.33.

Colour. As in male.

Prosoma. Carapace and chelicerae as shown in Fig. 85. Clypeus and eye group as in Fig. 118. Eye diameters and interdistances: AME 0.09(0.11), ALE 0.21, PLE 0.12, PME 0.10, AME-AME 0.18(0.16), ALE-AME 0.09(0.08), ALE-PLE 0.06, PLE-PME 0.04, PME-PME 0.39. Each cheliceral furrow with 10 promarginal teeth and 6-7 mesobasal denticles. Maxillae each with 5-7 relatively long cuspules.

LEGS. Scopula: distal on metatarsi I-II, entire on tarsi I-II and palpal tarsus, widely divided on tarsus III, elsewhere absent. Trichobothria: 2 rows of 8-9 each on tibiae, 10-12 on metatarsi, 11-13 on tarsi, 9 on palpal tarsus. Paired tarsal claws: outer and inner margins with 5-6 teeth, palpal claw with 4 teeth on inner margin.

SpinAtion. Femora I-IV with one basodorsal spine and 3 dorsal bristles alongside midline; femur III also with two prodorsal and retrodorsal rows of 2-3 bristles each; femur IV without prodorsal bristle row; palpal patella and patellae I-II aspinose. Palp: femur pd1; tibia v2-2-3; tarsus d8(9). Leg I: femur d1, pd1; tibia v1-1-1(0)-2(3); metatarsus v2-2-2. Leg II: femur d1, pd1; tibia p1-1, v1-1-2(3); metatarsus v2-2-2. Leg III: femur d1, rd1; patella p1, r1; tibia d1, p1-1, r1-1-1, v2-2-3; metatarsus pd1-1, p1-1, r1-1, v2-2-3. Leg IV: femur d1, rd1; patella r1; tibia d1, p1-1, r1-1, v2-2-2; metatarsus d1, p1-1-1-1, r1-1-1-1, v2-2-2.

Spermathecae. Broad, large and symmetrical, with receptacles close to each other (Fig. 199).

SPINNERETS. PMS: length 0.50; diameter 0.22. PLS: maximal diameter 0.52; length of basal, medial and apical segments $0.90,0.64,0.73$; total length 2.27 ; apical segment shortly digitiform.

\section{Variation}

Carapace length in males varies from 5.15 to 5.38 , in females from 4.55 to 5.20 . The copulative organs of both sexes do not show any significant variation.

\section{Ecology}

The type series was collected in a low open oak forest (Quercus sp. mixed with Crataegus sp.); all spiders were found under stones. 


\section{Distribution}

Eastern part of the Caucasus Minor (eastern Armenia, south-western Azerbaijan, far north-western Iran). See Figs 220 and 222.

Raveniola hyrcanica Dunin, 1988

Figs 6-9, 13-14, 21-22, 25, 29-30, 33, 35, 46-47, 62, 65, 70, 86, $104,119,131,151,176-177,200-201,220$

Raveniola hyrcanica Dunin, 1988: 1245, figs 1-7 (ぷํ).

Raveniola hyrcanica - Platnick 1993: 95. — Mikhailov 1997: 20.

\section{Diagnosis}

Different from other members of the same group by having a shorter embolus with a sharp embolic keel (Figs 176-177; cf. Figs 171-175, 178-179) and by possessing very wide and moderately long spermathecae with median and lateral receptacles spaced apart (Figs 200-201; cf. Figs 198-199, 202203).

\section{Material examined}

\section{Holotype}

AZERBAIJAN: $\widehat{\jmath}$, Talysh Mts, foothills $1 \mathrm{~km} \mathrm{SW}$ of Haftoni (also spelled as Gaftoni), $38^{\circ} 45.2^{\prime} \mathrm{N}$, 48²45.1' E, 300 m, 5 May 1985, P.M. Dunin leg. (ZISP).

\section{Paratypes $(3 \hat{\jmath}, 11$ 우 $)$}

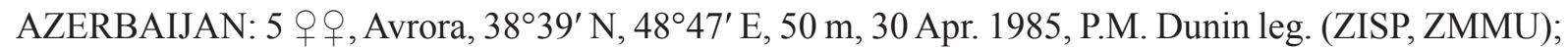

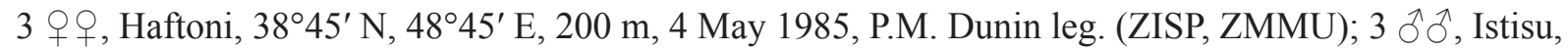
$38^{\circ} 27^{\prime} \mathrm{N}, 48^{\circ} 40^{\prime}$ E, $300 \mathrm{~m}, 7$ May 1985, P.M. Dunin leg. (ZMMU, ZISP, TAU); 1 ㅇ, Osakuca, $38^{\circ} 45^{\prime} \mathrm{N}$,

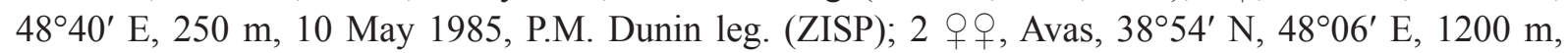
12 Jul. 1985, P.M. Dunin leg. (ZISP).

Additional material $(3 \hat{\jmath}, 6 \circ \rho, 2$ juvs)

AZERBAIJAN: 1 , , Alekseevka (environs of Avrora), 3 May 1936, A.V. Bogachev leg. (ZISP); 1 juv.,

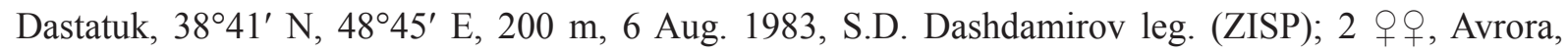
50-300 m, Jan. 1983, A.V. Tanasevich leg. (ZMMU); same locality but 3 Jul. 1983, 1 , , D.V. Logunov leg. (ZMMU); 2 우, same locality but 21 Sep. 1987, S.L. Zonstein leg. (TAU); 1 juv., Apo, 38 38' N,

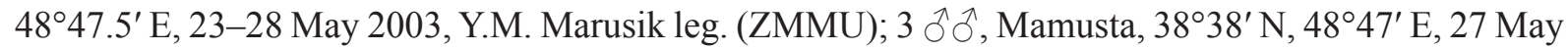
2003, Y.M. Marusik leg. (TAU).

\section{Redescription}

Male (holotype)

Habitus. See Fig. 46.

Measurements. TBL 21.90, CL 8.33, CW 7.70, LL 0.70, LW 1.87, SL 4.03, SW 3.85.

Colour. Carapace reddish chestnut with dense brownish black pilosity, eye tubercle not darkened but with partially fused blackish brown spots bordering eyes; chelicerae, almost whole leg I (except lighter tarsus), femora of palps and legs II-IV dorsally dark reddish chestnut; other parts of legs dorsally with lighter reddish chestnut coloration; sternum, labium, maxillae, palps and legs ventrally light brownish 
orange; abdomen dorsally light chestnut, with numerous, small lighter brownish spots, ventral abdominal surface and spinnerets light yellowish brown.

Prosoma. Carapace and chelicerae as shown in Fig. 70. Clypeus and eye group as in Fig. 104. Eye diameters and interdistances: AME 0.22(0.29), ALE 0.28, PLE 0.22, PME 0.16, AME-AME 0.17(0.10), ALE-AME 0.15(0.11), ALE-PLE 0.20, PLE-PME 0.10, PME-PME 0.56. Chelicerae: each furrow with 10-11 promarginal teeth and 0-1 mesobasal denticles. Maxillae with 8 large cuspules each. Sternal sigilla oval and submarginal, as shown in Fig. 62.

LEgs. Tibia and metatarsus I as shown in Fig. 131. Scopula (dense, scopuliform hairs moderately long): distal on metatarsi I-II, entire on tarsi I-II; absent on tarsi III-IV. Trichobothria: 2 rows of 9-12 each on tibiae, 13-18 on metatarsi, 15-19 on tarsi, 10 on cymbium. Paired tarsal claws: inner and outer margins with $7-8$ teeth each.

Spination. Palp: femur d0-1-1, pd1; tibia d1-1, p1-1-1, r1, pv1-1-1, v1-1; tarsus d4. Leg I: femur d1-1-0-0, pd1-1; tibia p1-1, v2-1-m-m. Leg II: femur d1-1-0-0, pd1-1; patella p1; tibia p1-1(0)-1, v1(2)-2(1)-3; metatarsus v2-2(1)-2. Leg III: femur d1-1-0-0, pd1; patella p1(0)-1, r1; tibia d1-1, p1-1, r1-1, v2-2-3; metatarsus d1-1, p1-1, r1-1-1-1, v2-2(3)-3. Leg IV: femur d0-1(0)-1(0)-0, pd1, rd1; patella p1, r1; tibia d1, p1-1-1, r1-1-1-1, v2-2-3; metatarsus d1-1, p1-1-1-1, r1-1-1-1-1, v22-1(2)-3. Metatarsus I and patella I aspinose.

PalP. Tibia, cymbium and palpal organ as shown in Fig. 151. Palpal organ with unusually short embolus, carrying a sharp keel (Figs 176, 177).

SPINNERETS. PMS: length 0.63; diameter 0.35. PLS: maximal diameter 0.70; length of basal, medial and apical segments 1.10, 0.77, 1.02; total length 2.89; apical segment shortly digitiform (Fig. 65).

LEG MEASUREMENTS. ${ }^{\lambda}(+)$.

\begin{tabular}{lcccccc}
\hline & Femur & Patella & Tibia & Metatarsus & Tarsus & Total \\
\hline Palp & $4.17(4.93)$ & $2.65(3.20)$ & $2.97(3.25)$ & - & $1.67(2.87)$ & $11.46(14.25)$ \\
Leg I & $6.23(6.70)$ & $4.37(4.75)$ & $5.05(5.07)$ & $5.27(4.15)$ & $2.95(2.67)$ & $23.87(23.34)$ \\
Leg II & $5.77(5.97)$ & $3.55(4.03)$ & $4.23(4.20)$ & $4.50(3.87)$ & $2.77(2.60)$ & $20.82(20.67)$ \\
Leg III & $5.10(5.03)$ & $3.03(3.35)$ & $3.35(3.50)$ & $4.67(4.35)$ & $2.65(2.53)$ & $19.00(18.76)$ \\
Leg IV & $6.47(7.05)$ & $3.83(3.67)$ & $4.93(5.03)$ & $6.25(6.30)$ & $2.97(2.73)$ & $24.45(24.78)$ \\
\hline
\end{tabular}

Female (paratype, from Haftoni)

Habitus. See Fig. 47.

MeAsurements. TBL 28.50, CL 9.57, CW 8.53, LL 1.10, LW 1.88, SL 4.70, SW 4.37.

CoLour. As in male, but legs I-IV dorsally uniformly reddish-chestnut.

Prosoma. Carapace and chelicerae as shown in Fig. 86, cephalic part noticeably elevated over thoracic part. Clypeus and eye group as in Fig. 119. Eye diameters and interdistances: AME 0.20(0.28), ALE 0.32, PLE 0.25, PME 0.16, AME-AME 0.22(0.15), ALE-AME 0.23(0.19), ALE-PLE 0.22, PLE-PME 0.08, PME-PME 0.71. Each cheliceral furrow with 10 promarginal teeth and 3-5 mesobasal denticles. Maxillae trapezoidal, each with 7-8 cuspules. 
LEgs. Scopula: dense, scopuliform hairs moderately long. Trichobothria: 2 rows of 10-12 each on tibiae, 12-17 on metatarsi, 13-16 on tarsi, 11 on palpal tarsus. Paired tarsal claws: outer margin with 5-6 teeth, inner one with 4-5 teeth. Palpal claw with 4 promarginal teeth.

SPINATION. Femora I-II with one basodorsal spine and 2-3 dorsal bristles; patellae I-II and palpal patella aspinose. Palp: femur d1, pd1(0); tibia v2-2-2(3); tarsus d7(8). Leg I: femur d1, pd1; tibia v2-1-22(3); metatarsus v2-2-2(3). Leg II: femur d1; pd1; tibia p1(0)-1, v2-2-3; metatarsus v2-2-2(3). Leg III: femur d1(0)-1, pd1, rd1(0)-1; patella p1, r1; tibia p1-1, r1-1, v2-2-3; metatarsus p1-1-1, r1-1-1, v2-1(0)-2-3. Leg IV: femur d1-1-1(0)-1(0), pd1, rd1; patella r1; tibia p1-1, r1-1, v2-2-3; metatarsus p1-1-1-1, r1-1-1-1, v2-2-1-2-2.

SPERMATHECAe. Low and broad, with very widely spaced receptacles (Fig. 201).

SPINNERETS. PMS: length 0.75 ; diameter 0.55. PLS: maximal diameter 0.78 ; length of basal, medial and apical segments $1.05,0.60,0.83$; total length 2.48 ; apical segment shortly digitiform.

\section{Variation}

Carapace length in males varies from 7.25 to 8.57 , in females from 6.88 to 10.13 . In some females, the dorsal abdominal pattern is almost indistinct. Spermathecae show a quite insignificant variation (cf. Figs 200-201).

\section{Ecology}

The species inhabits dense broad-leaved piedmont and montane forests dominated by Parrotia persica (DC.) C.A. Mey and Quercus castaneifolia C.A. Mey (see Figs 228-229). Unlike other congeners, the representatives of this species do not exclusively use natural hideouts but build simple open burrows in the forest floor. Burrow length reaches $30-35 \mathrm{~cm}$, with diameter varying from 2.5 to $3.0 \mathrm{~cm}$. It comprises a fairly straight vertical hole which then curves and ends in an expanded sub-horizontal dwelling chamber; no silk-lining was found (Dunin 1988 and our own observations).

\section{Distribution}

South Azerbaijan: Talysh Mts (the northwestern continuation of Alborz). See Fig. 220.

Raveniola pontica (Spassky, 1937)

Figs 3-5, 10, 15, 26, 48-49, 59-60, 71, 87, 105, 120, 132, 152, 178-179, 202, 219

Brachythele pontica Spassky, 1937: 368 (†).

Brachythele pontica - Spassky \& Minenkova 1940: 140. — Roewer 1942: 196. — Bonnet 1955: 912. — Zonstein 1985: 159.

Raveniola pontica - Zonstein 1987: 1015 - Platnick 1989: 90. — Mikhailov 1997: 20. — Ponomarev \& Chumachenko 2007: 157. — Ponomarev \& Mikhailov 2007: 130. — Kovblyuk \& Ponomarev 2008: 151, figs 36-40 (ð). — Ponomarev 2009: 144. — Kovblyuk et al. 2011: 37. — Ponomarev et al. 2012: 470.

\section{Diagnosis}

This species differs from other members of the same group by having a longer embolus with a rounded subapical keel (Figs 178-179; cf. Figs 171-177) and by possessing long and moderately wide spermathecae, with median and lateral receptacles located close to each other (Fig. 202; cf. Figs 198201, 203). 


\section{Material examined}

Lectotype (designated by Zonstein 1985: 159)

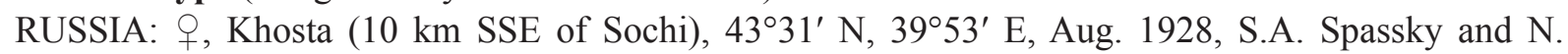
Spasskaya leg. (ZISP).

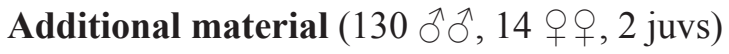

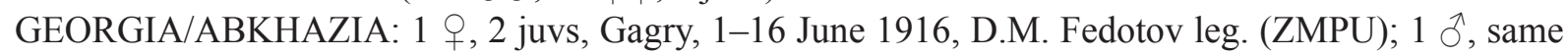

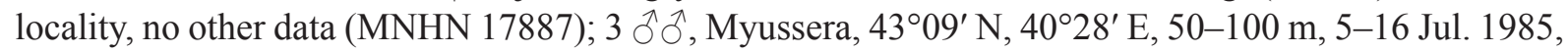

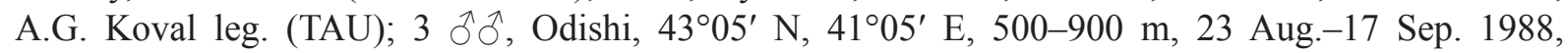

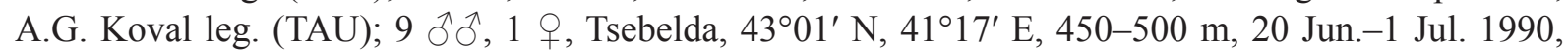
A.G. Koval leg. (TAU).

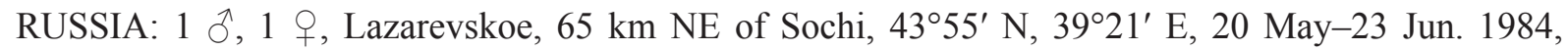
A.G. Koval leg. (TAU); $5 \widehat{\partial} \widehat{\partial}$, same collection data as preceding, 10 Aug. -6 Sep. 1984 (TAU); $6 \widehat{\delta} \widehat{\partial}$, 4 우, same collection data as preceding, 20 May-5 Jun. 1990, A.G. Koval leg. (TAU); 26 §ิ $\widehat{\delta}, 3$

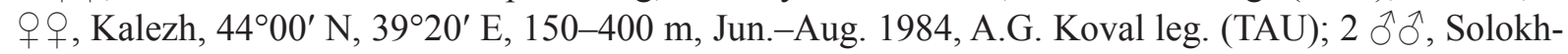

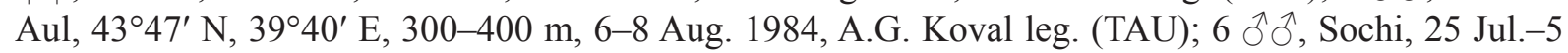
Sep. 1986, Y.V. Zaets leg. (TAU); 1 Oे $^{\top}$, Mt Fisht, $43^{\circ} 58^{\prime}$ N, 39 $55^{\circ}$ E, 1800 m, 7 Aug. 1988, A.G.

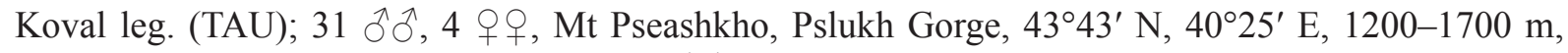

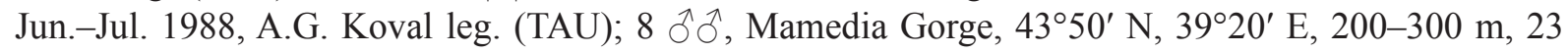

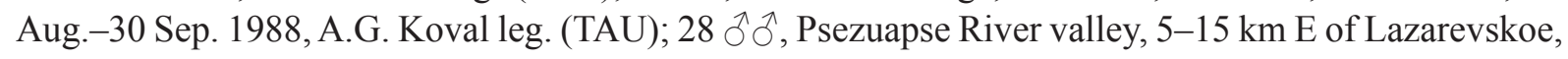
100-500 m, 1-25 Sep. 1988, A.G. Koval leg. (TAU).

\section{Description}

Male (from Lazarevskoe)

Habitus. See Fig. 48.

Measurements. TBL 13.10, CL 5.51, CW 4.78, LL 0.40, LW 0.85, SL 2.48, SW 2.37.

Colour. Carapace brownish rufous; eye tubercle with dark brown central and two symmetric lateral spots surrounding AMEs and lateral eyes, respectively; chelicerae and whole leg I intensive reddish brown; palps and legs II-IV brownish rufous; sternum, labium and maxillae light yellowish rufous; abdomen dorsally light greyish brown, with brown pattern represented by median lanceolate spot fused and crossed with few transverse fasciae, and with numerous small lighter spots on darker background; spinnerets and ventral surface of abdomen light yellowish grey.

Prosoma. Carapace and chelicerae as shown in Fig. 71. Clypeus and eye group as in Fig. 105. Eye diameters and interdistances: AME 0.15(0.19), ALE 0.23, PLE 0.15, PME 0.15, AME-AME 0.10(0.06), ALE-AME 0.08(0.06), ALE-PLE 0.05, PLE-PME 0.03, PME-PME 0.35. Each cheliceral furrow with 10 promarginal teeth and 7-8 mesobasal denticles. Maxillae with 7-8 cuspules each.

Legs. Tibia and metatarsus I as shown in Fig. 132. Scopula (thinner than in other congeners except for $R$. micropa): distal on metatarsi I-II, entire on tarsus I; divided by setae on tarsus II; only few scopuliform hairs on tarsi III-IV. Trichobothria: 2 rows of 10-11 each on tibiae, 11-13 on metatarsi, 11-14 on tarsi, 8-9 on cymbium. Paired claws: inner and outer margins with 7-8 teeth each on tarsi I-II, with 6-7 teeth each on tarsi III-IV.

Spination. Palp: femur d1-1-1, pd1; tibia d1-1, p1-1-1, r1, pv1-1-1, r1, v1-1; cymbium d6(7). Leg I: femur d1-1-1-1, pd1; tibia p1-1, pv1(0), rv1(0)-1-m-m. Leg II: femur d1-1-1-1, pd1-1-1; patella p1; tibia p1-1-1, v2-2-3; metatarsus p1, v2-2-2(3). Leg III: femur d1-1-1-1, pd1-1-1, $\operatorname{rd} 1(0)-1(0)-1$; 
patella p1-1, r1; tibia d1-1, p1-1, r1-1, v2-2-2(3); metatarsus d1-1-1, p1-1-1, r1-1-1, v2-2-3. Leg IV: femur d1-1-1-1, pd1-0-1, rd1-1; patella p1, r1; tibia d1-1, p1-1-1, r1-1-1, v2-2-3; metatarsus $\mathrm{d} 1-1-1-1, \mathrm{p} 1-1-1, \mathrm{r} 1-1-1, \mathrm{v} 2-1-2-3$. Metatarsus I and patella I aspinose.

PaLP. Tibia, cymbium and palpal organ as shown in Fig. 152. Surface of bulb with numerous shallow wrinkles (Fig. 4). Unlike in other members of same group, entire embolus relatively long, but its apical part between keel and tip apex very short and narrow (Figs 178-179).

SPINNERETS. PMS: length 0.45; diameter 0.27. PLS: maximal diameter 0.40; length of basal, medial and apical segments $0.63,0.36,0.48$; total length 1.47 ; apical segment shortly digitiform.

LEG MEASUREMENTS. $\precsim(+$ ) .

\begin{tabular}{lcccccc}
\hline & Femur & Patella & Tibia & Metatarsus & Tarsus & Total \\
\hline Palp & $2.85(2.65)$ & $1.70(1.60)$ & $2.28(1.87)$ & - & $1.12(1.72)$ & $7.95(7.84)$ \\
Leg I & $4.57(3.57)$ & $2.78(2.28)$ & $3.65(2.77)$ & $3.73(2.13)$ & $2.35(1.65)$ & $17.08(12.40)$ \\
Leg II & $3.98(3.23)$ & $2.37(2.05)$ & $3.18(2.37)$ & $3.23(2.15)$ & $2.07(1.70)$ & $14.83(11.50)$ \\
Leg III & $3.47(3.10)$ & $2.05(1.88)$ & $2.77(2.15)$ & $3.55(2.67)$ & $2.10(1.75)$ & $13.94(11.55)$ \\
Leg IV & $4.48(3.80)$ & $2.30(2.12)$ & $3.60(3.27)$ & $5.12(4.17)$ & $2.37(2.07)$ & $17.87(15.43)$ \\
\hline
\end{tabular}

Female (from Lazarevskoe)

Habitus. See Fig. 49.

Measurements. TBL 16.15, CL 5.05, CW 4.35, LL 0.44, LW 1.05, SL 2.33, SW 2.35.

Colour. As in male.

Prosoma. Carapace and chelicerae as shown in Fig. 87. Clypeus and eye group as in Fig. 120. Eye diameters and interdistances: AME 0.14(0.17), ALE 0.25, PLE 0.13, PME 0.13, AME-AME 0.10(0.07), ALE-AME 0.07(0.06), ALE-PLE 0.06, PLE-PME 0.03, PME-PME 0.38. Each cheliceral furrow with 9 promarginal teeth and 5-6 mesobasal denticles. Maxillae with 7-8 cuspules each.

Legs. Scopula: distal on metatarsi I-II, divided on tarsus I and palpal tarsus, widely divided on tarsus II, elsewhere absent. Trichobothria: 2 rows of 8-9 each on tibiae, 10-14 on metatarsi, 11-12 on tarsi, 9 on palpal tarsus. Paired claws: outer and inner margins with 5-7 teeth each. Palpal claw with 4 teeth on inner margin.

SpinAtion. All femora with one basodorsal spine and 2-3 dorsal bristles; palpal patella and patellae I-II aspinose. Palp: femur d1, pd1; tibia p1-1, v2-1-3; tarsus d5(6). Leg I: femur d1, pd1; tibia p1-1, v2-2-2; metatarsus v2-2-2. Leg II: femur d1, pd1; tibia p1-1, v2-2-2; metatarsus p1, v2-2-2. Leg III: femur d1, pd1, rd1-1; patella p1, r1; tibia d1, p1-1, r1-1, v2-2-3; metatarsus d1-1, p1-1-1, r1-11-1, v2-2-3. Leg IV: femur d1, rd1; patella p1, r1; tibia d1, p1-1, r1-1, v2-2-2(3); metatarsus d1-1, p1-1-1-1, r1-1-1-1-1, v2-2-2-3.

SpermathecAe. Moderately long and wide, with receptacles close set to each other (Fig. 202).

SPINNERETS. PMS: length 0.44; diameter 0.27. PLS: maximal diameter 0.48; length of basal, medial and apical segments $0.85,0.35,0.38$; total length 1.58 ; apical segment shortly digitiform. 


\section{Variation}

Carapace length in males varies from 4.40 to 5.75 , in females from 4.35 to $5.93 \mathrm{~mm}$. In some specimens the distal abdominal pattern is almost indiscernible. The copulative organs of both sexes do not show any significant variation.

\section{Ecology}

Judging from sample data and collecting localities, $R$. pontica is a very common spider species which occurs in different types of subcoastal and montane broad-leaved forests (see Figs 225-227). At the upper limit of their distribution $(1800 \mathrm{~m})$, the spiders have been found inhabiting subalpine meadows above the mid-mountain forest zone. The relatively rarely sampled females are believed to hide in cavities under stones, logs, trunks of fallen trees, etc., whereas the vagrant males have been collected mostly in pitfall traps.

\section{Distribution}

The currently known area inhabited by this species is shown in Fig. 219. It includes Abkhazia and the far south of Russia, i.e., the Black Sea coast and the adjacent NW-Caucasus area from Bolshoy Utrish Cape in the north-west $\left(44^{\circ} 45^{\prime} \mathrm{N}, 37^{\circ} 24^{\prime} \mathrm{E}\right)$ to the surroundings of Sokhumi (Sukhum) $\left(43^{\circ} 00^{\prime} \mathrm{N}, 41^{\circ} 00^{\prime} \mathrm{E}\right)$ in

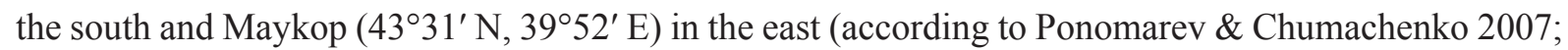
Ponomarev \& Mikhailov 2007; Kovblyuk \& Ponomarev 2008 and the aforementioned label data). When describing this species, Spassky (1937) also mentioned a female that had been collected at Batumi. However, this record in fact refers to $R$. adjarica sp. nov. (see below).

\section{Remarks}

Although males of Raveniola pontica and R. adjarica sp. nov. are well distinguishable from each other, the conspecific females could not be identified as belonging to either of these species without dissecting and examining the vulvae. This may explain why Spassky assigned both females at his disposal to the same species. It is much more difficult to understand, however, why both spiders collected from quite different localities were placed in the same vial. In addition, both females are of approximately equal size! As the material had been desiccated at least once and then macerated, the identification of these specimens has become problematic. Some time was devoted to understanding which of them was collected at Khosta and which at Batumi. Since the Khosta specimen was mentioned first and its characters were found to correspond better to the original description, it was designated as the lectotype (Zonstein 1985; erroneously called the "holotype").

Raveniola sinani sp. nov. urn:1sid:zoobank.org:act:AA810868-2431-4DCF-9E3E-FCFA348DF0B3

Figs 88, 121, 203, 221, 235

\section{Diagnosis}

The holotypic female differs from females in other species of the same group by having long and wide, highly arched spermathecae with median and lateral receptacles located ventrally (not laterally as in other species, Fig. 203; cf. Figs 198-202).

\section{Etymology}

The specific epithet is a patronym honoring Dr. Sinan Anlaş, a Turkish entomologist and a friend of the authors. 


\section{Material examined}

\section{Holotype}

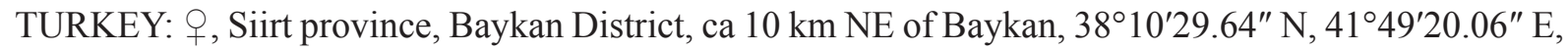
738 m, 18 May 2009, E.A. Yağmur and M. Uslu leg. (AUZM).

\section{Description}

Female (holotype)

Measurements. TBL 13.50, CL 4.11, CW 3.58, LL 0.33, LW 0.68, SL 2.13, SW 1.83.

CoLour. Prosoma and legs very light yellowish orange with only slightly darker radial pattern on carapace; eye tubercle in contrast almost dull black; chelicerae light orange-red; abdomen pale greyish yellow, with indistinct light brownish dorsal pattern consisting of few diffuse chevrons.

Prosoma. Carapace and chelicerae as shown in Fig. 88. Clypeus and eye group as in Fig. 121. Eye diameters and interdistances: AME 0.10(0.13), ALE 0.22, PLE 0.16, PME 0.12, AME-AME 0.12(0.09), ALE-AME 0.07(0.05), ALE-PLE 0.03, PLE-PME 0.03, PME-PME 0.25. Each cheliceral furrow with 9 promarginal teeth and 9 mesobasal denticles. Maxillae with 9-10 cuspules each.

LEGS. Scopula: distal on metatarsi I-II, narrowly divided on tarsus I and palpal tarsus, widely divided on tarsus II, elsewhere absent. Trichobothria: 2 rows of 8-9 each on tibiae, 12-14 on metatarsi, 11-13 on tarsi, 9 on palpal tarsus. Paired tarsal claws I-IV: outer and inner margins with 7-8 teeth each. Palpal claw with 4 teeth on inner margin.

LEG MEASUREMENTS.

\begin{tabular}{lcccccc}
\hline & Femur & Patella & Tibia & Metatarsus & Tarsus & Total \\
\hline Palp & 1.90 & 1.12 & 1.44 & - & 1.38 & 5.84 \\
Leg I & 2.80 & 1.92 & 2.21 & 1.80 & 1.34 & 10.07 \\
Leg II & 2.68 & 1.63 & 2.01 & 1.72 & 1.34 & 9.38 \\
Leg III & 2.36 & 1.33 & 1.77 & 2.28 & 1.37 & 9.11 \\
Leg IV & 3.21 & 1.73 & 2.74 & 3.34 & 1.53 & 12.55 \\
\hline
\end{tabular}

Spination. Palpal femur and femora I-II with 4-5 dorsal bristles (weak spines) arranged in longitudinal dorsal row; femora III-IV with one basodorsal spine and 3-4 dorsal bristles; palpal patella and patellae I-II aspinose. Palp: femur pd1; tibia p1-1, v1-2-3; tarsus v2-0-0. Leg I: femur pd1; tibia v1-1-2; metatarsus v2(3)-2-2. Leg II: femur pd1; tibia v1-1-2(3); metatarsus v2-2-2. Leg III: femur pd0-0-1, rd0-0-1; patella p1, r1; tibia d1-0-0, p1-1, r1-1, v2-2-3; metatarsus d1-1-0, p1-1-1-1, r1-1-1-1, v2-2-3. Leg IV: femur pd0-1-1, rd0-1-1; patella p1, r1; tibia d1-0-0, p1-1-1, r1-1-1(2), v2-2-3; metatarsus d1-1-1(0), p1-1-1-1, r1-1-1-1-1, v2-2-2-3.

SPERmatheCAe. Very long and wide, strongly arched, with receptacles set close to each other on ventral sides of spermathecae (Fig. 203).

SPINNERETS. PMS: length 0.44; diameter 0.17. PLS: maximal diameter 0.40; length of basal, medial and apical segments $0.80,0.55,0.48$; total length 1.83 ; apical segment shortly digitiform.

Male

Unknown. 


\section{Ecology}

The female holotype was collected in an open steppe biotope covered with shrubs (Fig. 231). The only known representative of this species was found inhabiting a shallow and weakly lined cavity under a stone (Figs 232-235).

\section{Distribution}

Known only from the type locality.

\section{Raveniola micropa group}

\section{Diagnostic characters}

Male palpal tibia moderately short and subcylindrical, without subapical sensilla (Figs 153-159). Embolus moderately long, hooked or spiraled, with more or less developed vertically-oriented keel (as in Figs 180-182), or with its rudiments (Fig. 183), or without keel (Figs 184-188). Spermathecae moderately wide, with lateral receptacles situated proximal to medians (Figs 204-207).

\section{Species included}

Raveniola anadolu sp. nov., R. arthuri Kunt \& Yağmur, 2010, R. birecikensis sp. nov., R. micropa (Ausserer, 1871), R. nana sp. nov. and R. turcica sp. nov.

\section{Key to species of micropa group}

\section{Males}

Male of Raveniola nana sp. nov. unknown.

1. Proximal part of embolus short and flattened; embolic keel well-developed (Figs 180-182) ...... R. biresecensis sp. nov.

- Proximal part of embolus longer, gradually tapering and curved; keel vestigial or absent (Figs 183188)

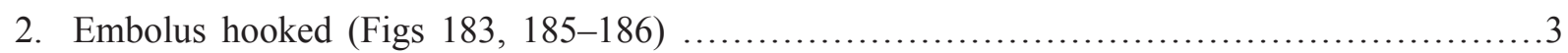

- Embolus corkscrew-shaped (Figs 184, 187-188) .........................................

3. Embolus with small keel vestige, subequal in length to tegulum, bent medially (Fig. 183) ...... R. anadolu sp. nov.

- Embolus without keel vestige, considerably longer than tegulum, bent subapically (Figs 185-186) R. turcica sp. nov.

4. Proximal part of embolus (preceding basal bend) equal in length to spiraled apical part (Fig. 184) R. arthuri Kunt \& Yağmur, 2010

- Proximal part of embolus (preceding basal bend) considerably longer than spiraled apical part (Figs 187-188) R. micropa (Ausserer, 1871)

\section{Females}

Females of Raveniola anadolu sp. nov., $R$. arthuri and $R$. birecikensis sp. nov. unknown.

1. Spermathecae moderately long: distance between median heads two times as long as spermathecae

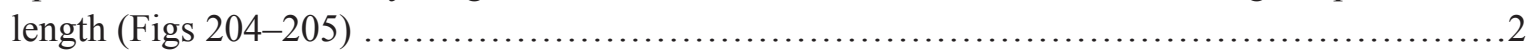

- Spermathecae short: distance between median heads three times as long as spermathecae length (Fig. 206) 
2. Median and lateral receptacles located close to each other (Fig. 204) .............. nana sp. nov.

- Median and lateral receptacles wide apart (Fig. 205) ...................... turcica sp. nov.

\author{
Raveniola birecikensis sp. nov. \\ urn:1sid:zoobank.org:act:1DB28F4C-3186-4E0E-9769-C533F62AB5D4
}

Figs $50,72-73,106,133-134,153-154,180-181,221$

\title{
Diagnosis
}

The male of this species differs from those of other members of the same group by having a welldeveloped keel in the flattened proximal part of the embolus (Figs 180-181; cf. Figs 183-188). Raveniola biresecensis sp. nov. can be distinguished from R. nana sp. nov. (male of the latter species is unknown) by its noticeably larger body size, more intensely brownish coloration, and relatively smaller AMEs and PMEs (Fig. 106; cf. 122).

\section{Etymology}

The specific epithet is a toponym that refers to the locality where the paratypes were collected: Birecik District, Şanlıurfa Province of Turkey.

\section{Material examined}

\section{Holotype}

TURKEY: O̊ , Şanlıurfa Province, Halfeti District, Şanlıurfa, N of Halfeti, $37^{\circ} 16^{\prime} \mathrm{N}, 37^{\circ} 51^{\prime} \mathrm{E}, 400$ 600 m, 7 Mar. 2006, A.E. Yağmur leg. (AUZM).

\section{Paratypes}

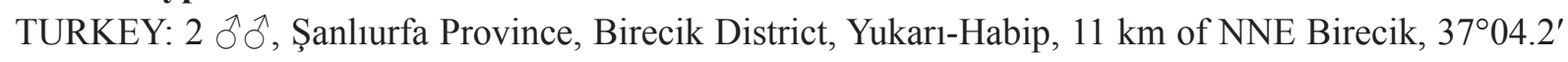
$\mathrm{N}, 38^{\circ} 00.5^{\prime} \mathrm{E}, 550-650 \mathrm{~m}, 1$ Apr. 2006, A.E. Yağmur leg. (AUZM, TAU).

Aditional material (5 possibly dwarf $え \precsim$ )

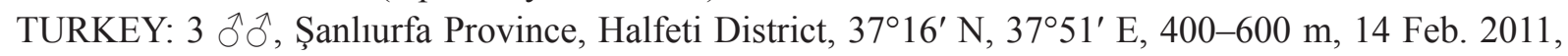
E.A. Yağmur leg. (AUZM and TAU); $2 \widehat{\partial}^{\top}{ }^{\top}$, surroundings of Birecik, $37^{\circ} 04^{\prime} \mathrm{N}, 38^{\circ} 00^{\prime} \mathrm{E}, 550-650 \mathrm{~m}$, 4 Feb. 2011, E.A. Yağmur leg. (AUZM, TAU).

\section{Description}

Male (holotype)

Habitus. See Fig. 50.

Measurements. TBL 14.77, CL 4.66, CW 4.08, LL 0.28, LW 0.66, SL 2.26, SW 2.02.

CoLour. Carapace, palps and legs dorsally light yellowish brown, with darkened cephalic area, thoracic grooves and leg I; eye tubercle dark brown; chelicerae medium cherry-red; sternum, labium, maxillae, palps and legs ventrally light yellowish brown; abdomen dorsally light yellowish grey, with indistinct darker dorsal pattern, ventral abdominal surface and spinnerets pale yellowish grey.

Prosoma. Carapace and chelicerae as shown in Fig. 72. Clypeus and eye group as in Fig. 106. Eye diameters and interdistances: AME 0.12(0.16), ALE 0.20, PLE 0.14, PME 0.07, AME-AME 0.19(0.16), ALE-AME 0.10(0.08), ALE-PLE 0.06, PLE-PME 0.05, PME-PME 0.44. Each cheliceral furrow with 9 promarginal teeth and 9-10 mesobasal denticles. Maxillae with 7 relatively small cuspules each. 
Legs. Tibia and metatarsus I as shown in Fig. 133. Scopula: distal on metatarsi I-II, entire on tarsi I-II; absent on tarsi III-IV. Trichobothria: 2 rows of 9-11 each on tibiae, 15-17 on metatarsi, 10 on tarsi I and II, 10-12 on tarsi III and IV, 7 on cymbium. Paired claws with $8-10$ teeth on each margin.

LEG MEASUREMENTS.

\begin{tabular}{lcccccc} 
& Femur & Patella & Tibia & Metatarsus & Tarsus & Total \\
\hline Palp & 2.40 & 1.35 & 1.88 & - & 0.84 & 6.47 \\
Leg I & 3.98 & 2.29 & 3.04 & 3.07 & 1.63 & 14.01 \\
Leg II & 3.61 & 2.17 & 2.67 & 2.68 & 1.64 & 12.77 \\
Leg III & 2.92 & 1.76 & 1.89 & 2.76 & 1.58 & 10.91 \\
Leg IV & 3.66 & 2.16 & 3.27 & 4.30 & 1.74 & 15.13 \\
\hline
\end{tabular}

Spination. Femora I-IV with one basodorsal spine and 3 distal bristles; patellae I and II aspinose. Palp: femur d1-1-1-1-1, pd1; patella p1; tibia d1-1, p1-1-1, r1, v1-1; cymbium d4(5). Leg I: femur pd0-0(1)-1; tibia rv0-1-m-m, v1-1(0)-01; metatarsus v0-0-2. Leg II: femur pd0-0-1; tibia p0-0-1, v2-2-3; metatarsus $\mathrm{p} 1, \mathrm{v} 2-2-3$. Leg III: femur $\mathrm{pd} 0-1-1$, rd0-1-1; patella $\mathrm{p} 1, \mathrm{r} 1$; tibia $\mathrm{d} 1-0-0$, p11(0)-1, r1-1-1, v2-2-3; metatarsus d0-1-0, p1-1-1, r1-1-1, v2-2-3. Leg IV: femur pd0-1-1, rd0-01; patella p1, r1; tibia d1-0-0, p1-1-1, r1-1-1, v2-2-3; metatarsus d0-1-1-0, p1-1-1-1, r1-1-1-1, v2-2-2-3.

PaLP. Tibia, cymbium and bulb as shown in Fig. 153. Wide and flattened basal part of embolus with subapical keel extending into twisted and flagelliform apical part (Figs 180-181).

SPINNERETS. PMS: length 0.49; diameter 0.13. PLS: maximal diameter 0.41 ; length of basal, medial and apical segments $0.67,0.42,0.47$; total length 1.56 ; apical segment shortly digitiform.

\section{Female}

Unknown.

\section{Variation}

Carapace length in males of the type series varies from 3.93 to 4.66. Colouration, eye arrangement, shapes of the palpal tibia, cymbium, palpal organ, tibia and metatarsus I in the paratypes do not differ significantly from those of the holotype (Figs 73, 134, 154). The appearance and the corresponding structures of the pale-coloured and possibly dwarf conspecific males (CL 2.16-3.41), possessing larger AMEs and an invariably shorter basal portion of the embolus, are shown in Figs 47, 74, 107, 135, 155 and 182 , respectively.

\section{Ecology}

The type series, which includes only males, was collected with pitfall traps in open steppe biotopes sparsely covered with low forest and shrubs (Fig. 230).

\section{Distribution}

The species is known from south-eastern Turkey (Şanlıurfa Province) and probably also occurs in the adjoining territory of Syria. See Fig. 221. 


\section{Raveniola nana sp. nov. urn:1sid:zoobank.org:act:C3C6CE26-9C99-4A76-9A63-46779FEFF1CA}

Figs 89, 122, 204, 221

\section{Diagnosis}

The structure of the spermathecae of Raveniola nana sp. nov. resembles that of $R$. turcica sp. nov. (the female of $R$. birecikensis sp. nov. is unknown), but differs in having the median and lateral receptacles situated considerably closer to each other (Fig. 204; cf. Fig. 205). Additionally, R. nana sp. nov. is considerably smaller and has a paler coloration than both the latter species.

\section{Etymology}

The specific epithet (a variable adjective from Ancient Greek võvos, meaning 'dwarf') refers to the very small size of this species.

\section{Material examined}

\section{Holotype}

TURKEY: + , Hatay Province, Hassa District, Küreci Village, 36²42'36.89" N, 36²7'14.44" E, 499 m, 15 Nov. 2010, Anlaş and Yağmur leg. (AUZM).

\section{Description}

Female (holotype)

MeAsurements. TBL 10.97, CL 3.69, CW 2.82, LL 0.29, LW 0.65, SL 1.84, SW 1.62.

Colour. Most parts of body pale brownish; eye tubercle with partially fused dark brown rings surrounding AMEs and lateral eyes; chelicerae light red; abdomen uniformly light yellowish grey without dorsal pattern, spinnerets pale yellowish grey.

Prosoma. Carapace and chelicerae as shown in Fig. 89. Clypeus and eye group as in Fig. 122. Eye diameters and interdistances: AME 0.09(0.12), ALE 0.13, PLE 0.10, PME 0.08, AME-AME 0.08(0.06), ALE-AME 0.05(0.04), ALE-PLE 0.05, PLE-PME 0.02, PME-PME 0.23. Each cheliceral furrow with 8 promarginal teeth and 7 mesobasal denticles. Maxillae each with 5-7 cuspules along heel.

LEGS. Scopula: distal on metatarsi I-II, entire on tarsus I and palpal tarsus, widely divided on tarsus II, elsewhere absent. Trichobothria: 2 rows of 8-9 each on tibiae, 9-10 on metatarsi, 10-11 on tarsi, 8 on palpal tarsus. Paired tarsal claws with 7-10 teeth on each margin. Palpal claw with 6 teeth on inner margin.

LEG MEASUREMENTS.

\begin{tabular}{lcccccc}
\hline & Femur & Patella & Tibia & Metatarsus & Tarsus & Total \\
\hline Palp & 1.82 & 1.24 & 1.26 & - & 1.15 & 5.47 \\
Leg I & 2.24 & 1.53 & 1.85 & 1.50 & 1.12 & 8.24 \\
Leg II & 2.17 & 1.35 & 1.65 & 1.45 & 1.16 & 7.78 \\
Leg III & 2.07 & 1.15 & 1.45 & 1.95 & 1.19 & 7.81 \\
Leg IV & 2.58 & 1.37 & 2.35 & 2.83 & 1.36 & 10.49 \\
\hline
\end{tabular}

Spination. Femora I-IV with one basodorsal spine and 3 dorsal bristles alongside midline; palpal femur dorsally with 3 bristles; palpal patella and patellae I-II aspinose. Palp: femur pd0-0-1; tibia v1-1-2; tarsus v2-0-0. Leg I: femur pd0-0-1; tibia v1-1-2; metatarsus v1-2-2. Leg II: femur pd0-0-1; tibia 
p0-0-1, v1-2-2; metatarsus v1(0)-1-2. Leg III: femur pd1-1-1, rd1-1-1; patella p1, r1; tibia d1-1(0)0 , p1-1-1, r1-1-1, v2-2-3; metatarsus pd0-1-0, p1-1-1, r1-1-1, v2-2-3. Leg IV: femur pd0-0-1, rd0-0-1; patella r1; tibia d1-0-0, p1-1-1, r1(0)-1-1, v2-2-3; metatarsus d0-1-1-0, p1-1-1-1, r1-1$1-1, \mathrm{v} 2-2-3$.

SpermatheCAe. Moderately broad with receptacles close to each other (Fig. 204).

SPINNERETS. PMS: length 0.36; diameter 0.16. PLS: maximal diameter 0.31; length of basal, medial and apical segments $0.55,0.35,0.34$; total length 1.24 ; apical segment shortly digitiform.

\section{Ecology}

The holotypic female was found in open forest under a stone.

\section{Distribution}

South-Eastern Turkey (Fig. 221).

\section{Note}

There is a possibility that the holotype of Raveniola nana sp. nov. is the unknown female of the allopatric $R$. biresekensis sp. nov. However, both these species differ in size and colouration ( $R$. nana sp. nov. is noticeably smaller and considerably paler than the latter species), as well as in the relative size of AMEs and PMEs (larger vs smaller, respectively). We thus prefer to consider these names as belonging to different species, until the currently missing males of $R$. nana sp. nov. and the unknown females of $R$. biresekensis sp. nov. are collected and identified.

Raveniola anadolu sp. nov.

urn:1sid:zoobank.org:act:D5C7C4A0-1FAD-4D2E-A531-E2F59280D327

Figs $51,75,108,136,156,183,221$

\section{Diagnosis}

In the structure of the palpal organ this species resembles Raveniola turcica sp. nov., but differs from the latter by the presence of a small triangular embolic keel vestige and by the basal bend being confined to the median part of a shorter embolus (Fig. 183; cf. Figs 185-186).

\section{Etymology}

The specific epithet is the Turkish name for Anatolia; the type locality of this species lies in the East Anatolia region of Turkey.

\section{Material examined}

\section{Holotype}

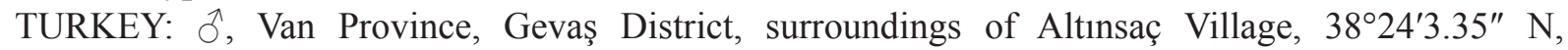
4253'27.89" E, 1690 m, 10 Sep. 2011, K.B. Kunt leg. (AUZM).

\section{Paratypes}

TURKEY: 4 $\widehat{\partial}$, collected together with the holotype (AUZM \& TAU).

\section{Description}

Male (holotype)

Habitus. See Fig. 51. 
MeAsurements. TBL 14.10, CL 4.93, CW 4.48, LL 0.36, LW 0.84, SL 2.56, SW 2.31.

Colour. Carapace, chelicerae, palps and first pair of legs dorsally dark brownish rufous; eye tubercle somewhat darker with brownish black rings around eyes; sternum, labium, maxillae and legs II-IV light brownish rufous; abdomen dorsally brownish grey with numerous darker transverse fasciae and small partially fused lighter spots, ventral abdominal surface and spinnerets pale brownish grey.

Prosoma. Carapace and chelicerae as shown in Fig. 75. Clypeus and eye group as in Fig. 108. Eye diameters and interdistances: AME 0.11(0.15), ALE 0.19, PLE 0.16, PME 0.16, AME-AME 0.11(0.08), ALE-AME 0.08(0.06), ALE-PLE 0.07, PLE-PME 0.03, PME-PME 0.36. Each cheliceral furrow with 9 promarginal teeth and 7-8 very small mesobasal denticles. Maxillae each with 20-22 cuspules arranged in triangle area.

Legs. Tibia and metatarsus I as shown in Fig. 136. Scopula: distal on metatarsi I-II, entire on tarsi I, divided on tarsi II; absent on tarsi III-IV. Trichobothria: 2 rows of 8-10 each on tibiae, 10-12 on metatarsi, $10-12$ on tarsi, 6-8 on cymbium. Paired tarsal claws with 9-13 teeth on each margin.

LEG MEASUREMENTS.

\begin{tabular}{lcccccc}
\hline & Femur & Patella & Tibia & Metatarsus & Tarsus & Total \\
\hline Palp & 2.55 & 1.50 & 2.16 & - & 0.90 & 7.11 \\
I & 4.51 & 2.41 & 3.44 & 3.44 & 1.97 & 15.77 \\
II & 4.09 & 2.08 & 2.92 & 2.86 & 1.69 & 13.64 \\
III & 3.61 & 1.83 & 2.35 & 3.05 & 1.81 & 12.65 \\
IV & 4.36 & 2.09 & 3.19 & 4.28 & 2.15 & 16.07 \\
\hline
\end{tabular}

Spination. Patellae I and II aspinose. Palp: femur d1-1-1-1, pd0-0-1, rd0-0-1; patella p1-1; tibia d1-1-1, p1-1-1-1, r1-1, pv1-1-1, v1-2-1; cymbium d5. Leg I: femur d1-1-1-1, pd0-1(0)-1; tibia p1-1-0, rv0-1-m-m, v1-0-1-0; metatarsus v0-0-2. Leg II: femur d1-1-1-1, pv1(0)-1-1; tibia p11-1, v2-2-2; metatarsus v2-2-2. Leg III: femur d1-1-1-1, pd1-1-1, rd1-1-1; patella p1, r1; tibia d1-1(0)-0, p0-1-1, r1-1-1, v2-2-3; metatarsus d1-1-2, p0-1-1, r1-1-1, v2-2-3. Leg IV: femur d11-1-1, pd0-0-1, rd0-0-1; patella r1; tibia d1-0-0, p1-1-1, r1-1-1-1, v2-2-3; metatarsus d1-1-2, $\mathrm{p} 1-1-1, \mathrm{r} 1-1-1-1, \mathrm{v} 2-2-3$.

PALP. Tibia, cymbium and palpal organ as shown in Fig. 156. Embolus with characteristic small, triangular vestige of dorsomedian keel (Fig. 183).

SPINNERETS. PMS: length 0.46; diameter 0.18. PLS: maximal diameter 0.39; length of basal, medial and apical segments $0.71,0.52,0.51$; total length 1.74 ; apical segment shortly digitiform.

\section{Female}

Unknown.

\section{Variation}

Carapace length in males varies from 4.22 to 5.04. The size and shape of the embolic keel vestige in all paratype males do not differ from those in the holotypic male.

\section{Ecology}

The type series, which includes only males, was collected with pitfall traps in an open rocky biotope sparsely covered with low Juniperus trees and shrubs. 


\section{Distribution}

Known only from the type locality. See Fig. 221.

Raveniola arthuri (Kunt \& Yağmur, 2010)

Figs 76, 109, 137, 157, 184, 221

Raveniola arthuri Kunt \& Yağmur, 2010: 306, figs 1a-e, 2a-d (ð).

\section{Diagnosis}

In the structure of its embolus this species is similar to Raveniola micropa, but differs from the latter by a considerably shorter and narrower proximal part of the embolus (Fig. 184; cf. Fig. 187-188).

\section{Material examined}

\section{Holotype}

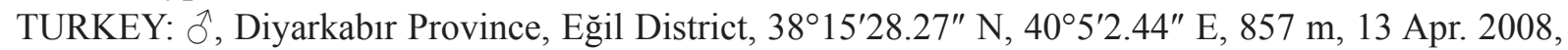
under stones, E.A. Yağmur, E. Tezcan and V. Ülgezer leg. (AUZM).

\section{Paratypes}

TURKEY: $2 \lesssim \precsim$, collection data as for holotype (AUZM).

\section{Description}

\section{Male (holotype)}

MeAsurements. TBL 14.85, CL 4.92, CW 4.16, LL 0.38, LW 0.78, SL 2.31, SW 2.11.

CoLour. Prosoma dorsally brownish orange, with darkened palp, leg I, cephalic area and radial grooves on carapace; eye tubercle dark brown; chelicerae medium cherry-red; sternum, labium, maxillae, palps and legs ventrally light reddish brown; abdomen dorsally light brownish grey with diffuse darker light brown dorsal pattern (several irregular transverse fasciae), ventral abdominal surface and spinnerets pale yellowish brown.

Prosoma. Carapace and chelicerae as shown in Fig. 76. Clypeus and eye group as in Fig. 109. Eye diameters and interdistances: AME 0.12(0.16), ALE 0.18, PLE 0.12, PME 0.12, AME-AME 0.15(0.11), ALE-AME 0.07(0.05), ALE-PLE 0.09, PLE-PME 0.03, PME-PME 0.34. Each cheliceral furrow with 11 promarginal teeth and 7-8 mesobasal denticles. Maxillae with 10-11 cuspules each.

Legs. Tibia and metatarsus I as shown in Fig. 137. Scopula: distal on metatarsi I-II, entire on tarsi III; absent on tarsi III-IV. Trichobothria: 2 rows of 9-10 each on tibiae, 11-14 on metatarsi, 11-13 on tarsi, 8 on cymbium. Paired tarsal claws with $6-8$ teeth on each margin.

LEG MEASUREMENTS.

\begin{tabular}{lcccccc}
\hline & Femur & Patella & Tibia & Metatarsus & Tarsus & Total \\
\hline Palp & 2.41 & 1.30 & 1.88 & - & 0.83 & 6.42 \\
Leg I & 4.03 & 2.30 & 3.01 & 3.10 & 1.68 & 16.13 \\
Leg II & 3.55 & 1.67 & 2.27 & 2.82 & $1.52)$ & 14.33 \\
Leg III & 3.19 & 2.03 & 2.78 & 2.78 & 1.67 & 12.62 \\
Leg IV & 4.04 & 2.07 & 3.11 & 4.09 & 1.70 & 16.61 \\
\hline
\end{tabular}


SpinATION. Femora I-IV with one basodorsal spine and 3-4 median and distal bristles; patellae I and II aspinose. Palp: femur d1-1-1-1, pd1; patella p1; tibia d1-1-0, p1-1-1, pv1-1-2, r0-0-1, rv1-1-0; cymbium d4. Leg I: femur pd0-0-1; tibia p0-1-0, rv1-1-1-m-m, metatarsus v0-0-2. Leg II: femur pd0-1-1; tibia p1-1-1, v2-1-1-3; metatarsus v2-2-2. Leg III: femur pd0-0-1, rd0-1-1; patella p1, r1; tibia d1-1-0, p1-1(2)-1, r1-1-1, v2(3)-2-3; metatarsus d0-0-1-0, p1-1-1-1-1, r1(0)-1-1, v1(2)-2-3. Leg IV: femur pd0-0-1, rd0-0-1; patella p1, r1; tibia d0-0-1-0, p1-1-1, r1(0)-1-1, v2-2-3; metatarsus d0-1-1-0, p1-1-1-1, r1-1-1-0, v2-2-3.

PaLP. Tibia, cymbium and bulb as shown in Fig. 157. Embolic keel lost; embolus corkscrew-shaped, with basal bend located submedially (Fig. 184).

SPINNERETS. PMS: length 0.42 ; diameter 0.15. PLS: maximal diameter 0.43 ; length of basal, medial and apical segments $0.73,0.58,0.51$; total length 1.82 ; apical segment shortly digitiform.

\section{Female}

Unknown.

\section{Variation}

Carapace length in males varies from 4.05 to 4.16 . The shape of the embolus in the holotype and both paratypic males is practically identical.

\section{Ecology}

The type series, containing only males, was collected in an open steppe biotope without trees; the spiders were found hiding under stones.

\section{Distribution}

Known only from the type locality. See Fig. 221.

Raveniola turcica sp. nov. urn:lsid:zoobank.org:act:72EFAE3C-75A1-4F9C-8741-EEC84382CDFC

Figs 77, 90, 110, 123, 138, 158, 185-186, 205, 221, 238

\section{Diagnosis}

In the structure of its palpal organ this species resembles Raveniola anadolu sp. nov., but differs from it by the absence of any traces of the embolic keel, and in having the basal bend confined to the subapical part of a longer embolus (Figs 185-186; cf. Fig. 183). Females of $R$. turcica sp. nov. have the spermathecae somewhat similar to those of the only known female of $R$. nana sp. nov., but both are well-distinguishable from each other: in $R$. turcica sp. nov. the median and lateral receptacles are wide apart, whereas in R. nana sp. nov. they are close to each other (cf. Figs 204-205).

\section{Etymology}

The specific epithet is a Latinized adjective of "turcia", the Medieval Latin name for Turkey.

\section{Material examined}

\section{Holotype}

TURKEY: ð̄, Diyarbakır Province, Silvan District, environs of Boyunlu Village (38 $13.7^{\prime} \mathrm{N}, 40^{\circ} 59.2^{\prime} \mathrm{E}$, 1000-1200 m), 15 Apr. 2010, under stones, E.A. Yağmur and M. Özkörük leg. (AUZM). 


\section{Paratype}

TURKEY: 1 , collection data as for holotype (AUZM).

\section{Description}

Male (holotype)

Measurements. TBL 12.40, CL 4.17, CW 3.48, LL 0.24, LW 0.61, SL 2.14, SW 1.86.

Colour. Prosoma light brownish orange, with darkened caput, thoracic grooves and leg I; eye tubercle dark brown; chelicerae medium cherry-red; sternum, labium, maxillae, palps and legs ventrally light yellowish brown; abdomen dorsally light yellowish grey with diffuse slightly darker brownish dorsal pattern consisting of few irregular transverse fasciae, ventral abdominal surface and spinnerets pale yellowish grey.

Prosoma. Carapace and chelicerae as shown in Fig. 77. Clypeus and eye group as in Fig. 110. Eye diameters and interdistances: AME 0.12(0.15), ALE 0.19, PLE 0.12, PME 0.10, AME-AME 0.10(0.07), ALE-AME 0.07(0.06), ALE-PLE 0.05, PLE-PME 0.02, PME-PME 0.35. Each cheliceral furrow with 8-9 promarginal teeth and 5-6 mesobasal denticles. Maxillae with 6-7 cuspules each.

LEgs. Tibia and metatarsus I as shown in Fig. 138. Scopula: distal and entire on metatarsi I-II, entire on tarsi I-II; absent on tarsi III-IV. Trichobothria: 2 rows of 9-10 each on tibiae, 10-12 on metatarsi, 10-11 on tarsi, 7 on cymbium. Paired tarsal claws with $6-7$ teeth on each margin.

SpinATIOn. Femora I-IV with 1-2 basodorsal spines and 2-3 distal bristles; patellae I-II and metatarsus I aspinose. Palp: femur d1-1-1-1(2), pd0-0-1; patella p1; tibia d1-1-0, p1-1-1, r0-0-1, pv1-1-1, rv0-1-0; cymbium d4(5). Leg I: femur pd0-1-1; tibia p1-1-0-0, rv0-1-0-m-m, v1-1-0. Leg II: femur pd0-0-1; tibia p1-1-0-1, v2-2-3; metatarsus p0-1-1, v2-2-2. Leg III: femur pd1-1-1, rd0-1-1; patella p1, r1; tibia d1-1-0, p0-1-1, r1-1-1, v2-2-3; metatarsus d0-1-0, p1-1-1, r1-1-1, v2-2-3. Leg IV: femur pd0-0-1, rd0-1(0)-1; patella p1, r1; tibia d1-0-1-0, p0-1-1, r0-1-1, v2-2-3; metatarsus d0-1-1-0, p1-1-1-1, r1(0)-1-1-1, v1 p1-2-2-3.

PALP. Tibia, cymbium and palpal organ as shown in Fig. 158. Embolus moderately long, narrow and curved subapically (Figs 185-186).

SPINNERETS. PMS: length 0.22; diameter 0.07. PLS: maximal diameter 0.28; length of basal, medial and apical segments $0.63,0.36,0.31$; total length 1.30 ; apical segment triangular.

LEG MEASUREMENTS. $\widehat{\jmath}($ ( $)$

\begin{tabular}{lcccccc}
\hline & Femur & Patella & Tibia & Metatarsus & Tarsus & Total \\
\hline Palp & $2.08(2.05)$ & $1.28(1.23)$ & $1.48(1.27)$ & - & $1.03(1.19)$ & $5.87(5.74)$ \\
Leg I & $3.27(3.02)$ & $2.05(1.86)$ & $2.52(2.01)$ & $2.29(1.46)$ & $2.03(1.09)$ & $12.16(9.44)$ \\
Leg II & $2.83(2.50)$ & $1.74(1.59)$ & $2.31(1.61)$ & $2.17(1.40)$ & $1.93(1.05)$ & $10.98(8.15)$ \\
Leg III & $2.53(2.26)$ & $1.29(1.30)$ & $1.78(1.42)$ & $2.56(1.91)$ & $1.93(1.23)$ & $10.09(8.12)$ \\
Leg IV & $3.22(3.05)$ & $1.75(1.62)$ & $2.82(2.34)$ & $3.73(2.98)$ & $2.27(1.54)$ & $13.79(11.53)$ \\
\hline
\end{tabular}

Female (paratype)

MEASUREMENTS. TBL 14.00-16.00? (abdomen absent in this female; prosoma including chelicerae 5.90 long), CL 4.15, CW 3.32, LL 0.39, LW 0.76, SL 2.08, SW 1.88. 
CoLour. Carapace and legs dorsally uniformly medium foxy brown; maxillae, labium and sternum paler in colour; chelicerae light brownish red; eye tubercle dark brown; dorsal abdominal pattern unknown.

Prosoma. Carapace and chelicerae as shown in Fig. 90. Clypeus and eye group as in Fig. 123. Eye diameters and interdistances: AME 0.10(0.14), ALE 0.22, PLE 0.14, PME 0.13, AME-AME 0.12(0.08), ALE-AME 0.08(0.06), ALE-PLE 0.04, PLE-PME 0.04, PME-PME 0.30. Each cheliceral furrow with 8 promarginal teeth and 7-8 mesobasal denticles. Maxillae with 8-9 cuspules each.

LeGs. Scopula: entire on metatarsus I, distal on metatarsus II, narrowly divided on tarsus I and palpal tarsus, widely divided by setae on tarsus II, elsewhere absent. Trichobothria: 2 rows of 7-9 each on tibiae, 9-10 on metatarsi, 9-11 on tarsi, 6-7 on palpal tarsus. Paired claws: outer and inner margins with 6-7 teeth each on tarsi I and II, with 7-8 teeth each on tarsi III and IV. Palpal claw with 4 teeth on promargin.

Spination. All femora with one thin basodorsal spine and 3-4 long bristles arranged in dorsal row. Palp: femur pd1; patella p1; tibia v2(0)-2(3)-3. Leg I: femur pd1; tibia v1-1-2; metatarsus v2-2(1)-2. Leg II: femur pd1; tibia v1-1-2; metatarsus v2-2-2. Leg III: femur pd0-0-1, rd0-1-1; patella p1, r1; tibia p1-1, r1(0)-1, v2-2-3; metatarsus pd0-1-1, p1-1-1, r1-1-1, v2(1)-2-3. Leg IV: femur rd0-0-1; patella $\mathrm{p} 1, \mathrm{r} 1$; tibia $\mathrm{d} 1-0-0, \mathrm{p} 1(0)-1-1, \mathrm{r} 1-1-1$, v2-2-3; metatarsus $\mathrm{d} 0-1-1-0, \mathrm{p} 1-1-1-1, \mathrm{r} 1-1-1-1$, v2-1-2-3. Patellae I-II and palpal tarsus aspinose.

Spermathecae. Moderately broad, with receptacles widely spaced (Fig. 205).

SPINNERETS. Distal portion of abdomen lost, shape of spinnerets thus unknown.

\section{Ecology}

The male holotype and female paratype were collected together in an open biotope covered with low shrubs (Fig. 238); the spiders were found hiding under stones.

\section{Distribution}

Known only from the type locality. See Fig. 221.

Raveniola micropa (Ausserer, 1871)

Figs 1, 2, 11, 16-17, 23-24, 32, 36, 53-54, 78, 91-92, 111, $124-125,139,159,187-188,206-207,221,239-246$

Brachythele micropa Ausserer, 1871: 177 (ㅇ).

Brachythele micropa - Reimoser 1919: 11. — Roewer 1942: 196. — Bonnet 1955: 912. — Zonstein 1985: 161.

Raveniola microps - Zonstein 1987: 1015 (an unjustified emendation). — Platnick 1989: 90.

Raveniola micropa - Le Peru 2011: 86.

\section{Diagnosis}

In the structure of its embolus, this species is similar to Raveniola arthuri, but differs from the latter by having a considerably longer and less wide proximal part of the embolus (Figs 187-188; cf. Fig. 184). In the shape of their spermathecae, however, females of $R$. micropa resemble those of $R$. zaitzevi from another species group (the female of $R$. arthuri is unknown), differing from them in having noticeably broader spermathecal bases and shorter median and smaller lateral receptacles (Figs 206-207; cf. Figs 208-209). 


\section{Material examined}

\section{Holotype}

TURKEY: + , labelled: "Brachythele micropa Auss. Brussa A D. 1863, A.N.I. 16 leg. Mann, 1 ex." = environs of Bursa (NMW 58).

Additional material ( $2 \hat{\partial} \hat{\partial}, 4$ q $q, 3$ juvs)

TURKEY: 1 juv., Bursa Province, Oylat, 3955'59" N, 29³5'20" E, 620 m, 23 Sep. 2010, S.L. Zonstein leg. (TAU); $2 \widehat{\jmath}, 4$ q, , 2 juvs, same province, Keles district, Uludağ Mts, vicinity of Baraklı Lake, $39^{\circ} 58^{\prime} 02^{\prime \prime}$ N, 29 $9^{\circ} 5^{\prime} 19^{\prime \prime}$ E, 1050 m, 25 Sep. 2010, K.B. Kunt, Yu.M. Marusik, E.A. Yağmur and S.L. Zonstein leg. (AUZM, TAU).

\section{Description}

Male (Uludağ Mts near Bursa; here described for the first time) Habitus. See Fig. 53.

Measurements. TBL 11.07, CL 4.34, CW 3.60, LL 0.38, LW 0.74, SL 2.17, SW 1.98.

Colour. Carapace, chelicerae, palps and first pair of legs dorsally light rufous brown; palp and leg I slightly darker in colour; eye tubercle with dark brown spots surrounding AMEs and lateral eyes; chelicerae light brownish red; sternum, labium, maxillae and legs II-IV light brownish reddish; abdomen and spinnerets pale yellowish brown; diffuse darker dorsal pattern consisting of partially fused transverse brown fasciae mixed with numerous small irregular lighter spots.

Prosoma. Carapace and chelicerae as shown in Fig. 78. Clypeus and eye group as in Fig. 111. Eye diameters and interdistances: AME 0.12(0.16), ALE 0.17, PLE 0.13, PME 0.09, AME-AME 0.12(0.08), ALE-AME 0.07(0.05), ALE-PLE 0.08, PLE-PME 0.04, PME-PME 0.40. Each cheliceral furrow with 10 promarginal teeth and 5-6 mesobasal denticles. Maxillae with 7-8 cuspules each.

Legs. Tibia and metatarsus I as shown in Fig. 139. Scopula: long, very scarce and distal on metatarsus I, long, entire and rather thin on tarsi I and II; elsewhere absent. Trichobothria: 2 rows of 8-9 each on tibiae, $9-10$ on metatarsi, 9-10 on tarsi, 7 on cymbium. Paired claws: inner and outer margins each with 6-7 teeth on legs I and II, with 7-8 teeth on legs III and IV.

SPinATIOn. Palp: femur d1-1-1-1, pd1; patella p1; tibia d1-1, p1-1-1, r0-0-2(1), v3(2)-2-2; cymbium d5. Leg I: femur d1-1-1-1, pd0-0-1; tibia p1-1(0)-0, pv1-1(0), rv0-1-m-m; metatarsus v1(0). Leg II: femur d1-1-1-1, pd1-1-1; tibia p1-1-1, v1(2)-2-3; metatarsus p1, v1-2-2-3. Leg III: femur d1-1-1-1, pd1-1-1, rd1-1-1; patella p1, r1; tibia d1-1-0, p1(0)-1-1, r1-1(0)-1, v2-2-3; metatarsus d0-1-0, p1-1-1-1, r1-1-1, v2-2-3. Leg IV: femur d1-1-1-1-1, pd0-0-1, rd0-0-1; patella r1; tibia $\mathrm{d} 1-1-0, \mathrm{p} 1-1-1, \mathrm{r} 1-1-1, \mathrm{v} 2-2-3$; metatarsus pd1-1-0, p1-1-1-1, r1-1-1-1, v2-1(2)-2-3. Patellae I and II aspinose.

PALP. Tibia, cymbium and palpal organ as shown in Fig. 159. Embolic keel lost; embolus corkscrewshaped, with bend located subapically (Figs 187-188).

SPINNERETS. PMS: length 0.35; diameter 0.17. PLS: maximal diameter 0.35; length of basal, medial and apical segments $0.58,0.43,0.55$; total length 1.56 ; apical segment shortly digitiform. 
LEG MEASUREMENTS. $\overbrace{}^{\lambda}(+)$.

\begin{tabular}{lcccccc}
\hline & Femur & Patella & Tibia & Metatarsus & Tarsus & Total \\
\hline Palp & $2.25(2.20)$ & $1.33(1.40)$ & $1.78(1.77)$ & - & $0.79(1.45)$ & $6.15(6.82)$ \\
Leg I & $3.46(3.20)$ & $2.15(2.10)$ & $2.66(2.35)$ & $2.55(2.20)$ & $1.56(1.28)$ & $12.38(11.13)$ \\
Leg II & $3.17(2.85)$ & $1.87(1.90)$ & $2.24(1.95)$ & $2.08(2.15)$ & $1.51(1.28)$ & $10.87(10.13)$ \\
Leg III & $3.20(2.20)$ & $1.60(1.55)$ & $1.92(1.73)$ & $2.63(2.67)$ & $1.59(1.45)$ & $10.49(9.60)$ \\
Leg IV & $4.35(3.35)$ & $1.93(1.95)$ & $2.78(2.67)$ & $3.74(3.30)$ & $1.80(1.75)$ & $13.74(13.02)$ \\
\hline
\end{tabular}

Female (holotype)

HaBitus. Habitus of females from Uludağ Mts as shown in Figs 54, 244-246.

MeAsurements. TBL 10.40, CL 4.75, CW 3.97, LL 0.47, LW 0.95, SL 2.33, SW 2.03.

CoLour. Carapace, palps and legs light brown, chelicerae light reddish brown, sternum pale yellowish brown; abdomen yellowish grey with brown dorsal pattern consisting of medial lanceolate stripe connected with 3 pairs of inclined and poorly developed lateral chevron-like bands.

Prosoma. Carapace and chelicerae as shown in Fig. 91 (conspecific female shown in Fig. 92). Clypeus and eye group as in Fig. 124 (conspecific female, Fig. 125). Eye diameters and interdistances: AME 0.13(0.17), ALE 0.22, PLE 0.16, PME 0.11, AME-AME 0.16(0.12), ALE-AME 0.16(0.14), ALEPLE 0.14, PLE-PME 0.02, PME-PME 0.31. Each cheliceral furrow with 9-10 promarginal teeth and 3 mesobasal denticles. Maxillae with 5-6 cuspules each.

LEGS. Scopula: entire on distal metatarsus I and tarsi of palp and leg I, narrowly divided on tarsus II. Trichobothria: 2 rows of 7 each on tibiae, 9-11 on metatarsi, 7-8 on tarsi. Paired tarsal claws with outer and inner teeth rows consisting of 5-6 teeth each. Palpal claw with 5 promarginal teeth.

SpinATION. Femora I-IV dorsally with 3 bristles; patellae I, II, IV and palpal patella aspinose. Palp: femur d1, pd1; tibia v2-2-4; tarsus v3-2. Leg I: femur pd1; tibia v1-1-2; metatarsus v2-2-2. Leg II: femur pd1; tibia v1-1-3; metatarsus v2-2-3. Leg III: femur pd1; patella p1, r1; tibia d1, p1, r1-1, v2-2-3; metatarsus p1-2-2, r1-1-1, v2-2-3. Leg IV: femur pd1; tibia d1, p1-1-1, r1, v2-2-3; metatarsus p1$1-1-1, \mathrm{r} 1(0)-1-1, \mathrm{v} 2-2-3$.

Spermathecae. As shown in Fig. 207.

SPINNERETS. PMS: length 0.35, diameter 0.15. PLS: maximal diameter 0.40; length of basal, medial and apical segments $0.63,0.33,0.37$, respectively; total length 1.33 ; apical segment shortly digitiform.

\section{Variation}

Carapace length in males varies from 4.34 to 4.85 , in females from 3.97 to 4.69 . Spermathecae show a quite insignificant variation (see Figs 206-207).

\section{Ecology}

The spiders collected in the surroundings of Oylat and Baraklı Lake were found hiding in soil cavities under stones in broad-leaved mountain forest dominated by Quercus sp. (Figs 239-246).

\section{Distribution}

Western Turkey (Bursa Province). See Fig. 221. 


\section{Raveniola niedermeyeri group}

\section{Diagnostic characters}

The subapical part of the male palpal tibia dilated retrolaterally and provided with a bare flattened area carrying a ventral sensilla (Figs 189-197). Embolus relatively long, curved or gently twisted, with a rudimentary subapical keel (Figs 191-194), or vestiges of the embolic keel are lost (Figs 189-190, 195-197). Spermathecae relatively narrow, F-shaped (Figs 208-212).

\section{Species included}

Raveniola marusiki sp. nov., R. mazandaranica Marusik, Zamani \& Mirshamsi, 2014, R. niedermeyeri (Brignoli, 1972), R. vonwicki Zonstein, 2000 and R. zaitzevi (Charitonov, 1948).

\section{Key to species of niedermeyeri group}

\section{Males}

1. Subapical part of embolus corkscrew-shaped (Figs 189-196)

- Subapical part of embolus gradually curved (Fig. 197) ............ . niedermeyeri (Brignoli, 1972)

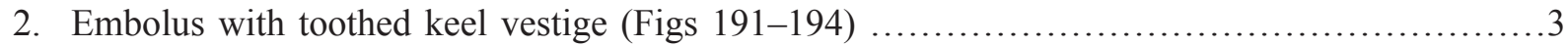

- Embolus smooth, without keel vestige (Figs 189-190, 195-196) ............................4

3. Keel vestige high and pectinate, with two large and a few smaller teeth (Figs 191-192) ... R. marusiki sp. nov.

- Keel vestige low and densely dentate, with several tiny, uniform and equal-sized teeth (Figs 193194)

R. zaitzevi (Charitonov, 1948)

4. Embolus gently spiraled; proximal part of embolus (preceding basal bend) equal in length to following apical part (Figs 189-190) ...R. mazandaranica Marusik, Zamani \& Mirshamsi, 2014

- Embolus sharply spiraled; proximal part of embolus (preceding basal bend) considerably longer than following spiraled apical part (Figs 195-196)

R. vonwicki Zonstein, 2000

\section{Females}

Females of Raveniola marusiki sp. nov. and R. mazandaranica are unknown.

1. Median and lateral receptacles subequal in size or median ones slightly larger than laterals (Figs 210-212)

- Median receptacles considerably smaller than laterals (Figs 208-209)

R. zaitzevi (Charitonov, 1948)

2. Median and lateral receptacles subequal in size; lateral ones with distinct stalk (Fig. 210)

R. vonwicki Zonstein, 2000

- Median receptacles slightly larger than laterals; lateral heads sessile (Figs 211-212)

R. niedermeyeri (Brignoli, 1972)

Raveniola mazandaranica Marusik, Zamani \& Mirshamsi, 2014

Figs 79, 112, 140, 160, 189, 190, 222, 247

Raveniola mazandaranica Marusik, Zamani \& Mirshamsi, 2014: 5, figs 12-18 (ð). 


\section{Diagnosis}

In the shape of the subapically spiraled embolus males of $R$. mazandaranica resemble those of $R$. marusiki sp. nov., $R$. vonwicki and $R$. zaitzevi, but differ from them in having the distal corkscrew-shaped part of the embolus longer and more gently spiraled than in all the mentioned members of the same group (Figs 189-190; cf. Figs 191-196). Female characters are unknown.

\section{Material examined}

\section{Holotype}

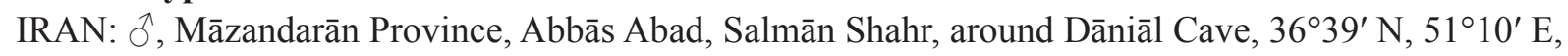
Apr. 2014, P. Beyhaghi leg. (SMF).

\section{Redescription}

Male (holotype)

Habitus. See Fig. 247.

Measurements. TBL 14.50, CL 5.07, CW 4.68, LL 0.38, LW 0.77, SL 2.57, SW 2.06.

Colour. Carapace, chelicerae, palps and legs dorsally brownish rufous; eye tubercle brownish black; sternum, labium, maxillae, palps, and legs ventrally light brownish rufous; abdomen dorsally brown with darker pattern consisting of partially fused irregular dark brown spots; ventral surface of abdomen light greyish brown.

Prosoma. Carapace and chelicerae as shown in Fig. 79. Clypeus and eye group as in Fig. 112. Eye diameters and interdistances: AME 0.15(0.21), ALE 0.33, PLE 0.22, PME 0.17, AME-AME 0.12(0.06), ALE-AME 0.07(0.04), ALE-PLE 0.05, PLE-PME 0.04, PME-PME 0.33. Each cheliceral furrow with 9 promarginal teeth and 1-2 mesobasal denticles. Maxillae with 10-11 relatively large cuspules each.

LEgS. Tibia and metatarsus I as shown in Fig. 140. Scopula: distal on metatarsi I-II, entire on tarsi I-II; absent on tarsi III-IV. Trichobothria: 2 rows of 9-12 each on tibiae, 14-19 on metatarsi, 11-14 on tarsi, $8-9$ on cymbium. Paired claws on tarsi I-II with $8-11$, on tarsi III-IV with $7-8$ teeth on each margin.

LEG MEASUREMENTS.

\begin{tabular}{lcccccc}
\hline & Femur & Patella & Tibia & Metatarsus & Tarsus & Total \\
\hline Palp & 2.71 & 1.48 & 2.24 & - & 0.89 & 7.32 \\
Leg I & 4.02 & 2.27 & 3.36 & 3.24 & 1.81 & 14.70 \\
Leg II & 3.85 & 2.02 & 2.73 & 2.76 & 1.82 & 13.18 \\
Leg III & 3.37 & 1.69 & 3.27 & 3.28 & 1.76 & 13.37 \\
Leg IV & 4.22 & 1.99 & 3.36 & 4.78 & 2.02 & 16.37 \\
\hline
\end{tabular}

SPINATIOn. Patella I and metatarsus I aspinose. Palp: femur d1-1-1, pd1; patella p1; tibia d2-1-0, pd01-1, r0-0-1, pv1-1-2, rv1-1-0; cymbium d7. Leg I: femur d1-1-1-1, pd0-1-1; tibia p1-1-0, pv v11-0, rv1-1-m-m. Leg II: femur d1-1-1-1, pd1(0)-1-1; patella p1; tibia p1-1-1, v2-2-3; metatarsus p0-1-0, v2-2-2. Leg III: femur d1-1-1-1(0), pd1-1-1, rd0-1-1; patella p1, r1; tibia d1-1-0, p1-1-1, r1-1-1, v2-2-3(2); metatarsus d1-1-0, p1-1-1, r1-1-1, v3-2-3(2). Leg IV: femur d1-1-1-1, pd1-1-1, rd0-1-1; patella p1-1, r1; tibia d1(0)-1, p1-1-1-1(0), r1-1-1-1, v2-2-3; metatarsus d2-1-1-1, p1-1$1-1, \mathrm{r} 1-1-1-1, \mathrm{v} 3-2-2-3$. 
PALP. Tibia, cymbium and palpal organ as shown in Fig. 160. Embolic keel lost; embolus slightly corkscrew-shaped with bend located submedially (Figs 189-190).

SPINNERETS. PMS: length 0.31; diameter 0.16. PLS: maximal diameter 0.34; length of basal, medial and apical segments $0.46,0.36,0.37$; total length 1.19 ; apical segment shortly digitiform.

\section{Female}

Unknown.

\section{Ecology}

The male holotype was collected in a deciduous broad-leaved montane forest.

\section{Distribution}

Known only from the type locality (Fig. 222).

Raveniola zaitzevi (Charitonov, 1948)

Figs 12, 18, 27-28, 31, 34, 55-56, 61, 63, 66, 80, 93, 113, 126, 141, 161, 193-194, 208-209, 220

Brachythele zaitzevi Charitonov, 1948: 135 (†).

Brachythele recki Mcheidze, 1983: 122, fig. 1 ()). syn. nov.

Brachythele zaitzevi - Brignoli 1983: 123. — Zonstein 1985: 160.

Raveniola zaitzevi - Zonstein 1987: 1015. — Dunin 1988: 1247; 1989: 33. — Platnick 1989: 91. -

Mikhailov 1997: 20. — Guseinov, Aliev \& Snegovaya 2003: 192. — Guseinov \& Alieva 2008: 281. Raveniola recki-Zonstein 1987: 1015. — Platnick 1989: 90. — Mikhailov 1997: 20.

\section{Diagnosis}

In the general shape of its embolus Raveniola zaitzevi is similar to $R$. vonwicki and $R$. marusiki sp. nov. (Figs 193-194; cf. Figs 195-196), but differs from the former in possessing an embolic keel, and from the latter by having completely different configuration of that keel (very low and evenly micro-serrate in $R$. zaitzevi, and high heterogeneous in $R$. marusiki sp. nov). However, in the shape of the spermathecae, $R$. zaitzevi shows some resemblance to $R$. micropa from another species group, because they both share relatively short and conical spermathecal bases (but it should be noted that females of two closer relatives of $R$. zaitzevi, namely $R$. mazandaranica and $R$. marusiki sp. nov., are as yet unknown). Nevertheless, females of $R$. zaitzevi are well-distinguishable from those of $R$. micropa, because they have longer spermathecae with large globular lateral receptacles which are considerably wider than the medians (in R. micropa spermathecae wider and shorter, and lateral receptacles are subequal to medians, Figs 208209; cf. Figs 206-207).

\section{Material examined}

\section{Holotype}

GEORGIA: + , Lagodekhi, 11 Jun. 1937, A.F. Zaitzev leg. (ZMPU).

\section{Paratypes}

GEORGIA: 2 $\uparrow$, collection data as for holotype (ZMPU).

Additional material $(10 \hat{\partial} \hat{\sigma}, 62$ q $q, 8$ juvs)

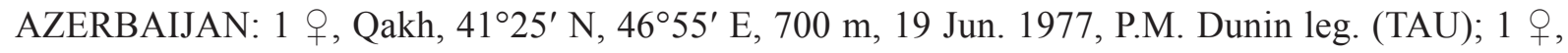

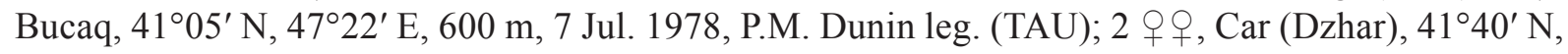




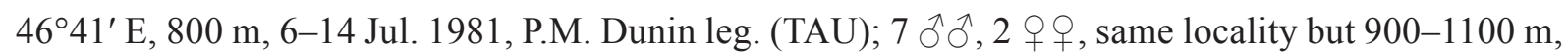
17 Sep. 1987, S.L. Zonstein leg. (TAU); 1 , Zaqatala, $41^{\circ} 38^{\prime}$ N, 46³8' E, 650 m, 10 Jul. 1981, P.M. Dunin leg. (TAU); 12 우, Qalaybugurt, $40^{\circ} 45^{\prime} \mathrm{N}, 48^{\circ} 34^{\prime}$ E, 900 m, 12 Jul. 1982, P.M. Dunin leg.

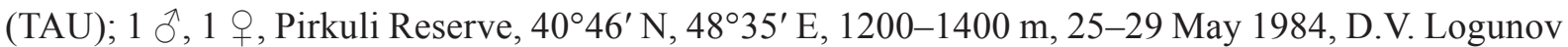

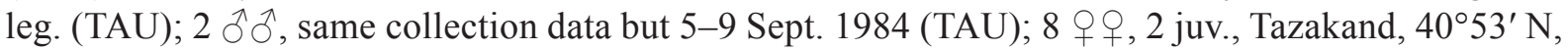

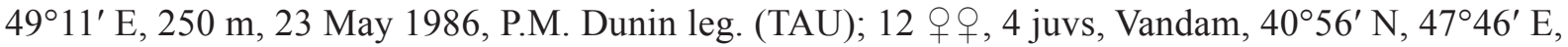
700 m, 17 Jun. 1986, P.M. Dunin leg. (TAU); 3 우, 2 juvs, Qusanca, $40^{\circ} 44^{\prime}$ N, 48 $48^{\circ} 06^{\prime}$ E, 900 m,

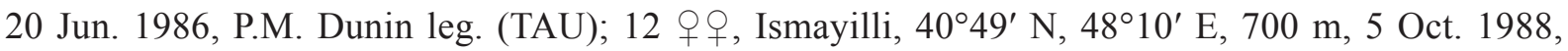
I. Pashenko leg. (TAU).

GEORGIA: 7 우, Lagodekhi Reserve, $41^{\circ} 51^{\prime} \mathrm{N}, 46^{\circ} 17^{\prime} \mathrm{E}, 600-1200$ m, 24 Jul. 1982, Y.M. Marusik leg. (ZMMU).

\section{Description}

Male (Car; described here for the first time)

Habitus. See Fig. 55.

MeAsurements. TBL 13.80, CL 5.40, CW 4.67, LL 0.36, LW 0.87, SL 2.42, SW 2.28.

CoLour. Carapace, palps and legs dorsally brownish orange; eye tubercle with three brownish black spots surrounding AMEs and each of two groups including PME and lateral eyes; chelicerae orangered; sternum, labium, maxillae, palps and legs ventrally pale reddish brown; entire abdomen light greyish brown, with darker brown dorsal pattern represented by interrupted median lanceolate spot and few pairs of also interrupted transverse fasciae located posteriorly, spinnerets pale yellowish brown.

Prosoma. Carapace and chelicerae as shown in Fig. 80. Clypeus and eye group as in Fig. 113. Eye diameters and interdistances: AME 0.13 (0.18), ALE 0.23, PLE 0.13, PME 0.13, AMEAME 0.12(0.07), ALE-AME 0.10(0.08), ALE-PLE 0.09, PLE-PME 0.03, PME-PME 0.35. Each cheliceral furrow with 10-11 promarginal teeth and 8-10 mesobasal denticles. Maxillae with 8-9 cuspules each.

Legs. Tibia and metatarsus I as shown in Fig. 141. Scopula: distal on metatarsi I-II, entire on tarsi I, narrowly divided on tarsi II, elsewhere absent. Trichobothria: 2 rows of 9-11 each on tibiae, 10-11 on metatarsi, 9-11 on tarsi, 8-9 on cymbium. Paired claws: inner and outer margins with $6-8$ teeth each.

Spination. Palp: femur d1-1-1, pd1, rd1; tibia d1-1-1, p1-1-1, r1, v2-3-2; cymbium d7(9). Leg I: femur d1-1-1-1(0), pd1-1, dr1-1; tibia p1-1, pv2-1(2), rv1-1-m-m; metatarsus p1, v1-2-2(3). Leg II: femur d1-1-1-1(0), pd1-1; patella p1-1; tibia p1-1-1, v2-2-3; metatarsus p1-1(0)-1, v2-2-3. Leg III: femur d1-1-1-1, pd1-1-1, rd1-1; patella p1-1, r1; tibia d1, p1-1, r1-1-1, v2-2-3; metatarsus d1-1, p1-1-1, r1-1-1, v2-2-3. Leg IV: femur d1-1-1-0, pd1-1-1, rd1; patella p1(0)-1, r1; tibia d1-1, p1-1, r1-1-1, v2-2-3; metatarsus d1-1-2-1, p1-1-1, r1-1(0)-1, v2-1-1-3. Patella I aspinose.

Palp. Tibia, cymbium and palpal organ as shown in Fig. 161. Embolic keel vestige represented by very low micro-serrate edge formed by numerous uniformly-shaped denticles; subapical part of embolus corkscrew-shaped (Figs 193-194).

SPINNERETS. PMS: length 0.35; diameter 0.18. PLS: maximal diameter 0.37; length of basal, medial and apical segments $0.78,0.63,0.60$; total length 2.01 ; apical segment shortly digitiform. 
LEG MEASUREMENTS. $\widehat{\jmath}($ $(+)$.

\begin{tabular}{lcccccc}
\hline & Femur & Patella & Tibia & Metatarsus & Tarsus & Total \\
\hline Palp & $3.10(3.32)$ & $1.27(1.85)$ & $2.05(2.17)$ & - & $0.99(1.95)$ & $7.41(9.29)$ \\
Leg I & $4.77(4.10)$ & $2.58(2.47)$ & $3.62(3.03)$ & $3.02(2.30)$ & $1.90(1.83)$ & $15.89(13.73)$ \\
Leg II & $4.05(3.65)$ & $2.27(2.38)$ & $2.97(2.88)$ & $2.98(2.32)$ & $1.83(1.77)$ & $14.10(13.00)$ \\
Leg III & $3.43(3.17)$ & $1.83(1.95)$ & $2.32(2.17)$ & $3.30(2.75)$ & $1.86(1.83)$ & $12.72(11.87)$ \\
Leg IV & $4.62(4.05)$ & $2.00(2.37)$ & $3.53(3.25)$ & $4.47(3.97)$ & $2.12(2.13)$ & $16.74(15.77)$ \\
\hline
\end{tabular}

Female (from Lagodekhi)

Habitus. See Fig. 56.

MeAsurements. TBL 17.20, CL 6.22, CW 4.97, LL 0.57, LW 1.10, SL 2.87, SW 2.60.

Colour. As in male, but chelicerae slightly darker, cherry-red; clypeus lighter, yellowish brown.

Prosoma. Carapace and chelicerae as shown in Fig. 93. Clypeus and eye group as in Fig. 126. Eye diameters and interdistances: AME 0.12(0.16), ALE 0.26, PLE 0.12, PME 0.10, AME-AME 0.17(0.13), ALE-AME 0.11(0.09), ALE-PLE 0.05, PLE-PME 0.08, PME-PME 0.40. Each cheliceral furrow with 10-11 promarginal teeth and 6-7 denticles. Maxillae with 9-12 cuspules each. Sternal sigilla small, oval and submarginal as shown in Fig. 63.

Legs. Scopula: distal on metatarsi I-II, entire on tarsus I and palpal tarsus, narrowly divided on tarsus II, elsewhere absent. Trichobothria: 2 rows of 9-10 each on tibiae, 11-15 on metatarsi, 10-13 on tarsi, 8 on palpal tarsus. Paired tarsal claws: 6-7 teeth on inner margin, 5-6 on outer margin. Palpal claw with 4 promarginal teeth.

SPINATION. All femora dorsally with one basodorsal spine and 3-6 bristles (undeveloped spines) located medially and distally; palpal patella and patellae I-II aspinose. Palp: femur pd1; tibia v2-2-3; tarsus v8(9). Leg I: femur pd1; tibia v2-2-3; metatarsus v2-2-1. Leg II: femur d1, pd1; tibia p1-1, v2-23; metatarsus v2-2-2. Leg III: femur pd1-1, rd1-1; patella p1-1, r1; tibia d1, p1-1, r1-1, v2-2-3; metatarsus pd1-1, p1-1-1, r1-1, v2-2-2(3). Leg IV: femur pd 1(0), rd1; patella r1; tibia p1-1, r1(0)-11 , v2-2-3; metatarsus p1-1-1, r1-1-1-1, v2-2-2-2(3).

SPERMATHECAE. Moderately narrow and relatively short, with large globular lateral receptacles (Fig. 208).

SPINNERETS. See Fig. 66. PMS: length 0.50; diameter 0.21. PLS: maximal diameter 0.60; length of basal, medial and apical segments $0.85,0.53,0.60$; total length 1.98 ; apical segment shortly digitiform.

\section{Variation}

Carapace length in males varies from 4.42 to 5.57, in females from 4.70 to 6.45 . The dorsal abdominal pattern in specimens collected from eastern, less humid part of the geographical range, is weakly developed to indistinct. In some females, independent of the localities they were taken from, the posterior half of the carapace looks somewhat lighter in colour than the anterior one (as in specimens T.S. Mcheidze used to describe as Brachythele recki). The structure of the spermathecae in all females examined shows a quite insignificant variation (see Figs 208-209). 


\title{
Ecology
}

The spiders were found inhabiting soil cavities under stones and logs in broad-leaved forests of the low mountain zone and of the midlands. These forests are dominated by Quercus iberica M.Bieb. and Fagus orientalis Lipsky, respectively.

\section{Distribution}

Southern slope of Caucasus Major east of $46^{\circ} \mathrm{E}$ (north-eastern Georgia, north-western Azerbaijan). See Fig. 220.

\section{Notes}

Mcheidze (1983) considered some differences in the colouration of the carapace, in the tarsal claw dentition, and in the number of cuspules sufficient to consider two females from Lagodekhi, Georgia as representatives of a distinct species, Brachythele recki. Having examined the available material, we found that all these differences lay within the limits of intraspecific variability. We thus regard $B$. recki to be a synonym of B. zaitzevi Charitonov, 1948.

\author{
Raveniola marusiki sp. nov. \\ urn:lsid:zoobank.org:act:C48F164E-60BD-4454-A24D-FC7459D30BDF
}

Figs $81,114,142,162,191-192$

\section{Diagnosis}

In the shape of the distally spiraled embolus, the holotype of Raveniola marusiki sp. nov. resembles males of $R$. vonwicki and R. zaitzevi, but differ from them, as well as from other species of the same group, by the unique shape of its pectinate embolic keel (Fig. 191).

\section{Etymology}

The specific epithet is given in honour of our friend and colleague Yuri Marusik for his immense contribution to the study of the spider fauna of Turkey and Iran.

\section{Material examined}

\section{Holotype}

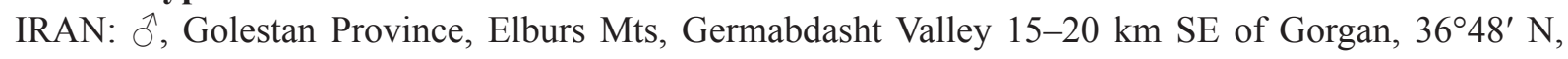
54³4' E, 500-1000 m, 7-9 Oct. 1903, N.A. Zarudny leg. (ZMMU).

\section{Description}

\section{Male (holotype)}

Measurements. TL 14.50, CL 5.64, CW 4.96, LL 0.49, LW 0.97, SL 2.58, SW 2.53.

Colour. Carapace, palps and legs dorsally brownish rufous; eye tubercle anteriorly brownish black, chelicerae reddish brown; sternum, labium, maxillae, palps and legs ventrally yellowish brown; abdomen dorsally brown, with darker pattern consisting of partially fused dark brown irregular spots; ventral surface of abdomen light greyish brown.

Prosoma. Carapace and chelicerae as shown in Fig. 81. Clypeus and eye group as in Fig. 114. Eye diameters and interdistances: AME 0.15(0.19), ALE 0.25, PLE 0.18, PME 0.13, AME-AME 0.10(0.05), ALE-AME 0.08(0.06), ALE-PLE 0.11, PLE-PME 0.04, PME-PME 0.37. Each cheliceral furrow with 9 promarginal teeth and 6 mesobasal denticles. Maxillae: each with 9 relatively small cuspules. 
Legs. Tibia and metatarsus I as shown in Fig. 142. Scopula: distal on metatarsi I-II, entire on tarsi III; absent on tarsi III-IV. Trichobothria: 2 rows of 9-10 each on tibiae, 10-14 on metatarsi, 10-12 on tarsi, 7-8 on cymbium. Paired claws with $8-11$ teeth on each margin.

LEG MEASUREMENTS.

\begin{tabular}{lcccccc}
\hline & Femur & Patella & Tibia & Metatarsus & Tarsus & Total \\
\hline Palp & 3.01 & 1.72 & 2.37 & - & 0.95 & 8.05 \\
I & 4.59 & 2.76 & 3.67 & 3.36 & 2.18 & 16.56 \\
II & 3.90 & 2.14 & 3.03 & 3.24 & 2.00 & 14.31 \\
III & 3.76 & 1.88 & 2.51 & 3.57 & 2.01 & 13.73 \\
IV & 4.75 & 2.25 & 3.70 & 5.12 & 2.28 & 18.10 \\
\hline
\end{tabular}

Spination. Patella I aspinose. Palp: femur d0-1-1-1, pd1; patella p1; tibia d1-1-0, p2-2-2, r1-1, pv0-0-1, rv1-1-0; cymbium d6. Leg I: femur d1-1-1-1, pd1-1-1, rd0-0-1; tibia p1-1-0, pv v1-0-1-0; rv0-1-0$\mathrm{m}-\mathrm{m}$; metatarsus v0-0-2. Leg II: femur d1-1-1-1, pd0-1-1; tibia p1-1-1, v2-2-2; metatarsus p0-1-0; v2-2-2. Leg III: femur d1-1-1-1, pd1-1-1, rd1-1-1; patella p1-1(0), r1; tibia d1-1-0, p1-1-1, r1-11, v2-2-3; metatarsus d1-0-1, p1-1-1, r1-1-1, v2-2-3. Leg IV: femur d1-1-1-1, pd1-1-1, rd0-0-1; patella r1; tibia d1-1-0, p1-1-1, r1-1-1, v2-2-3; metatarsus d1-0-1-0, p2-2-1-1, r1-1-1-1, v2-2-2-3.

PaLP. Tibia, cymbium and palpal organ as shown in Fig. 162. Short pectinate embolic keel consists of two large and a few smaller teeth; embolus gently corkscrew-shaped, with proximal bend located submedially (Figs 191-192).

SPINNERETS. PMS: length 0.48; diameter 0.21. PLS: maximal diameter 0.45; length of basal, medial and apical segments $0.71,0.55,0.58$; total length 1.84 ; apical segment shortly digitiform.

\section{Female}

Unknown.

\section{Ecology}

Judging from the label data, the holotypic male was collected in the broad-leaved forest zone of Alborz Mts. Other details are unknown.

\section{Distribution}

Known only from the type locality.

Raveniola vonwicki Zonstein, 2000

Figs 64, 67, 82, 94, 115, 127, 143, 163, 195-196, 210, 222

Raveniola vonwicki Zonstein, 2000: 49, figs 1-3 (ð゚+ $)$.

\section{Diagnosis}

In the shape of the bulb this species resembles $R$. marusiki sp. nov. and $R$. zaitzevi. It differs from both species by a noticeably longer apical segment of the PLS (Fig. 67; cf. Fig. 66). The males can be distinguished in having a slightly longer embolus lacking dentate keels (Figs 195-196; cf. Figs 191194) and a more slender palpal tibia (Fig. 163; cf. Figs 161-162). The female of $R$. vonwicki differs from those in the same species group in having longer spermathecae with stalked, not sessile, lateral receptacles (Fig. 210; cf. Figs 208-209, 211-212). 


\section{Material examined}

\section{Holotype}

IRAN: §̋, Gilan Province, Hishtpar District, E slope of Bogrovdagh Mts, 7 Apr. 1914, N.S. von Wick leg. (ZISP 454-914).

\section{Paratype}

IRAN: 1 , collected together with the holotype.

\section{Redescription}

Male (holotype)

Measurements. TBL 12.00, CL 5.53, CW 4.15, LL 0.43, LW 0.87, SL 2.53, SW 2.27.

Colour. Carapace, palps and legs dorsally dark brownish rufous; chelicerae reddish brown; sternum, labium, maxillae, palps and legs ventrally light brown; abdomen dorsally brown, with dense light brown spots; ventral surface of abdomen brownish grey.

Prosoma. Carapace and chelicerae as shown in Fig. 82. Clypeus and eye group as in Fig. 115. Eye diameters and interdistances: AME 0.16(0.21), ALE 0.27, PLE 0.13, PME 0.14, AME-AME 0.11(0.06), ALE-AME 0.11(0.09), ALE-PLE 0.09, PLE-PME 0.05, PME-PME 0.35. Each cheliceral furrow with 9-10 promarginal teeth and 4-5 mesobasal denticles. Maxillae with 20-24 cuspules each (Fig. 64).

Legs. Tibia and metatarsus I as shown in Fig. 143. Scopula: distal on metatarsi I-II, entire on tarsi I-II, vestigial on tarsi III, absent on tarsi IV. Trichobothria: 2 rows of 7-8 each on tibiae, 11-14 on metatarsi, 11-12 on tarsi, 9 on cymbium. Paired tarsal claws: outer margin with 8-9 teeth, 6-9 teeth on inner margin.

SPINATIOn. Palp: femur d1-1-1, pd1, rd1; patella r1; tibia d1-1-1, p1-1-1, v7(8); tarsus d5. Leg I: femur d1-1-b-b, pd1-1-1, rd1(0); tibia p1-1, pv1, rv1-1-1-m-m; metatarsus v2. Leg II: femur d1-1-b-b, pd1-1-1; patella p1; tibia p1-1-1, v2-2-3; metatarsus p1, v1-2-3. Leg III: femur d1-1-b-b, pd1-1-1, rd1-1-1; patella p1, r1; tibia d1-1, p1-1, r1-1-1, v2-2-2; metatarsus d1-1-1, pd1-1-1, p1-1-1, r11-1, v2-2-3. Leg IV: femur d1-1-b-b, pd1-1-1, pr1-1-1; patella p1, r1; tibia d1-1, p1-1-1, r1-1-1, v2-2-3; metatarsus d1-1-1, p1-1-1, r1-1-1, v3-2-2-2. Patella I aspinose.

PALP. Tibia, cymbium and palpal organ as shown in Fig. 163. Embolus consisting of almost straight and slightly dilated proximal part lacking keels and of sharply narrowed, spiraled and flattened apical part (Figs 195-196).

SPINNERETS. See Fig. 67. PMS: length 0.53, diameter 0.17. PLS: maximal diameter 0.45; length of basal, medial and apical segments $0.70,0.63,0.77$; total length 2.10 ; apical segment digitiform.

LEG MEASUREMENTS. $\overbrace{}^{\lambda}(+)$

\begin{tabular}{lcccccc}
\hline & Femur & Patella & Tibia & Metatarsus & Tarsus & Total \\
\hline Palp & $2.75(3.40)$ & $1.82(2.23)$ & $2.53(2.65)$ & - & $0.97(2.17)$ & $8.08(10.45)$ \\
Leg I & $4.47(4.47)$ & $2.85(3.07)$ & $3.93(3.05)$ & $3.55(2.65)$ & $2.20(2.03)$ & $17.00(15.27)$ \\
Leg II & $4.10(4.05)$ & $2.43(2.85)$ & $3.30(3.13)$ & $3.25(2.70)$ & $2.13(2.07)$ & $15.21(14.80)$ \\
Leg III & $3.65(3.73)$ & $2.10(2.15)$ & $2.25(2.63)$ & $3.77(3.50)$ & $2.20(2.07)$ & $13.97(14.08)$ \\
Leg IV & $4.57(4.70)$ & $2.17(2.63)$ & $3.97(3.87)$ & $5.85(4.95)$ & $2.43(2.27)$ & $17.99(18.42)$ \\
\hline
\end{tabular}


Female (paratype)

Measurements. TBL 16.50, CL 6.45, CW 5.67, LL 0.57, LW 1.10, SL 3.25, SW 2.87.

Colour. As in male.

Prosoma. Carapace and chelicerae as shown in Fig. 94. Clypeus and eye group as in Fig. 127. Eye diameters and interdistances: AME 0.18(0.23), ALE 0.31, PLE 0.20, PME 0.18, AME-AME 0.22(0.17), ALE-AME 0.12(0.09), ALE-PLE 0.13, PLE-PME 0.05, PME-PME 0.54. Each cheliceral furrow with 10 promarginal teeth and 6-8 mesobasal denticles. Maxillae with 22-23 cuspules each.

LEGS. Scopula: distal on metatarsi I-II, entire on palpal tarsus and tarsi I-II, absent on tarsi III-IV. Trichobothria: 2 rows of 5-7 each on tibiae, 7-11 on metatarsi, 8-10 on tarsi. Paired tarsal claws: outer margin with 5-6 teeth, 5-7 teeth on inner margin. Palpal claw with 5 promarginal teeth.

Spination. All femora with one basodorsal spine and 3-4 stiff dorsal bristles (weak spines) located medially and distally; patella I aspinose. Palp: femur pd1; patella p1; tibia v2-2-3; tarsus v3(8). Leg I: femur pd1; tibia p1-1, v2-2-3; metatarsus v1-2-2(2-2-3). Leg II: femur pd1; patella p1; tibia p1-1, v2-2-3; metatarsus v2-2-3. Leg III: femur pd1, rd1-1; patella p1, r1; tibia d1(0), p1-1, r1-1, v2-2-3; metatarsus d1-1, p1-1-1-1, r1-1-1-1, v2-2-2-3. Leg IV: femur pd1, rd1; patella p1, r1; tibia d1, p1-1, r1-1, v2-2-3; metatarsus d1-1, p1-1-1-1, r1-1-1-1, v2-2-2-3.

SPERMATHECAE. Narrow and relatively long, with stalked lateral receptacles (Fig. 210).

SPINNERETS. PMS: length 0.73, diameter 0.25. PLS: maximal diameter 0.70; length of basal, medial and apical segments 1.15, 0.85, 1.10; total length 3.10; apical segment digitiform.

\section{Ecology}

Unknown.

\section{Distribution}

Known only from the type locality.

Raveniola niedermeyeri (Brignoli, 1972)

Figs 57-58, 83, 95, 116, 128, 144, 164, 197, 211-212, 222, 249-253

Brachythele niedermeyeri Brignoli, 1972: 412, figs 1-2 (ぷ+).

Brachythele niedermeyeri - Brignoli 1983: 123. - Zonstein 1985: 159.

Raveniola niedermeyeri - Zonstein 1987: 1015. — Platnick 1989: 90. — Mozaffarian \& Marusik 2001: 70. - Ghavami 2006: 1843. - Ghahari \& Marusik 2009: 4. - Zonstein \& Marusik 2010: 52, figs $1-9(\widehat{\jmath}+$ ) $)$.

\section{Diagnosis}

This species differs from all other members of the same group by having a gradually tapering and subapically curved embolus (Fig. 197) and by the unusually narrow, laterally inclined spermathecae with small and sessile lateral receptacles (Figs 211-212). In the structure of the embolus, Raveniola niedermeyeri also shows some similarities with a few other congeners, such as $R$. bellula (Li \& Zonstein, 2015), R. ferghanensis (Zonstein, 1984), R. hebeinica Zhu, Zhang \& Zhang, 1999 and R. virgata (Simon, 1891). However, it can be distinguished from them by having a sharply curved subapical part of the 
embolus (vs the more gently curved embolus in those Eastern and Central Asian species, Fig. 197; cf. Figs 165-166; Zonstein \& Marusik 2012: fig. 39; Li \& Zonstein 2015: figs 3A-C, 5A-C).

\section{Material examined}

\section{Holotype}

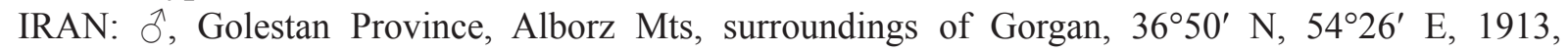
O.R. Niedermeyer leg. (MHNG).

\section{Paratypes}

IRAN: $3 \widehat{\partial} \widehat{\partial}, 2$ + + , collection data as for holotype (MHNG).

Additional material $(3 \hat{\partial} \widehat{\partial}, 5 \stackrel{+}{ } \uparrow, 1 \uparrow$ subad., 15 juvs)

IRAN: 1 ऽ, Golestan Province, surroundings of Gorgan, Sep. 2004, H. Ghahari leg. (TAU); 1 q, 7 juv.,

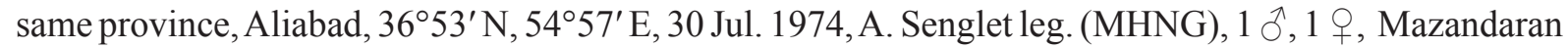
Province, Alborz Mts, oak forest, Jun. 2004, H. Ghahari leg. (ZMMU); 1 +, 1 ㅇ subad., 3 juvs, same

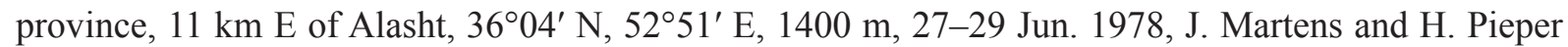
leg. (SMF); 1 , 1 juv., same province, Noor Reserve, $36^{\circ} 35^{\prime} \mathrm{N}, 52^{\circ} 03^{\prime} \mathrm{E}$, near seashore, 29 Jun. 1978 , J. Martens and H. Pieper leg. (SMF); 1 juv., same province, Klard, $20 \mathrm{~km} \mathrm{~S}$ of Amol, $36^{\circ} 28^{\prime} \mathrm{N}, 52^{\circ} 21^{\prime} \mathrm{E}$, 500 m, 24 May 1978, J. Martens and H. Pieper leg. (SMF); 3 juv., same province, Heraz, 25 km S of Amol, 490-560 m, 29 Jun. 1978, J. Martens and H. Pieper leg. (SMF); 1 , Razavi Khorasan Province,

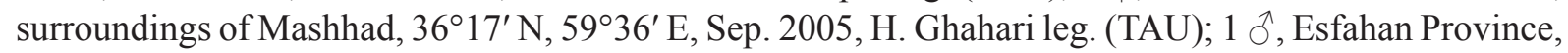

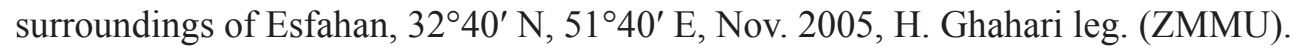

\section{Redescription}

Male (holotype)

Habitus. See Fig. 57.

Measurements. TBL 13.80, CL 5.32, CW 4.55, LL 0.42, LW 0.87, SL 2.45, SW 2.28.

CoLour. Carapace, chelicerae, palps and first pair of legs dorsally intensive rufous-brown; eye tubercle with darker spots surrounding AMEs and lateral eyes; sternum, labium, maxillae and legs II-IV light brownish rufous; abdomen dorsally light greyish brown; dorsal pattern poorly visible, consisting of longitudinal median spot crossed by few transverse fasciae, ventral abdominal surface and spinnerets pale greyish brown.

Prosoma. Carapace and chelicerae as shown in Fig. 83. Clypeus and eye group as in Fig. 116. Eye diameters and interdistances: AME 0.14(0.18), ALE 0.26, PLE 0.18, PME 0.16, AME-AME 0.12(0.08), ALE-AME 0.07(0.05), ALE-PLE 0.07, PLE-PME 0.06, PME-PME 0.33. Chelicerae: each furrow with 9-10 promarginal teeth and 7-8 mesobasal denticles. Maxillae with 6-7 cuspules each.

Legs. Tibia and metatarsus I as shown in Fig. 144. Scopula: distal on metatarsus I, entire on tarsus I, divided on tarsus II; elsewhere absent. Trichobothria: 2 rows of 8-11 each on tibiae, 10-13 on metatarsi, 10-12 on tarsi, 8 on cymbium. Paired tarsal claws: inner and outer margins with $8-10$ teeth each.

SPinAtion. Palp: femur d1-1-0, pd1, rd1; patella p1-1; tibia d1-1, p1-1-1, r1-1-1, v2-1-1-1; cymbium d4(5). Leg I: femur d1-1-0-0, pd1-1-1, rd 1(0)-1-1(0); tibia p1-1-0, v3-2-m-m; metatarsus v1(0)-1. Leg II: femur d1-1-0-0, pd1-1; tibia p1-1-1, v2-2-3; metatarsus p1, v1-2-2-2. Leg III: femur d1-1$0-0$, pd0-1-1, rd0-1-1; patella p1-1, r1; tibia d1-1, p1-1-1, r1-1-1, v2-2-2(3); metatarsus d1-1-2, p1-1-1, r1-1-1, v2(3)-2-3. Leg IV: femur d1-1-0-0, pd0-1-1, rd0-1-1; patella p1, r1; tibia d1-1-2, p1-1-1, r1-1-1, v2-2-2(3); metatarsus pd1-1-2, p1-1-1, r1-1-1, v2-1-2-1(0)-3. Patella I aspinose. 
PALP. Tibia, cymbium and palpal organ as shown in Fig. 164. Bulb with long, gently tapering embolus curved subapically and lacking embolic keel (Fig. 197).

SPINNERETS. PMS: length 0.25 ; diameter 0.15. PLS: maximal diameter 0.35 ; length of basal, medial and apical segments $0.67,0.55,0.37$; total length 1.59 ; apical segment triangular.

LEG MEASUREMENTS. $\widehat{\jmath}(+)$

\begin{tabular}{lcccccc}
\hline & Femur & Patella & Tibia & Metatarsus & Tarsus & Total \\
\hline Palp & $2.75(2.25)$ & $1.68(1.50)$ & $2.23(1.72)$ & - & $0.98(2.01)$ & $7.64(7.48)$ \\
Leg I & $4.17(3.47)$ & $2.68(2.30)$ & $3.27(2.57)$ & $3.00(2.02)$ & $1.77(1.45)$ & $14.89(11.81)$ \\
Leg II & $3.70(3.05)$ & $2.32(2.02)$ & $2.70(2.15)$ & $2.67(1.93)$ & $1.75(1.47)$ & $13.14(10.62)$ \\
Leg III & $3.27(2.77)$ & $1.78(1.77)$ & $2.25(1.80)$ & $3.15(2.45)$ & $1.63(1.52)$ & $11.98(10.31)$ \\
Leg IV & $4.25(3.63)$ & $2.13(2.23)$ & $3.32(2.92)$ & $4.53(3.85)$ & $2.02(1.90)$ & $16.25(14.53)$ \\
\hline
\end{tabular}

Female (paratype)

Habitus. See Fig. 58.

MeAsurements. TL 15.90, CL 5.35, CW 4.23, LL 0.54, LW 1.06, SL 2.38, SW 2.30.

Colour. As in male, but better preserved dorsal abdominal pattern, consisting of numerous and irregularly located small yellowish brown spots on darker brown background.

Prosoma. Carapace and chelicerae as shown in Fig. 95. Clypeus and eye group as in Fig. 128. Eye diameters and interdistances: AME 0.12(0.15), ALE 0.26, PLE 0.20, PME 0.13, AME-AME 0.13(0.10), ALE-AME 0.09(0.07), ALE-PLE 0.08, PLE-PME 0.04, PME-PME 0.38. Each cheliceral furrow with 9 promarginal teeth and 5 mesobasal denticles. Maxillae with 10-11 cuspules each.

LEGS. Scopula: distal on metatarsi I-II, narrowly divided on palpal tarsus and tarsus I, widely divided on tarsus II, elsewhere absent. Trichobothria: 2 rows of 7-9 each on tibiae, 11-14 on metatarsi, 11-14 on tarsi, 9 on palpal tarsus. Paired tarsal claws: outer and inner margins with 5-7 teeth each. Palpal claw with 4 teeth on inner margin.

SPINATION. All femora with one basodorsal bristle-like spine and few stiff bristles (weak spines) located medially and distally; palpal patella and patella I aspinose. Palp: femur d1, pd1; tibia v2-1-2; tarsus v5(6). Leg I: femur d1, pd1; tibia v2-1-2; metatarsus v2-2-2. Leg II: femur d1, pd1; patella p1; tibia p1-1, v2-1-3; metatarsus v2-2-2. Leg III: femur d1, pd 1-1, rd 1-1; patella p1-1, r1; tibia d1, p1-1, r1-1, v2-2-3; metatarsus pd1-1, p1-1-1, r1-1-2, v2-1-3-3. Leg IV: femur d1, rd1; patella p1, r1; tibia p1-1, r1-1-1, v2-2-3; metatarsus d1-1-1, p1-1-1-1, r1-1-1-1, v2-1(2)-2(3)-3.

SpermatheCAe. Narrow; lateral receptacles sessile and vestigial (Fig. 211).

SPINNERETS. PMS: length 0.42; diameter 0.20. PLS: maximal diameter 0.55; length of basal, medial and apical segments $0.65,0.48,0.40$; total length 1.53 ; apical segment triangular.

\section{Variation}

Carapace length in males varies from 4.34 to 5.45; in females from 4.67 to 7.05 . In all examined males the embolus has a practically identical shape. The shape of the spermathecae and the dorsal pattern of the abdomen show some variation (cf. Figs 211-212, 252-253). 


\section{Distribution}

Iran: Alborz, Khorasan and Zagros Mts (Gilan, Mazandaran, Golestan, Razavi Khorasan and Isfahan Provinces). See Fig. 222.

\section{Ecology}

In the Alborz Mts the spiders were collected predominantly in dense montane broad-leaved forests of the hyrcan type as shown in Figs 236-237, dominated by Quercus castaneifolia C.A. Mey. Like in most Western Asian congeners, females use cavities under rocks to build short and very simple retreats almost without any silk lining (Figs 248-251). Wandering males were recorded between June and November.

\section{Discussion}

\section{Taxonomic characters}

Male Cheliceral tumescence. This structure is a pallid and weakly sclerotized cuticular area situated proximally on the prolateral side of the chelicera, opposite the tip of the closed fang in males of some Mygalomorphae. Within the Nemesiidae, the more or less distinctly developed intercheliceral tumescence is present throughout the family, except some Neotropical and Australian genera, and in the entire Paleotropical subfamily Bemmerinae (Raven 1985). It should be specially noted that all intercheliceral tumescences found previously are confined to the inner vertical cheliceral surface (see op. cit., figs 124, 129; Indicatti et al. 2015: fig. 36). However, in males of the Western Asian species of Raveniola the corresponding pallid, softened and possibly glandular area is situated in a more or less developed cavity on the ventral (not the prolateral) surface of the chelicera (Figs 60-61). Goloboff (1995) mentioned a small and slightly excavated glandular area on the ventral cheliceral side near the end of the fang furrow. Since this structure is found in both sexes of some South American nemesiids (op. cit., figs 5-6) and can be present together with a "classical" intercheliceral tumescence in males, he considered these structures as not homological, evolved independently. However, in the Western Asian species of Raveniola, a well-developed cavity and a pale softened area on the cavity bottom were found only in males, never in the conspecific females (see Figs 59-61). Among species of Sinopesa, similar, though less strongly developed structures were detected in males of S. chinensis (Kulczyński, 1901) and S. kumensis (Shimojana \& Haupt, 2000). Within the rest of Raveniola, the presence of a smaller and shallower depression with a vestigial pale area is evident in $R$. fedotovi, $R$. redikorzevi and one undescribed species from Tajikistan, but was not found in other males from this study. Whether this rudiment represents a precursor or a remnant of the male intercheliceral tumescence is uncertain.

MaXiLlary CuSPULEs. In most Western Asian species of Raveniola the number of cuspules confined to the proximal part of the maxillary heel varies from 5 to 10 , with only members of two species $(R$. anadolu sp. nov., $R$. vonwicki) having 20-24 cuspules. This is also characteristic for species of Sinopesa in which usually 4-10 cuspules are arranged alongside the maxillary heel (see Zhu \& Mao 1983: fig. c; Shimojana \& Haupt 2000: fig. 2C; Li \& Zonstein 2015: fig. 20G). The only exception is S. maculata Raven \& Schwendinger, 1995 with 14-17 cuspules. Among the rest of Raveniola, R. guangxi Raven \& Schwendinger, 1995, R. gracilis Li \& Zonstein, 2015 and $R$. spirula Li \& Zonstein, 2015 have only 3-9 cuspules per maxilla (Zonstein \& Marusik 2012: fig. 15; Li \& Zonstein 2015: fig. 15G), whereas other congeners possess 15-70 (generally 20-30) maxillary cuspules arranged in a fairly wide triangular area (Zonstein 2009: figs 3-4; Zonstein \& Marusik 2012: figs 16-21; Li \& Zonstein 2015: figs 1G, 11G, $13 \mathrm{G})$.

CUticle AND LEg Microstructures. In species of Raveniola the cuticle of the carapace is finely granular, while in Sinopesa it is rather smooth (see Zonstein \& Marusik 2012: 96). In contrast, the leg microstructures such as the trichobotrial bases and tarsal organs are very similar in all studied representatives of these two genera (see Figs 7-18, 37-40; Raven \& Schwendinger 1995: fig. 4B-D). 
Male Pedipalps And legs. In Western Asian species of Raveniola the male palpal tibia appears to be noticeably shorter than in most other congeners (Figs 149-162), similar to that in the related genus Sinopesa (Fig. 170). In only two species is it somewhat longer than usual (Figs 163-164) but still shorter than in most members of Raveniola (see below). Correspondingly, the sexual dimorphism in leg length in Western Asian species of Raveniola is less pronounced and male legs (especially the anterior pairs) are generally noticeably shorter and thicker than in most other congeners, resembling those in Sinopesa (see Figs 129-148; Raven \& Schwendinger 1995: fig. 7H, L; Shimojana \& Haupt 2000: fig. 3C-E; Zonstein 2009: figs 5, 7; Zonstein \& Marusik 2012: figs 2, 25-29; Li \& Zonstein 2015: figs 1E, 3E, $9 \mathrm{E}, 11 \mathrm{E}, 15 \mathrm{E}, 17 \mathrm{E})$. Within the rest of Raveniola, males of only a few species have rather similar short or very moderately elongate legs (see Zonstein \& Marusik 2012: fig. 24; Li \& Zonstein: figs 6E, 13E).

Cymbium. In Western Asian members of Raveniola, the cymbium seems to be only moderately short (Figs 149-164). Its shape and relative size vary only slightly among these species (see Figs 159, 163). In other congeners the male palpal tibia generally varies from long to very long, but the cymbium is rather short to very short, almost globular in the latter case (Figs 165-169; Zonstein 1987: figs 5-6, 2000: fig. 4, 2009: fig. 6; Song et al 1999: fig. 17J-K; Zonstein \& Marusik 2012: figs 30-31, 33-35; Li \& Zonstein 2015: figs 1A-C, 2A-C, 6A-C, 7A-C, 9A-C, 10A-C, 15A-C, 16A-C, 17A-C, 19A-C). There are a few exceptions though (Zonstein \& Marusik 2012: fig. 32; Li \& Zonstein 2015: figs 3A-C, $5 \mathrm{~A}-\mathrm{C})$.

MALE PALPAl ORGAN. In most species of Raveniola occurring outside the studied region, the palpal organ generally occupies, with a few exceptions (e.g., in R. montana, see Li \& Zonstein 2015: fig. 11A, C), a more apical position on the cymbium than in Western Asian congeners. This is probably caused by the longer apical part of the cymbium in the latter case (see Figs 149-170). In Raveniola the palpal organ appears unmodified, whereas in Sinopesa it is fairly enlarged (Fig. 170; Raven \& Schwendinger 1995: fig. 7D-E; Song et al. 1999: fig. 17H; Shimojana \& Haupt 2000: fig. 3A-B; Li \& Zonstein 2015: figs 20A-C, 21A-C). Within Raveniola, the embolus varies from a more or less broadly tipped and keeled state (Figs 167, 177, 180) to a corkscrew-shaped or awl-shaped structure (Figs 165-166, 168-169, 183-197), with many parallelisms in species originated from different parts of the genus range (cf. Zonstein \& Marusik 2012: figs 39, 42-43; Li \& Zonstein: figs 1A-C, 3A-C, 6A-C, 13A-C, $15 \mathrm{~A}-\mathrm{C}, 17 \mathrm{~A}-\mathrm{C})$. However, in some species groups of Raveniola, a characteristic shape of the embolus can indicate the group affiliation. The Central Asian $R$. caudata and $R$. redikorzevi, which constitute the caudata species group, share a short, broadly tipped and distinctively shaped embolus (Zonstein 2009: figs 8-9). Males of the hyrcanica species group are distinguishable from other congeners in having a spiraled embolus with the embolic keel raised and twisted subapically (Figs 171-179).

SpermatheCAe. Females of Raveniola and most species of Sinopesa possess their paired spermathecae distinctly divided, each with two separate receptacles (Figs 198-217; Zhu \& Mao 1983: fig. b; Raven \& Schwendinger 1995: fig. 7G; Xu \& Yin 2002: fig. 7). Within Raveniola, many species, regardless of their relationship, have almost the same configuration of the spermathecae (see Figs 210, 213, 216; Zonstein 1984: figs 6, 12; Li \& Zonstein 2015: figs 4A, 5D). On the other hand, members of the hyrcanica species group share the unique broad spermathecal bases (Figs 198-202), with no parallelisms in other congeners.

POSTERIOR MEDIAN SPINNERETS. The pronounced reduction of the posterior median spinnerets is a very conspicuous feature, common in Raveniola and Sinopesa. Within Raveniola the moderately large PMS, normally provided with functional spigots, are found in $R$. caudata and $R$. redikorzevi. All Western Asian Raveniola spp., as well as $R$. concolor and some undescribed Central Asian congeners, have considerably shorter PMS, which are as long as $0.4-0.7$ times the length of the shortened basal segment of PLS, with a few spigots confined to the apex (as shown in Figs 25-30, 41); the same is true for 
Sinopesa chinensis and S. kumensis. In R. ferghanensis, R. virgata and some Eastern Asian members of Raveniola, the PMS are rudimentary and shorter than 0.2-0.4 times the length of the basal PLS segment; they generally lack functional spigots, as shown on Fig. 42. Judging from its description (see Xu \& Yin 2002: fig. 6), S. chengbuensis Xu \& Yin, 2002 may also belong to the latter group. In S. maculata, S. ninhbinhensis Li \& Zonstein, 2015, R. fedotovi, R. kopetdaghensis, as well as in R. guangxi and some other Chinese species of Raveniola, the PMS are completely lost. We thus conclude that all Western Asian members of Raveniola are closer to the initial stages of PMS reduction than to the final step of this process.

POSTERIOR LATERAL SPINNERETS. In the Nemesiidae the posterior lateral spinnerets are plesiomorphically relatively long, ending in a digitiform apical segment (Raven 1985). Within Raveniola this form of apical PLS segment is found in most Western Asian species (Figs 43-46, 50-56, 65-67). Only $R$. niedermeyeri was shown to have a shortened and triangular rather than digitiform apical segment of the PLS (Zonstein \& Marusik 2010). Approximately the same form of this segment has been revealed in the course of this study in R. turcica sp. nov. In the rest of Raveniola, as well as in Sinopesa, the apical segment varies generally from digitiform to shortly digitiform (Zhu \& Mao 1983: fig. d; Raven \& Schwendinger 1995: figs 7J, 8B; Shimojana \& Haupt 2000: fig. 2G; Li \& Zonstein 2015: figs 6D, G, 11D, $\mathrm{G}, 15 \mathrm{G}, 17 \mathrm{G}, 20 \mathrm{D}, \mathrm{G})$. However, in $R$. caudata and $R$. redikorzevi this segment is considerably longer (Zonstein 2009: fig. 2), possibly a result of the secondary elongation. Vice versa, in $R$. ferghanensis, $R$. virgata, $R$. hebeinica Zhu, Zhang \& Zhang, 1999 and some other congeners, the apical segment of the PLS is shorter and almost triangular, as shown in Zhu et al. (1999: fig. 6).

\section{Relationships}

The Western Asian representatives of Raveniola seem to be more closely related to each other than to any other congeners outside the three considered groups. Their members share a specific construction of the male chelicerae, with a well-expressed basoventral cavity carrying a pallid softened area, like those shown in Figs 60-61. We consider this structure a possible analogy of a poorly developed intercheliceral tumescence. So deeply excavated cheliceral cavities are unknown for the rest of this genus and Sinopesa. These species were also found to generally have a shorter male palpal tibia, a longer cymbium and fewer maxillary cuspules than most other congeners. However, the latter characters are of a certainly lesser taxonomic significance, because separately they have a scattered distribution throughout the rest of Raveniola. The shape of the PMS and PLS appears to be more uniform (and closer to their precursors) in Western Asian congeners, while in other species of the genus it has a wider range of variation.

Among the Western Asian species groups, the hyrcanica group appears to be the most properly defined. The five members of this group share the uniformly shaped bases of the spermathecae (Figs 198-202), which are unusually wide for Raveniola spp. The structure of the embolus, with a characteristic screwshaped keel (Figs 171-179), unique for the congeners, is common to all males of the hyrcanica group (except for $R$. sinani sp. nov., whose males are unknown). Within the group, $R$. pontica possesses a longer embolus, with a somewhat smaller keel (Figs 178-179; cf. Figs 171-177), and shorter spermathecae (Fig. 202; cf. Figs 198-201, 203) than those in other members, and can thus be considered as being separate from the rest of this group.

The niedermeyeri species group seems to be less well defined than the preceding one. Strictly speaking, it can currently be constituted almost exclusively on the unique male palpal characters. In all males of this group a dilated subapical part of the palpal tibia bears a bare flattened area and ventral sensilla (Figs 189-197). However, the spermathecae in the niedermeyeri group are less distinctive and their shape resembles that in the Raveniola females belonging to other species groups (Figs 208-212; cf. Figs 206-207, 213, 216). In addition, in this group the females are known for only three of the five known species. It should be noted that all members of this group, except for R. niedermeyeri (Fig. 197), 
share a general shape of a corkscrewed subapical part of the embolus (see Figs 189-196). Within this core of the niedermeyeri species group, $R$. mazandaranica has the subapical part of the embolus curved more gently and relatively longer (Figs 189-190; cf. Figs 191-196), which separates it from the other species.

The micropa species group includes the rest of the Western Asian Raveniola spp. It comprises the species which cannot be assigned to any of the two preceding groups. In members of the micropa group the male palpal tibia is less modified than in species of the niedermeyeri group, lacking the hump provided with a characteristic ventrodistal sensilla (Figs 153-159; cf. Figs 161-164). The keel, even if present in the proximal or median part of the embolus, is not twisted as in the representatives of the hyrcanica group (Figs 180-183; cf. Figs 171-179). The spermathecae in members of the micropa group only differ slightly in shape (they are faintly wider) from those in species of the niedermeyeri species group (Figs 180-183; cf. Figs 171-179). Since four of the six species belonging to the micropa group are known for only one sex, the lack of available taxonomic characters within this species group is more pronounced than in the preceding two. We thus conclude that only $R$. biresekensis sp. nov., which has a raised embolic keel (Figs 180-181; cf. Figs 183-188), can currently be separated from the rest of this group, which looks very uniform.

\section{Biogeography}

Members of Raveniola (R. micropa) and Nemesia (an undescribed species) were found inhabiting the same habitat in Oylat, western Turkey (39 $55^{\prime} 59^{\prime \prime}$ N, 29 $35^{\prime} 20^{\prime \prime}$ E). Apart from that, the geographical ranges of these genera are separated. Most areas lying inside the distributional range of Nemesia belong to the Mediterranean biome (Decae 2012). The distribution of Raveniola in Western Asia stretches over continental Asia east of the Mediterranean region (Fig. 218).

The known geographical range inhabited by spiders belonging to the three Western Asian species groups of Raveniola somewhat exceeds $2700 \mathrm{~km}$ from west to east, and extends about $1800 \mathrm{~km}$ in the north-south direction. The minimal distance between the localities of Raveniola spp., belonging to the Western and Central Asian species groups, respectively (between Mashhad in Iran for $R$. niedermeyeri and Zulfagar Mts in Turkmenistan for $R$. redikorzevi), is about $140 \mathrm{~km}$. As the north-western part of Iran is not well investigated, there is a possibility of finding more localities there with members of different species groups.

The geographical range of the hyrcanica species group is confined mostly to the entire Caucasus Minor and to the western part of Caucasus Major, where the members of this group occur in the absence of other congeners (Figs 219-220, 222). Only R. sinani sp. nov. was found outside this area, in Diyarbakir Province situated in the south-eastern part of Anatolia (Fig. 221). This biogeographical "split" could simply beexplained by the fact that the eastern regions of Anatolia, lying between the two abovementioned parts of the group range, appear not to be well investigated.

Regarding the members of the micropa species group, the known area of their distribution is entirely restricted to the Asian part of Turkey. Most species occur in the south-eastern and eastern parts of Anatolia, within a relatively narrow area alongside the national border from the Gulf of Iskenderun in the south-west to Lake Van in the north-east. The distribution of R. micropa is confined to the Marmara Region in the far western part of Turkey (see Fig. 221). We thus see a vast empty space between these two groups of localities. This gap is most probably the result of the incomplete inventory. It should be reminded that prior to this study, $R$. micropa was known only for the holotypic female.

The geographical range of the niedermeyeri species group is limited to the south-eastern part of the Caucasus Major and predominantly to the northern provinces of Iran (Fig. 222; the unusual occurrence 
of $R$. niedermeyeri in the central part of Iran might be based on a label error). Apart from the range mentioned above, its distribution area appears interrupted and split into two parts, with an isolated range for $R$. zaitzevi. In this case, the gap is connected with the distribution of two members of the hyrcanica species group, $R$. dunini sp. nov and $R$. hyrcanica, which is "wedged" in between the localities inhabited by $R$. zaitzevi and $R$. vonwicki, respectively. It is unclear whether this interruption can be considered real or if it is simply based on incomplete information. The spider fauna of the Talysh Mts, which includes the entire geographical range of $R$. hyrcanica, is relatively well investigated (see Otto 2015). Unfortunately, the same cannot be said regarding the spider fauna of Caucasus Minor, encompassing a few known localities of $R$. dunini sp. nov.

\section{Acknowledgements}

We thank Yuri Marusik (Institute for Biological Problems of the North, Magadan), Vladimir Ovcharenko (the former curator of the ZISP spider collection), Peter Schwendinger (MHNG), Shuqiang Li (ICAZ), Peter Jäger and Julia Altmann (SMF), Nikolai Pakhorukov (the former curator of the MZPU spider collection), Alexander Koval (VIZR), the late Pyotr Dunin (Baku, Azerbaijan, later Tolyatti, Russia), Kirill Mikhailov (ZMMU), Jürgen Gruber (the former curator of the NMW spider collection), Christine Rollard and Elise-Anne LeGuin (MNHN), and Laura Leibensperger (MCZ) for providing nemesiid specimens for study. We are grateful to our Turkish colleagues, Rahşen Kaya (Uludağ University, Bursa) and Recep Sulhi Özkütük (Anadolu University, Eskişehir), for help and assistance while collecting in Turkey in September 2010 and Mehmet Özkörük for his help during field trips in south-eastern Anatolia. Our colleagues Mykola Kovblyuk (Tavrida University, Crimea) and Natalia Snegovaya (Research Institute of Zoology, Baku) kindly provided us with photographs of relevant Caucasian landscapes. Kadir Kunt and Ersen Yağmur thank Alireza Zamani (University of Tehran, Iran) for photographs showing nemesiid localities in Iran, live spiders and their retreats. Special thanks go to Seppo Koponen (ZMUT) for providing us with museum facilities. An early draft of the manuscript was kindly edited by Naomi Paz (TAU). We thank Shuqiang Li and Peter Schwendinger for their valuable comments and recommendations which helped to improve the original manuscript. This study was supported in part by the Ministry of Absorption, Israel.

\section{References}

Ausserer A. 1871. Beiträge zur Kenntnis der Arachniden-Familie Territelariae Thorell (Mygalidae Autor). Verhandlungen der kaiserlich-königlichen zoologisch-botanischen Gesellschaft in Wien 21: $177-224$.

Bonnet P. 1955. Bibliographia araneorum Vol. 2 (1). Douladoure, Toulouse.

Brignoli P.M. 1972. Une nouvelle Brachythele de l'Iran (Arachnida, Araneae, Dipluridae). Revue suisse de Zoologie 79: 409-413.

Brignoli P.M. 1983. A Catalogue of the Araneae described between 1940 and 1981. Manchester University Press, Manchester.

Charitonov D.E. 1948. A new species of Brachythele from Georgia. Soobshcheniya Akademii Nauk Gruzinskoi SSR 9: 135-139. [In Russian and Latin]

Decae A.E. 2012. Geography-related sub-generic diversity within the Mediterranean trapdoor spider genus Nemesia (Araneae, Mygalomorphae, Nemesiidae). Arachnologische Mitteilungen 43: 24-28. https://doi.org/10.5431/aramit4304

Dunin P.M. 1988. Mygalomorphic spiders (Aranei, Mygalomorphae) of Azerbaijan. Zoologicheskii Zhurnal 67 (8): 1245-1248. [In Russian with English summary] 
Dunin P.M. 1989. Fauna and altitudinal distribution of spiders (Arachnida, Aranei) of the Azerbaijan part of the southern macroslope of the Caucasus Major. In: Lange A.B. (ed.) Fauna i Ekologiya Paukov i Skorpionov: 31-39. Nauka, Moscow. [In Russian]

Ghahari H. \& Marusik Y.M. 2009. New data on spider fauna of Iran (Araneae). Turkish Journal of Arachnology 2: 1-8.

Ghavami S.M. 2006. Renewed checklist of spiders (Araneae) of Iran. Pakistan Journal of Biological Sciences 9 (10): 1839-1851.

Goloboff P.A. 1995. A revision of the South American spiders of the family Nemesiidae (Araneae, Mygalomorphae). Part I: species from Peru, Chile, Argentina, and Uruguay. Bulletin of the American Museum of Natural History 224: 1-189.

Guseinov E.F. \& Alieva T.V. 2008. The fauna of spiders (Arachnida: Araneae) of Pirkuli Reserve, Azerbaijan. Proceedings of the Azerbaijan Society of Zoologists 1: 281-287. [In Russian with English summary]

Guseinov E.F., Aliev H.A. \& Snegovaya N.Y. 2003. To the knowledge of the spider fauna of Ismailly Reserve. Materials of the 1st Congress of Azerbaijan Society of Zoologists: 191-195. [In Azerbaijani with English summary]

Indicatti R.P., Folly-Ramos E., Vargas A.B., Lucas S.M. \& BrescovitA.D. 2015. Two new tiny Nemesiidae species from Reserva Biológica do Tinguá, Rio de Janeiro, Brazil (Araneae: Mygalomorphae). Zoologia (Curitiba) 32 (2): 123-138. https://doi.org/10.1590/S1984-46702015000200003

Kovblyuk M.M. \& Ponomarev A.V. 2008. New and interesting spiders (Aranei: Agelenidae, Corinnidae, Gnaphosidae, Nemesiidae, Thomisidae) from the West Caucasus. Caucasian Entomological Bulletin 4 (2): 143-154. [In Russian with English summary]

Kovblyuk M.M., Marusik Y.M., Ponomarev A.V., Gnelitsa V.A. \& Nadolny A.A. 2011. Spiders (Arachnida: Aranei) of Abkhazia. Arthropoda Selecta 20 (1): 21-56. [In Russian with English summary]

Kunt K.B. \& Yağmur E.A. 2010. A new species of the mygalomorph spider genus Raveniola Zonstein, 1987 (Araneae; Nemesiidae) from Turkey. Turkish Journal of Zoology 34: 305-309. https://doi.org/10.3906/zoo-0906-40

Le Peru B. 2011. The Spiders of Europe, a Synthesis of Data: Volume 1. Atypidae to Theridiidae. Mémoires de la Société Linnéenne de Lyon 2, Société Linnéenne, Lyon.

Li S. \& Zonstein S. 2015. Eight new species of the spider genera Raveniola and Sinopesa from China and Vietnam (Araneae, Nemesiidae). ZooKeys 519: 1-32. https://doi.org/10.3897/zookeys.519.8784

Marusik Y.M., Zamani A. \& Mirshamsi O. 2014. Three new species of mygalomorph and filistatid spiders from Iran (Araneae, Cyrtaucheniidae, Nemesiidae and Filistatidae). ZooKeys 463: 1-10. https://doi.org/10.3897/zookeys.463.8692

Mcheidze T.S. 1983. A new spider species, Brachythele recki sp. nov., from Georgia. In: Eliashvili T. (ed.) Fauna i Ekologia Bespozvonochnykh Gruzii: 155-159. Metzniereba Publishing House, Tbilisi. [In Russian]

Mikhailov K.G. 1997. Catalogue of the Spiders of the Territories of the Former Soviet Union (Arachnida, Aranei). Zoological Museum of the Moscow State University, Moscow.

Mozaffarian F. \& Marusik Y.M. 2001. A checklist of Iranian spiders (Aranei). Arthropoda Selecta 10 (1): 67-74.

Otto S. 2015. Caucasian Spiders. A faunistic database on the spiders of the Caucasus. Version 1.4.3. Available from http://caucasus-spiders.info/ [accessed 25 Feb. 2017]. 
Platnick N.I. 1989. Advances in Spider Taxonomy 1981-1987: A Supplement to Brignoli's A Catalogue of the Araneae described between 1940 and 1981. Manchester University Press, Manchester and New York.

Platnick N.I. 1993. Advances in Spider Taxonomy 1988-1991, with Synonymies and Transfers 19401980. The New York Entomological Society, New York.

Ponomarev A.V. 2009. New species and finds of spiders (Aranei) from the south of Russia and Western Kazakhstan. Caucasian Entomological Bulletin 5 (2): 143-146. [In Russian]

Ponomarev A.V. \& Chumachenko Y.A. 2007. Arachnida in ground mesofauna of yew-box grove of the Caucasian biospheric reserve. In: Lebedeva N.V. (ed.) Studies of the Southern Scientific Center of the Russian Academy of Sciences. Issue III: Biodiversity and Transformation of Mountain Ecosystems of Caucasus:151-163. SSC RAS Publishing, Rostov-on-Don. [In Russian]

Ponomarev A.V. \& Mikhailov K.G. 2007. Addition to the fauna of spiders (Aranei) of the Russian Caucasus. In: Lebedeva N.V. (ed.) Studies of the Southern Scientific Center of the Russian Academy of Sciences. Issue III: Biodiversity and Transformation of Mountain Ecosystems of Caucasus:130-150. SSC RAS Publishing, Rostov-on-Don. [In Russian]

Ponomarev A.V., Kovblyuk N.M., Chumachenko Y.A. \& Volkova D.D. 2012. Preliminary data on the fauna of spiders of the Republic of Adygea. In: Matishov G.G. \& Khunagov P.O. (eds) Social-Humane and Ecological Problems of Development of Contemporary Adygea: 447-481. SSC RAS Publishing, Rostov-on-Don. [In Russian]

Raven R.J. 1980. The Australian mygalomorph spider genus Ixamatus Simon (Dipluridae: Diplurinae) and its affinities. Bulletin of the British Arachnological Society 5: 43-49.

Raven R.J. 1984. Systematics of the Australian curtain-web spiders (Ischnothelinae: Dipluridae: Chelicerata). Australian Journal of Zoology (Suppl. Ser.) 93: 1-102.

Raven R.J. 1985. The spider infraorder Mygalomorphae (Araneae): cladistics and systematics. Bulletin of the American Museum of Natural History 182 (1): 1-180.

Raven R.J. \& Schwendinger P.J. 1995. Three new mygalomorph spider genera from Thailand and China (Araneae). Memoirs of the Queensland Museum 38: 623-641.

Reimoser E. 1919. Katalog der echten Spinnen (Araneae) des paläarktischen Gebietes. Abhandlungen der Zoologische-Botanischen Gesellschaft in Wien 10 (2): 1-280.

Roewer C.F. 1942. Katalog der Araneae von 1758 bis 1940. Volume 1. Natura, Bremen.

Shimojana M. \& Haupt J. 2000. A new nemesiid spider (Arachnida, Araneae) from the Ryukyu Archipelago, Japan. Zoosystema 22: 709-717.

Schwendinger P.J. 2009. A taxonomic revision of the genus Phyxioschema (Araneae, Dipluridae), I: species from Thailand. Zootaxa 2126: 1-40.

Schwendinger P.J. \& Zonstein S.L. 2011. A taxonomic revision of the genus Phyxioschema (Araneae, Dipluridae), II: species from central Asia. Zootaxa 2815: 28-48.

Song D.X., Zhu M.S. \& Chen J. 1999. The Spiders of China. Hebei Science and Technology Publishing House, Shijiazhuang.

Spassky S.A. 1937. Araneae palaearcticae novae. Mygalomorphae. I. Festschrift Embrik Strand 3: 361368.

Spassky S.A. \& Minenkova K. 1940. New data on spiders of the group Mygalomorphae in the USSR and some conclusions from their geographical distribution. Trudy Rostovskogo biologicheskogo Obshchestva 4: 138-141. [In Russian] 
World Spider Catalog. 2017. World Spider Catalog, version 18.0. Natural History Museum Bern. Available from http://wsc.nmbe.ch [accessed 15 Feb. 2017].

Xu X. \& Yin C.M. 2002. A new species of the genus Raveniola from Baiyundong Cave, Hunan Province (Araneae: Nemesiidae). Acta Zootaxonomica Sinica 27: 474-476.

Zhu C.D. \& Mao J.Y. 1983. A new species of spider of the genus Macrothele from China (Araneae: Dipluridae). Journal of the Bethune Medical University 9 (Suppl.): 133-134. [In Chinese]

Zhu M.S., Zhang F. \& Zhang J.X. 1999. A new mygalomorph spider (Nemesiidae: Raveniola) from China. Journal of Hebei University 19: 366-368. [In Chinese]

Zonstein S.L. 1984. New species of mygalomorph spiders of the genus Brachythele (Aranei: Dipluridae: Diplurinae) in southern Kirghizia. In: Utochkin A.S. (ed.) Fauna and Ecology of Arachnids. Perm University 41-45. [In Russian]

Zonstein S.L. 1985. Preliminary data on the fauna of the spider suborder Mygalomorphae from the USSR. Trudy zoologicheskogo Instituta AN SSSR 139: 156-161. [In Russian with English summary]

Zonstein S.L. 1987. A new genus of mygalomorph spiders of the subfamily Nemesiinae (Aranei, Nemesiidae) in the Palearctic fauna. Zoologicheskii Zhurnal 66 (7): 1013-1019. [In Russian with English summary]

Zonstein S.L. 2000. Two new species of the mygalomorph spider genus Raveniola Zonstein, 1987 (Araneae, Nemesiidae) from southwestern Asia. Tethys Entomological Research 2: 49-52.

Zonstein S.L. 2009. A review of the mygalomorph spiders of the Raveniola caudata species-group (Araneae, Nemesiidae). Zootaxa 2217: 37-42.

Zonstein S. \& Marusik Y.M. 2010. Raveniola niedermeyeri from Iran: redescription and new data on distribution (Araneae, Nemesiidae). ZooKeys 57: 51-57. https://doi.org/10.3897/zookeys.57.497

Zonstein S. \& Marusik Y.M. 2012. A review of the genus Raveniola (Araneae, Nemesiidae) in China, with notes on allied genera and description of four new species from Yunnan. ZooKeys 211: 71-99. https://doi.org/10.3897/zookeys.211.3060

Zonstein S. \& Marusik Y.M. 2016. A revision of the spider genus Zaitunia (Araneae, Filistatidae). European Journal of Taxonomy 214: 1-97. https://doi.org/10.5852/ejt.2016.214

Manuscript received: 21 September 2016

Manuscript accepted: 16 June 2017

Published on: 30 January 2018

Topic editor: Rudy Jocqué

Desk editor: Kristiaan Hoedemakers

Printed versions of all papers are also deposited in the libraries of the institutes that are members of the EJT consortium: Muséum national d'Histoire naturelle, Paris, France; Botanic Garden Meise, Belgium; Royal Museum for Central Africa, Tervuren, Belgium; Natural History Museum, London, United Kingdom; Royal Belgian Institute of Natural Sciences, Brussels, Belgium; Natural History Museum of Denmark, Copenhagen, Denmark; Naturalis Biodiversity Center, Leiden, the Netherlands; Museo Nacional de Ciencias Naturales-CSIC, Madrid, Spain; Real Jardín Botánico de Madrid CSIC, Spain. 

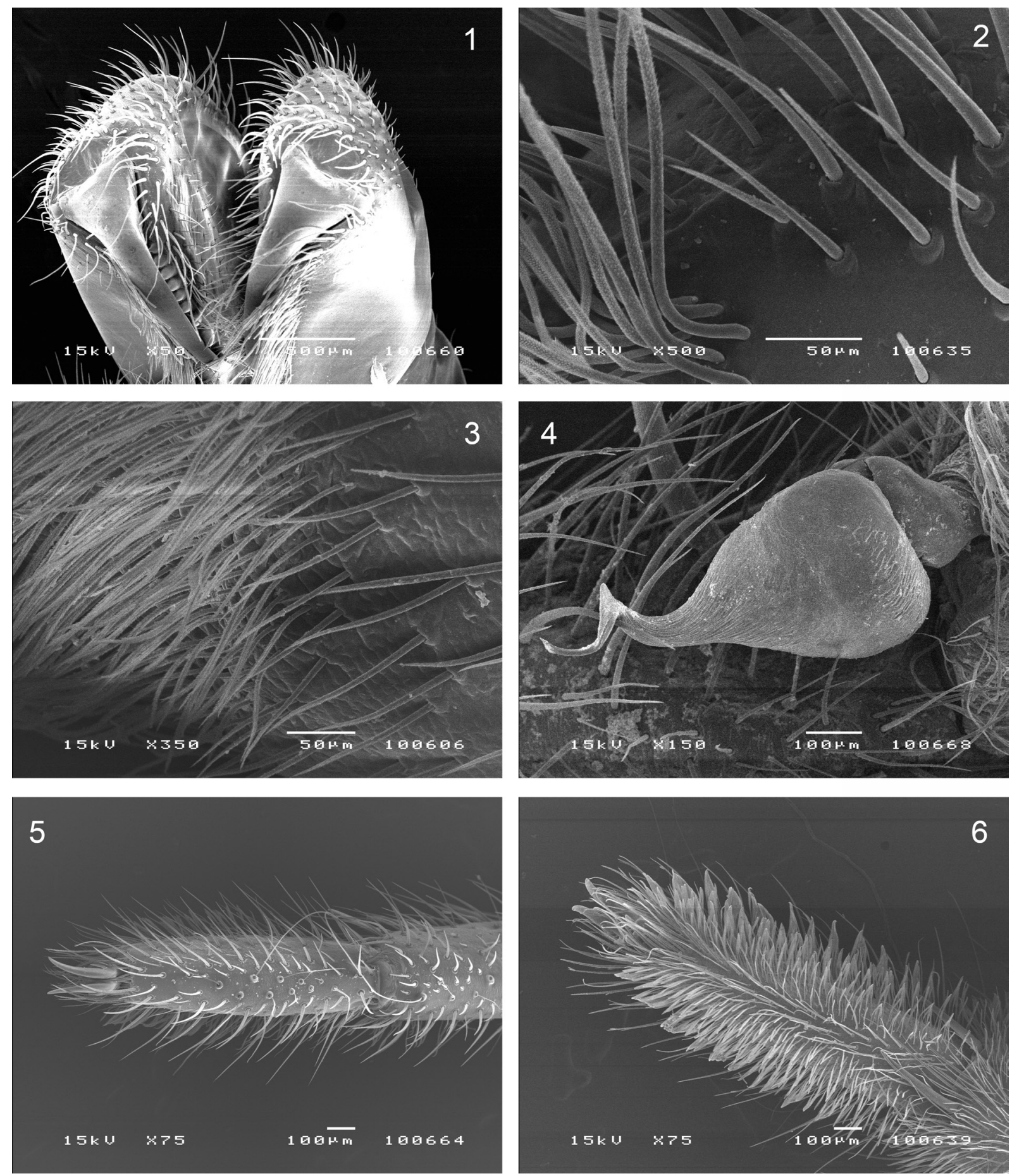

Figs 1-6. Raveniola spp., $\rightarrow \propto(1-3,5-6)$ and $\widehat{\partial}(4)$. Chelicerae (1), apical edge of maxilla (2-3), palpal organ (4) and tarsus I (5-6); ventroapical (1), ventral $(2-4,6)$ and dorsal (5) views. - 1-2. R. micropa (Ausserer, 1871). 3-5. R. pontica (Spassky, 1937). 6. R. hyrcanica Dunin, 1988. 

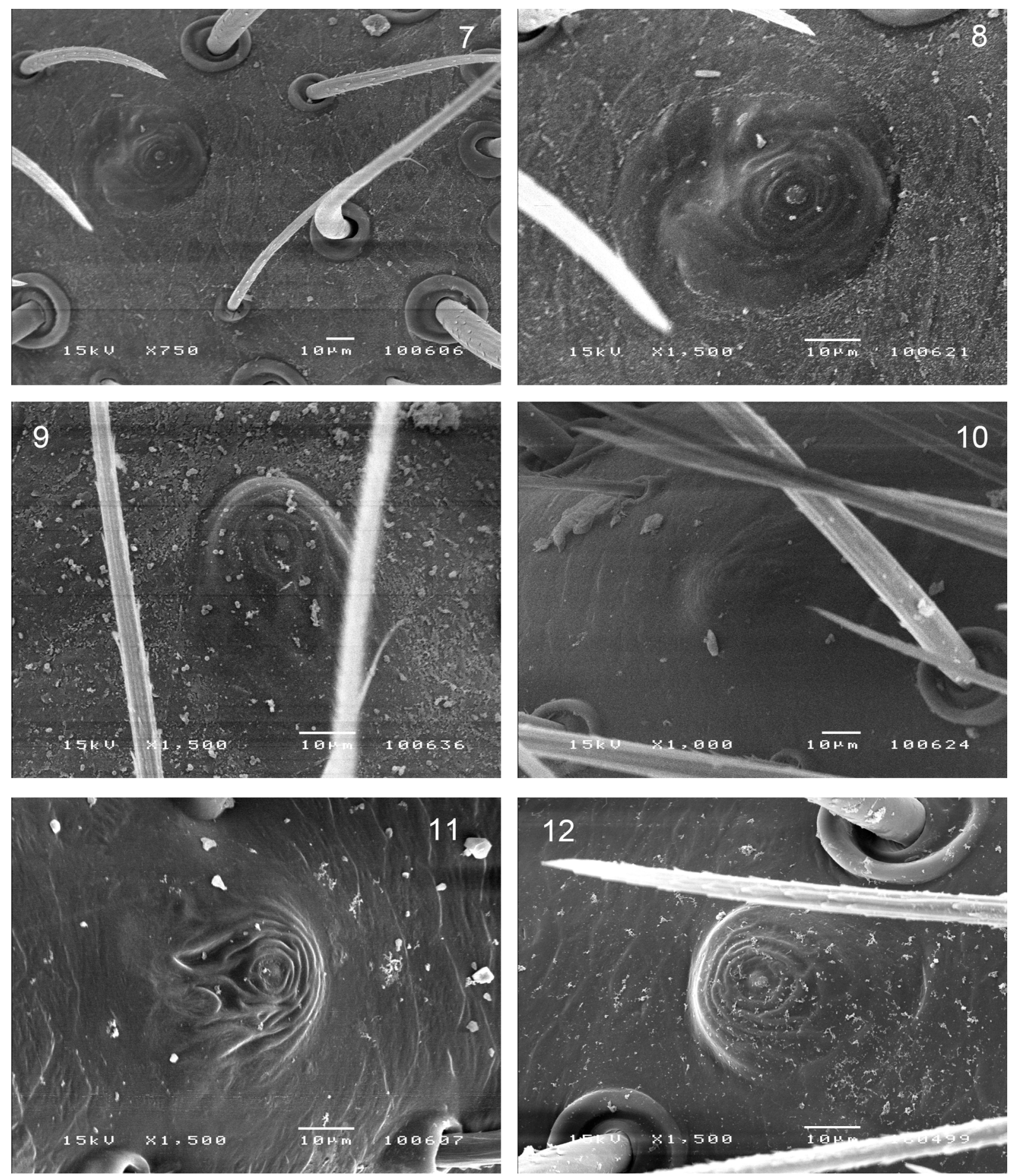

Figs 7-12. Raveniola spp., $q$. . Tarsal organ, legs I $(7-8,10,12)$ and IV $(9,11)$, dorsal views. 7-9. R. hyrcanica Dunin, 1988. 10. R. pontica (Spassky, 1937). 11. R. micropa (Ausserer, 1871). 12. R. zaitzevi (Charitonov, 1948). 


\section{ZONSTEIN S. et al., Revision of Raveniola (I): species from western Asia}
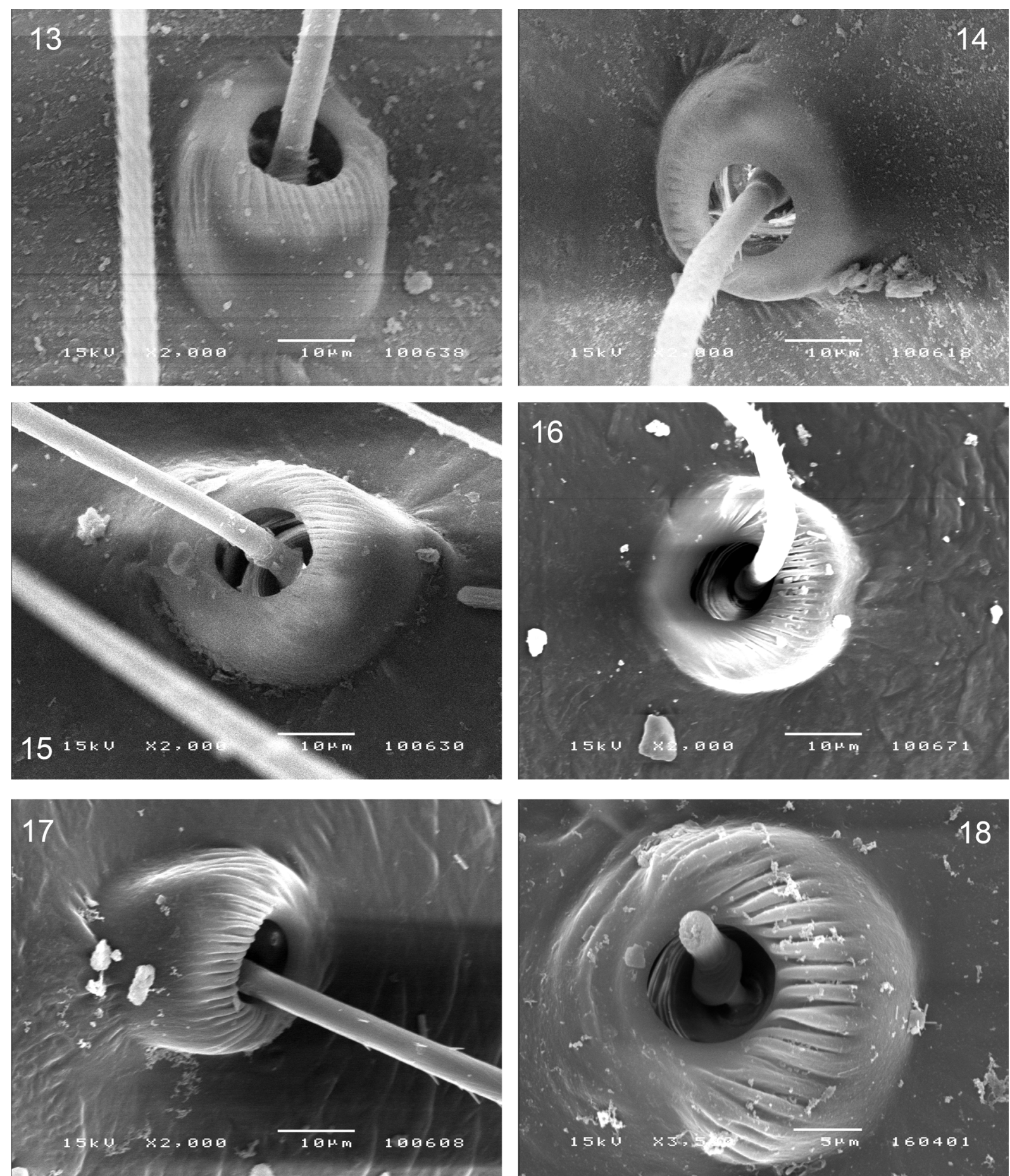

Figs 13-18. Raveniola spp., $ㅇ$ ․ Bases of trichobothria, legs I $(13,15-16,18)$ and IV $(14,17)$, dorsal views. - 13-14. R. hyrcanica Dunin, 1988. 15. R. pontica (Spassky, 1937). 16-17. R. micropa (Ausserer, 1871). 18. R. zaitzevi (Charitonov, 1948). 

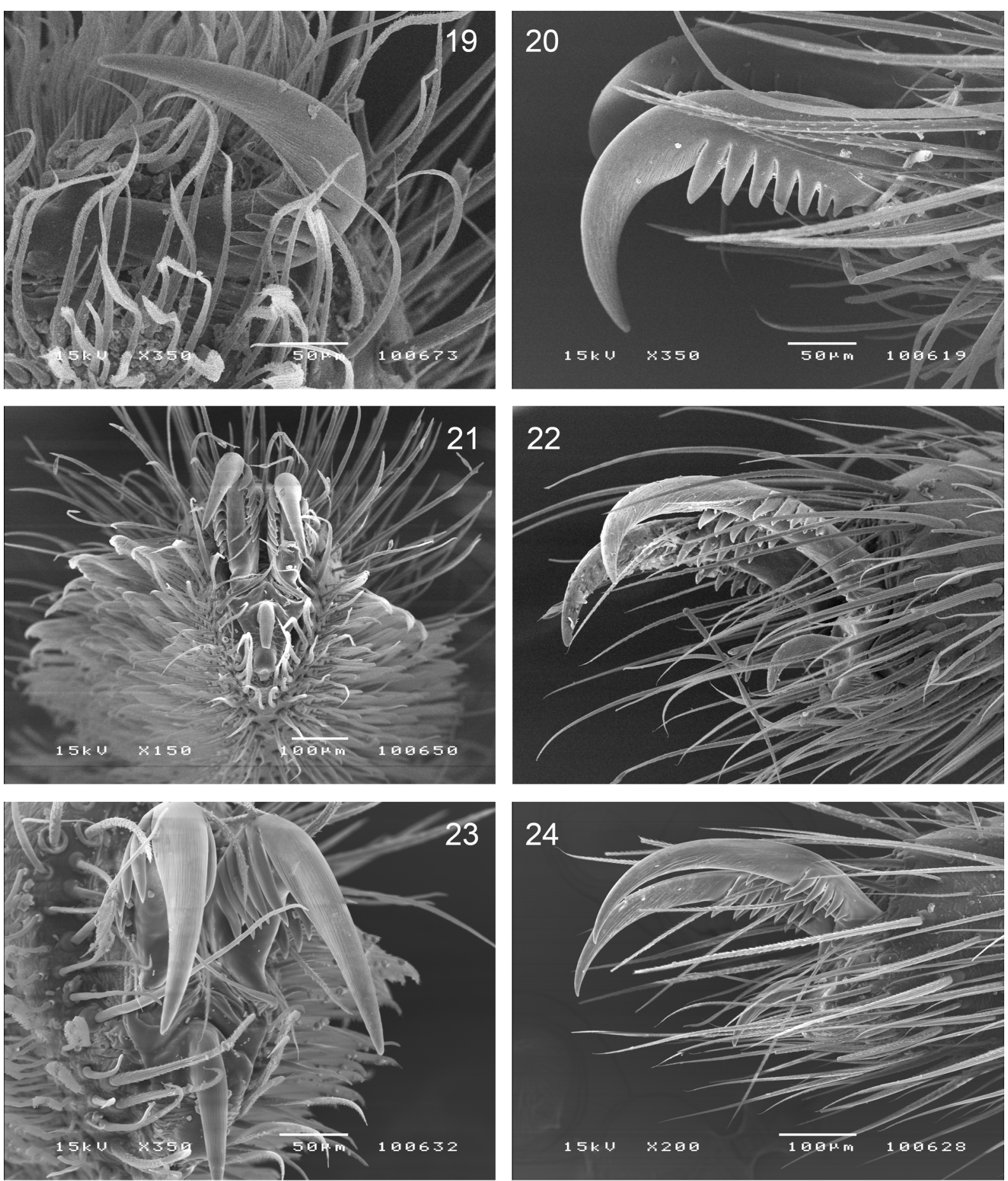

Figs 19-24. Raveniola spp., + +. Palpal (19) and tarsal (20-24) claws; apical $(19,21,23)$ and lateral (20, 22, 24) views. - 19-20. R. pontica (Spassky, 1937). 21-22. $R$. hyrcanica Dunin, 1988, legs I and IV. 23-24. R. micropa (Ausserer, 1871), legs I and IV. 


\section{ZONSTEIN S. et al., Revision of Raveniola (I): species from western Asia}
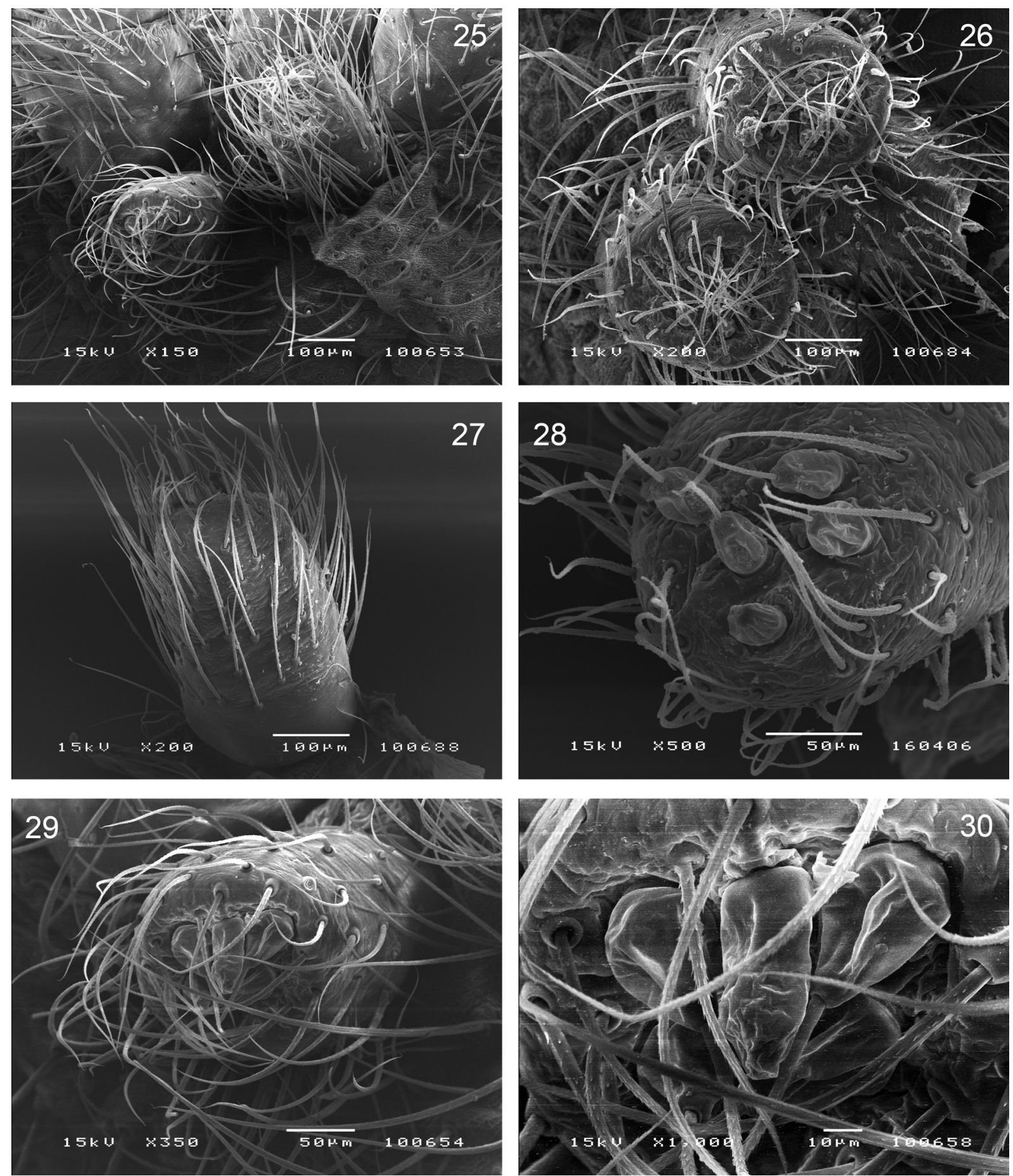

Figs 25-30. Raveniola spp., $q$ 우. Posterior median spinnerets (25-27), details of spigots (28-30); apical (25-26, 28-30) and ventral (27) views. - 25, 29-30. R. hyrcanica Dunin, 1988. 26. R. pontica (Spassky, 1937). 27-28. R. zaitzevi (Charitonov, 1948). 

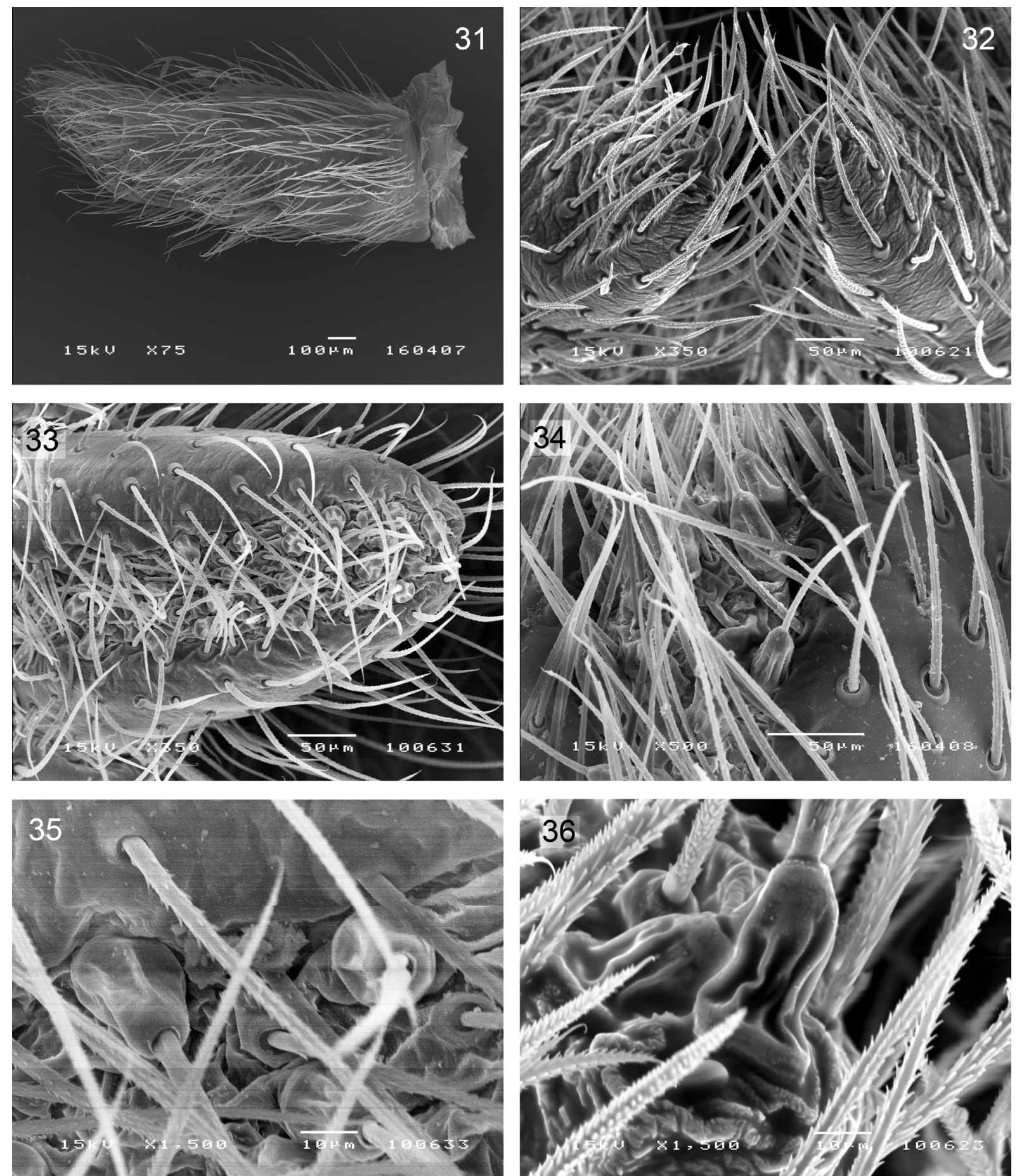

Figs 31-36. Raveniola spp., + ㅇ. Posterior lateral spinnerets (31-33), with spigots in close-up view (34-36); proventral $(31)$, apical $(32,36)$ and ventral $(33-35)$ views. - 31, 34. R. zaitzevi (Charitonov, 1948). 32, 36. R. micropa (Ausserer, 1871). 33, 35. R. hyrcanica Dunin, 1988. 


\section{ZONSTEIN S. et al., Revision of Raveniola (I): species from western Asia}
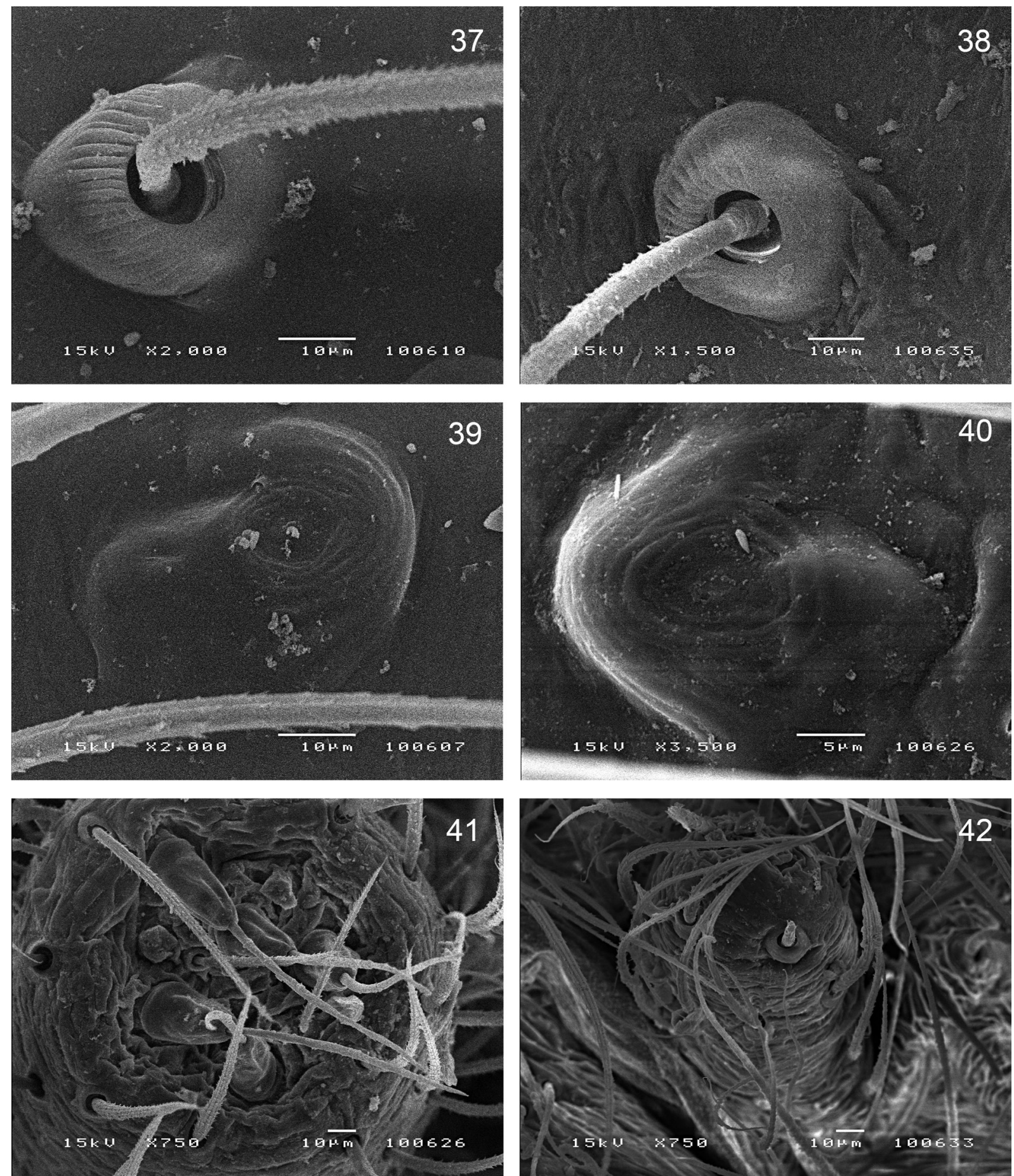

Figs 37-42. Raveniola spp., 우 tarsal organ, leg I (39-40) and posterior median spinnerets (41-42); dorsal (37-39) and apical (41-42) views. - 37, 39. Undescribed Raveniola sp. H (Uzbekistan). 38, 41. Undescribed Raveniola sp. M (Tadjikistan). 40, 42. R. virgata (Simon, 1891) (Kyrghyzstan). 


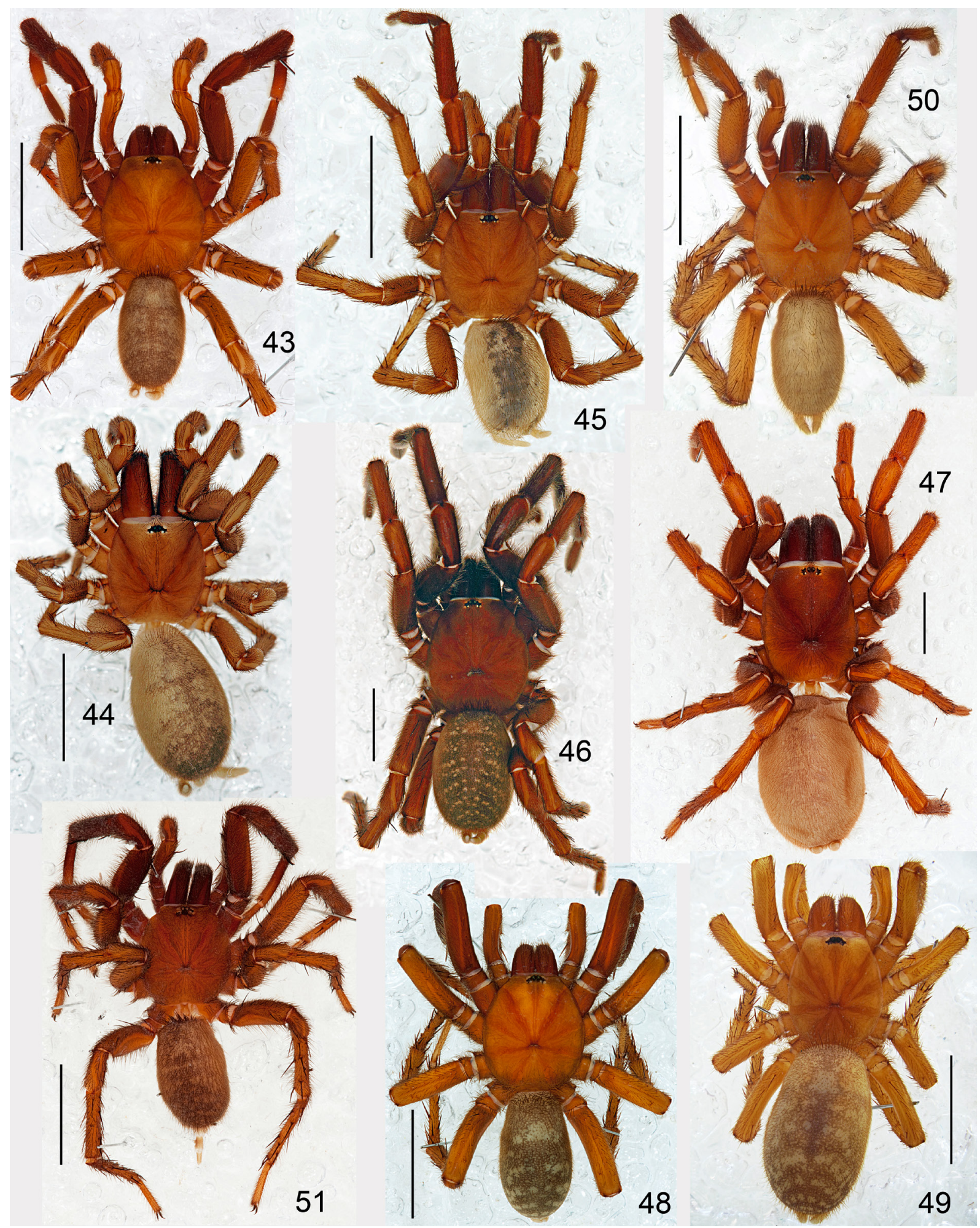

Figs 43-51. Raveniola spp., habitus of $\partial^{\lambda} \partial^{\lambda}(43,45-46,48,50-51)$ and $q$ + $(44,47,49)$, dorsal views. 43-44. $R$. adjarica sp. nov. 45. $R$. dunini sp. nov. 46-47. R. hyrcanica Dunin, 1988. 48-49. R. pontica (Spassky, 1937). 50. R. birecikensis sp. nov. 51. R. anadolu sp. nov. Scale bars: $5.0 \mathrm{~mm}$. 


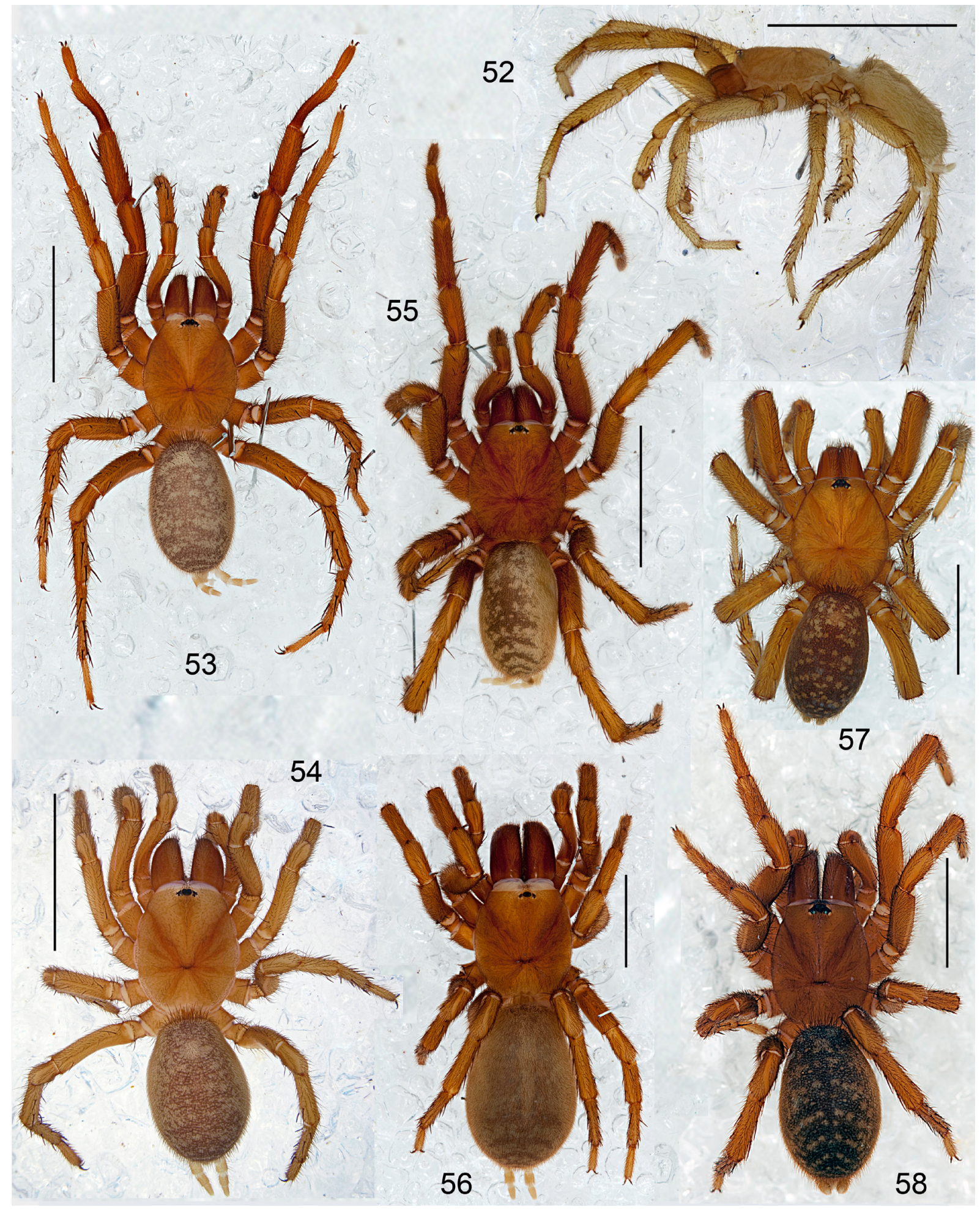

Figs 52-58. Raveniola spp., habitus of $\widehat{\partial} \widehat{\partial}(52-53,55,57)$ and $ㅇ ㅜ(54,56,58)$, lateral $(52)$ and dorsal (53-58) views. - 52. R. biresekensis sp. nov. (dwarf conspecific male?). 53-54. R. micropa (Ausserer, 1871). 55-56. $R$. zaizevi (Charitonov, 1948). 57-58. R. niedermeyeri (Brignoli, 1972). Scale bars: $5.0 \mathrm{~mm}$. 

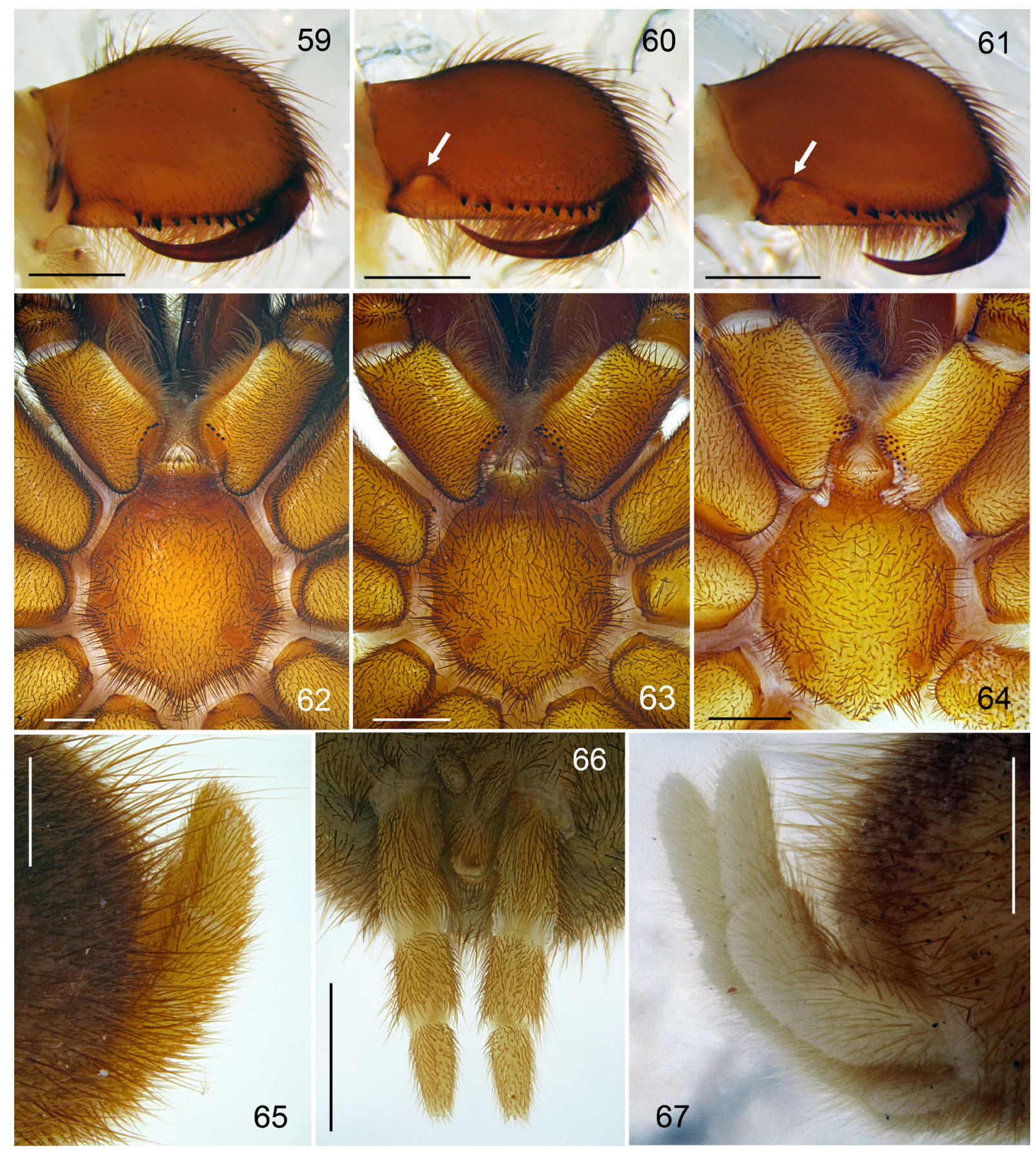

Figs 59-67. Raveniola spp., $q$ + $(59,63,66)$ and $\widehat{\partial}(60-62,64-65,67)$. Left chelicera (59-61; white arrow indicates male intercheliceral organ), sternum, labium and maxillae (62-64), and spinnerets (6567); prolateral $(59-61,65,67)$ and ventral $(62-64,66)$ views. - 59-60. . pontica (Spassky, 1937). 61, 63, 66. $R$. zaizevi (Charitonov, 1948). 62, 65. R. hyrcanica Dunin, 1988. 64, 67. R. vonwicki Zonstein, 2000. Scale bars: $5.0 \mathrm{~mm}$. 


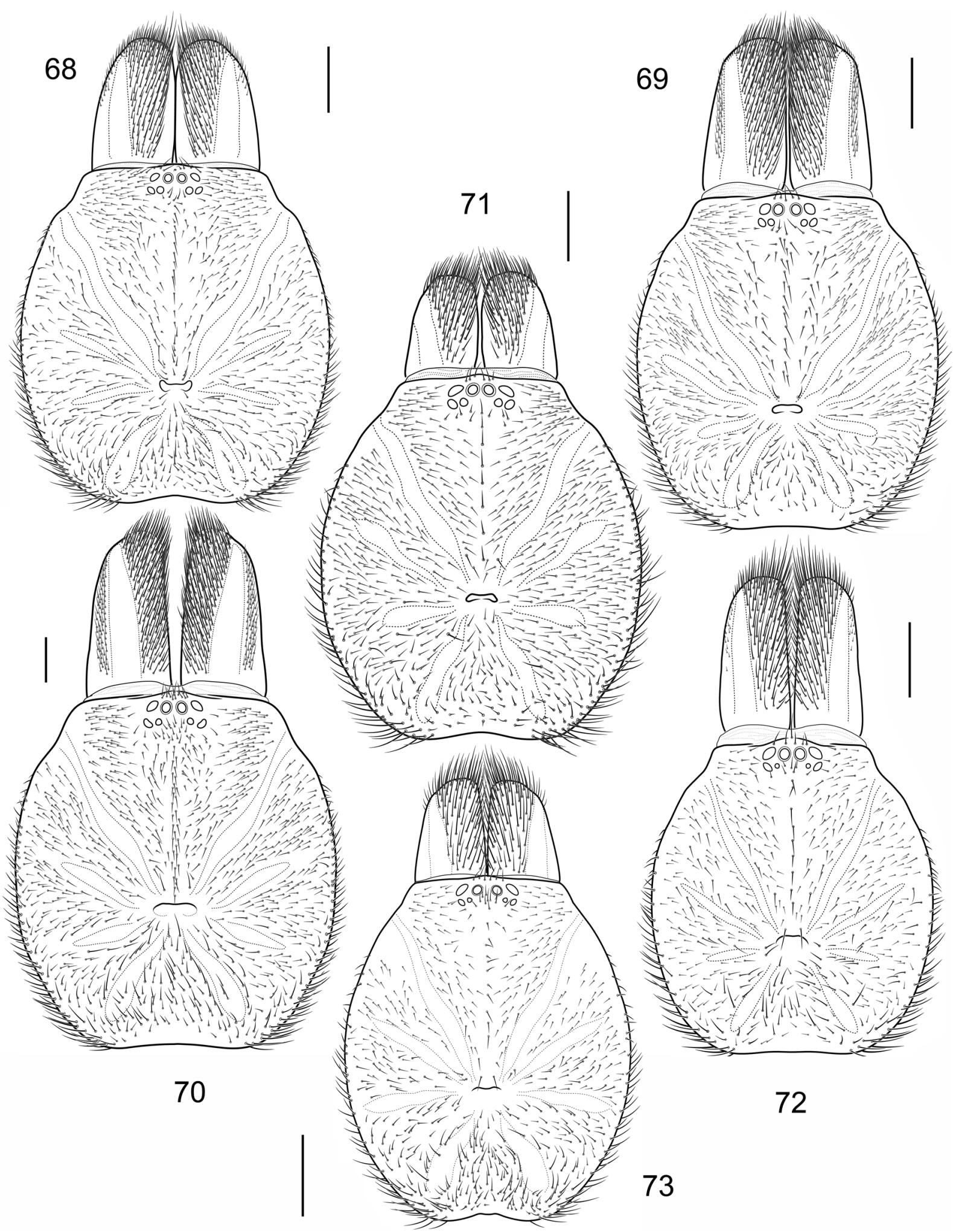

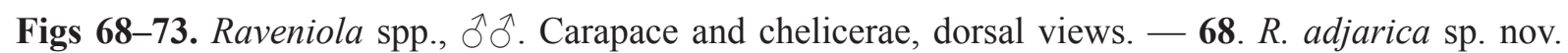
(holotype). 69. R. dunini sp. nov. (holotype). 70. R. hyrcanica Dunin, 1988 (holotype). 71. R. pontica (Spassky, 1937) (Lazarevskoe). 72. R. birecikensis sp. nov. (holotype). 73. Same species as preceding (paratype, Birecik). Scale bars: $1.0 \mathrm{~mm}$. 


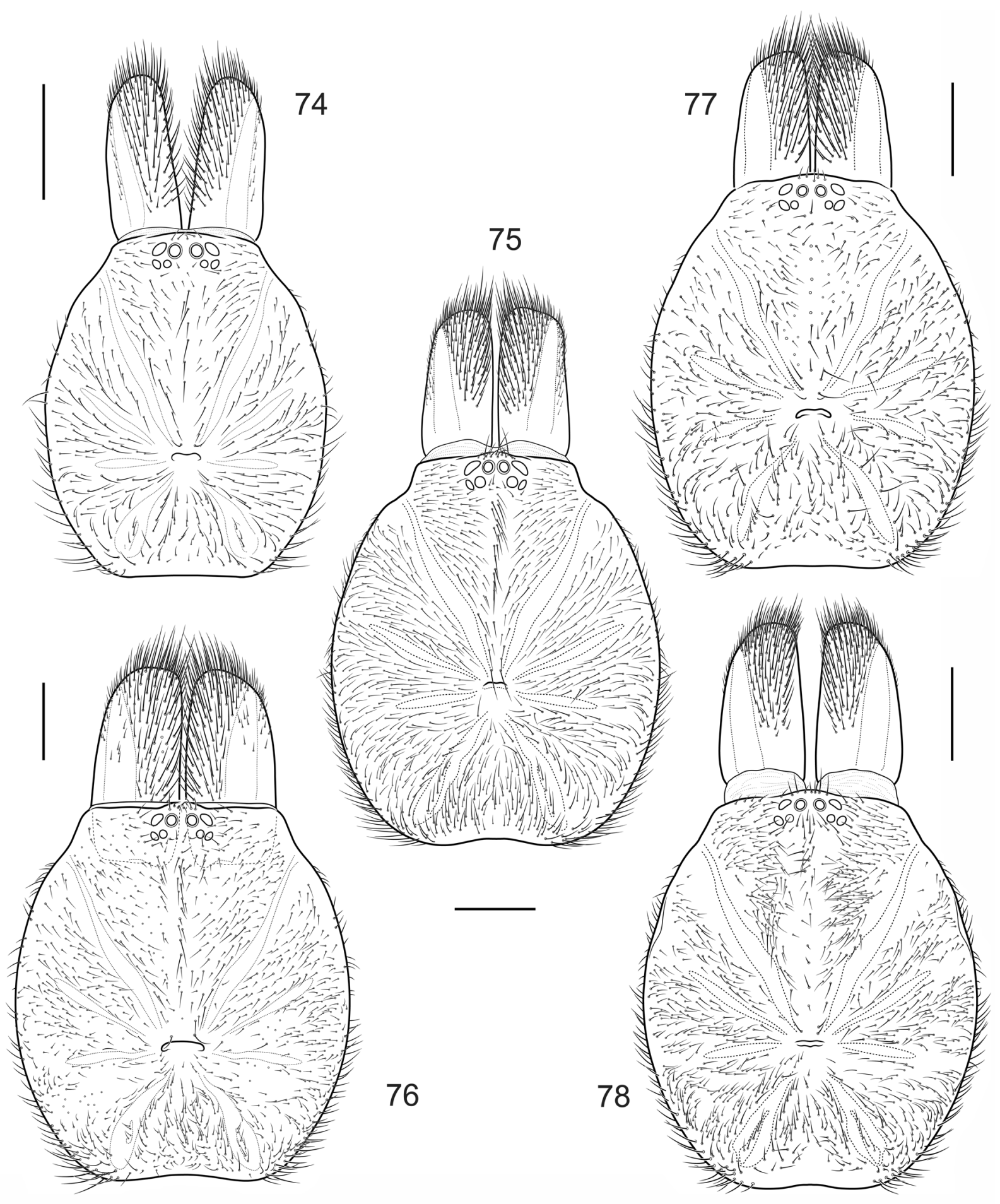

Figs 74-78. Raveniola spp., $\widehat{\partial}$. Carapace and chelicerae, dorsal views. - 74. R. biresekensis sp. nov. (dwarf conspecific male?). 75. R. anadolu sp. nov. (holotype). 76. R. arthuri Kunt \& Yağmur, 2010 (holotype). 77. R. turcica sp. nov. (holotype). 78. R. micropa (Ausserer, 1871) (Uludağ). Scale bars: 1.0 $\mathrm{mm}$. 


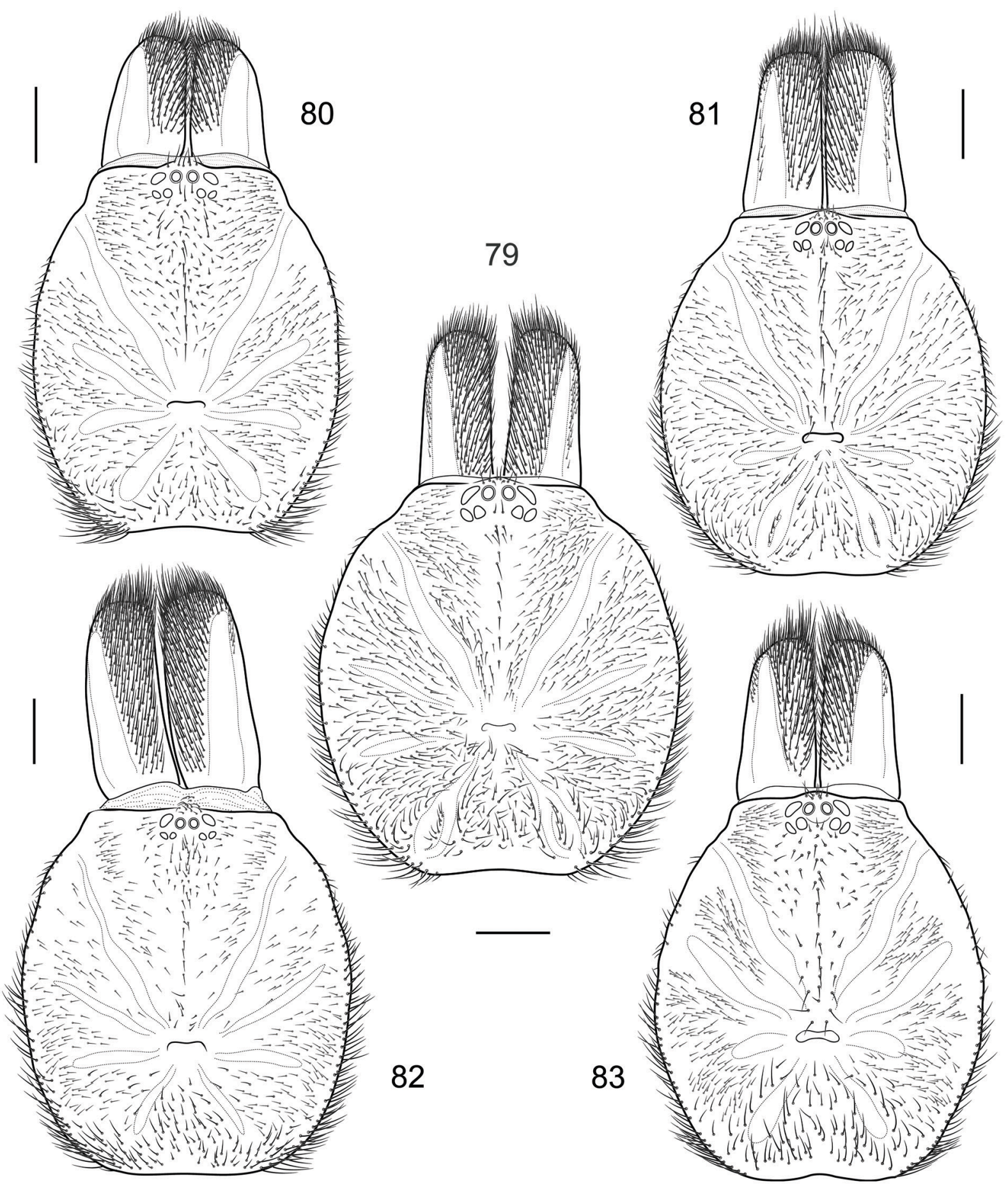

Figs 79-83. Raveniola spp., $\widehat{\partial}$. Carapace and chelicerae, dorsal views. - 79. R. mazandaranica Marusik, Zamani \& Mirshamsi, 2014 (holotype). 80. R. zaitzevi (Charitonov, 1948) (Car). 81. R. marusiki sp. nov. (holotype). 82. R. vonwicki (Zonstein, 2000) (holotype). 83. R. niedermeyeri (Brignoli, 1972) (holotype). Scale bars: $1.0 \mathrm{~mm}$. 


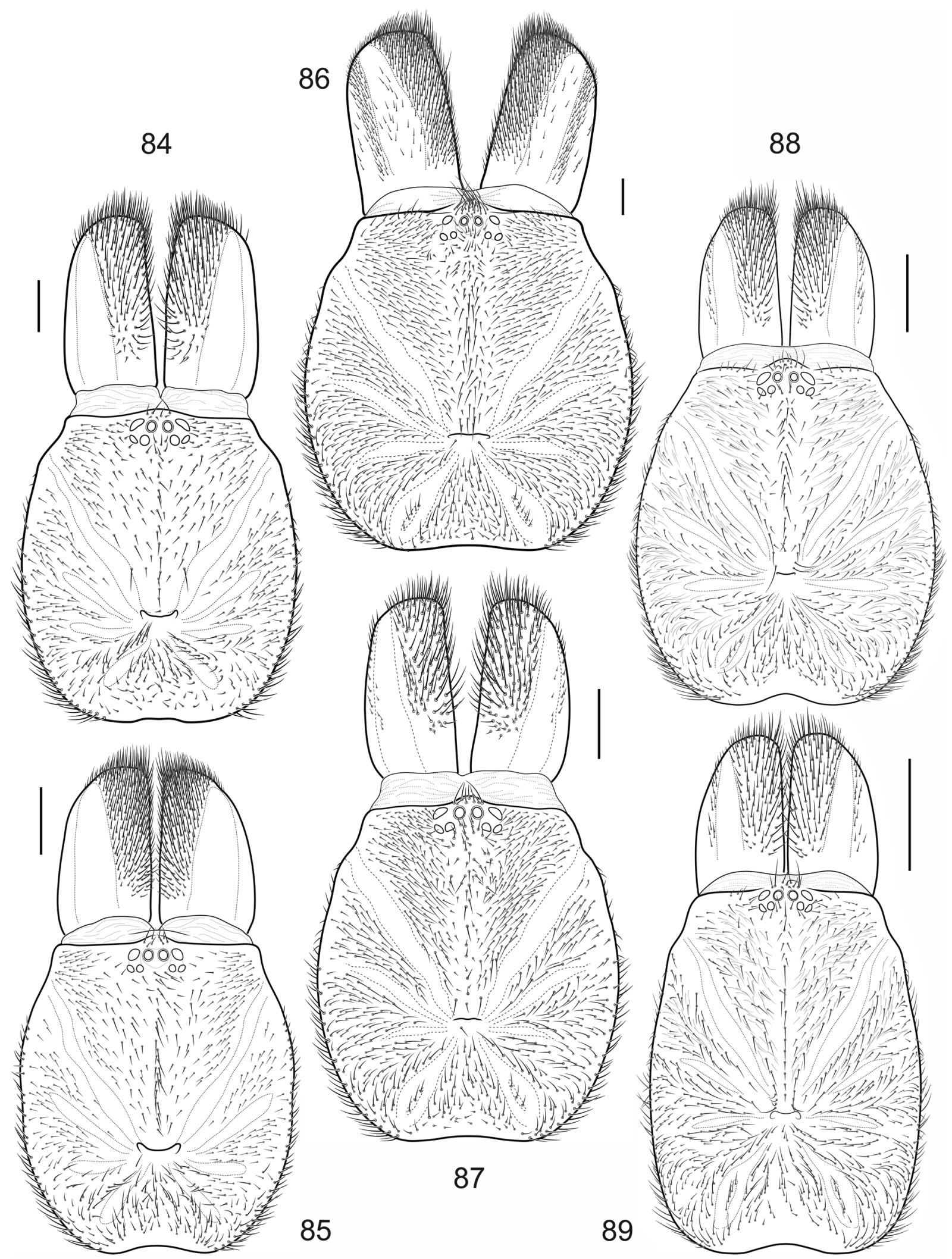

Figs 84-89. Raveniola spp., + + . Carapace and chelicerae, dorsal views. - 84. $R$. adjarica sp. nov. (paratype). 85. R. dunini sp. nov. (paratype). 86. $R$. hyrcanica Dunin, 1988 (paratype). 87. R. pontica (Spassky, 1937) (Lazarevskoe). 88. R. sinani sp. nov. (holotype). 89. R. nana sp. nov. (holotype). Scale bars: $1.0 \mathrm{~mm}$. 


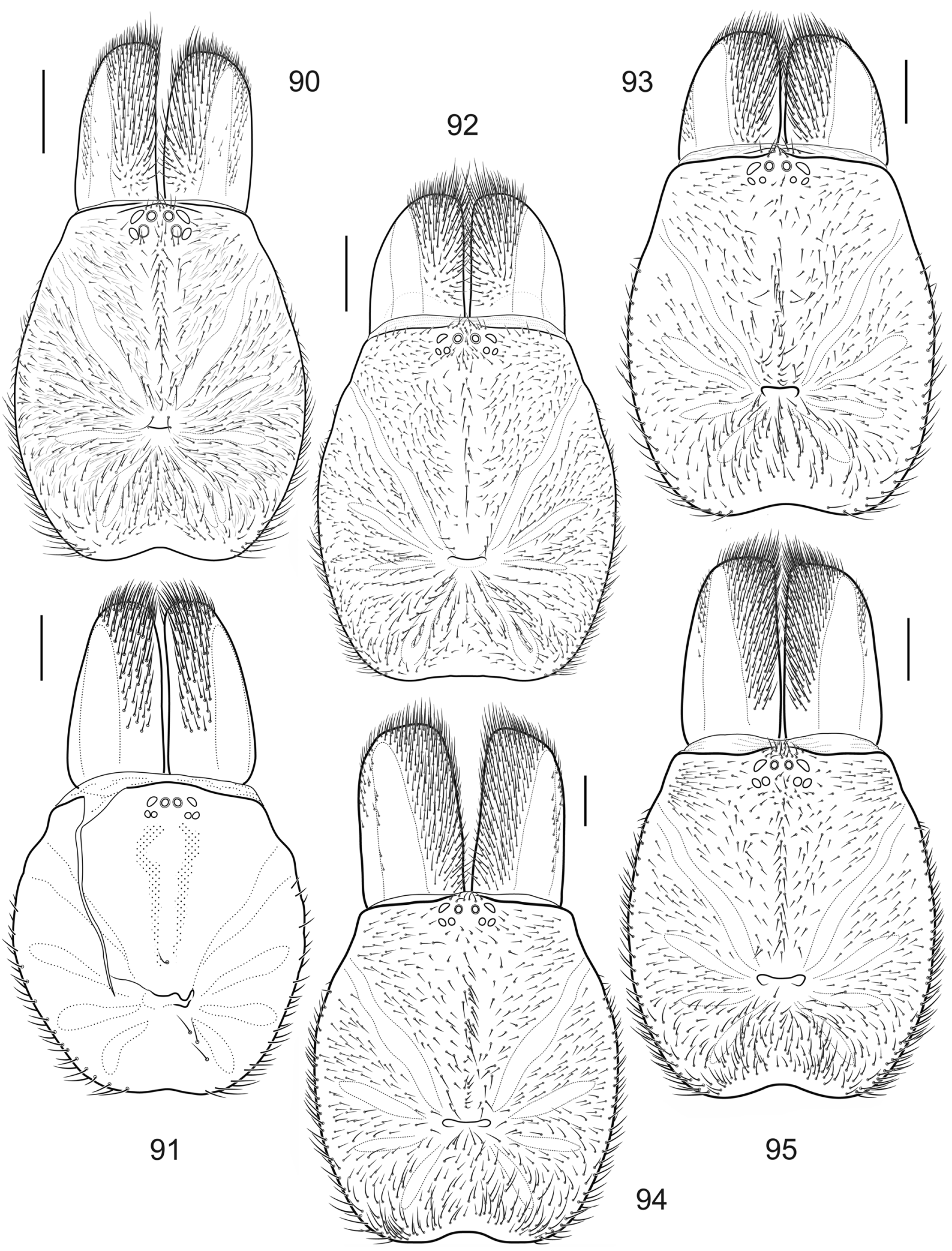

Figs 90-95. Raveniola spp., $\wp_{+}$. Carapace and chelicerae, dorsal views. - 90. R. turcica sp. nov. (paratype). 91. $R$. micropa (Ausserer, 1871) (holotype). 92. Same species as preceding (Uludağ). 93. $R$. zaitzevi (Charitonov, 1948) (Lagodekhi). 94. $R$. vonwicki Zonstein, 2000 (paratype). 95. $R$. niedermeyeri (Brignoli, 1972) (paratype). Scale bars: $1.0 \mathrm{~mm}$. 


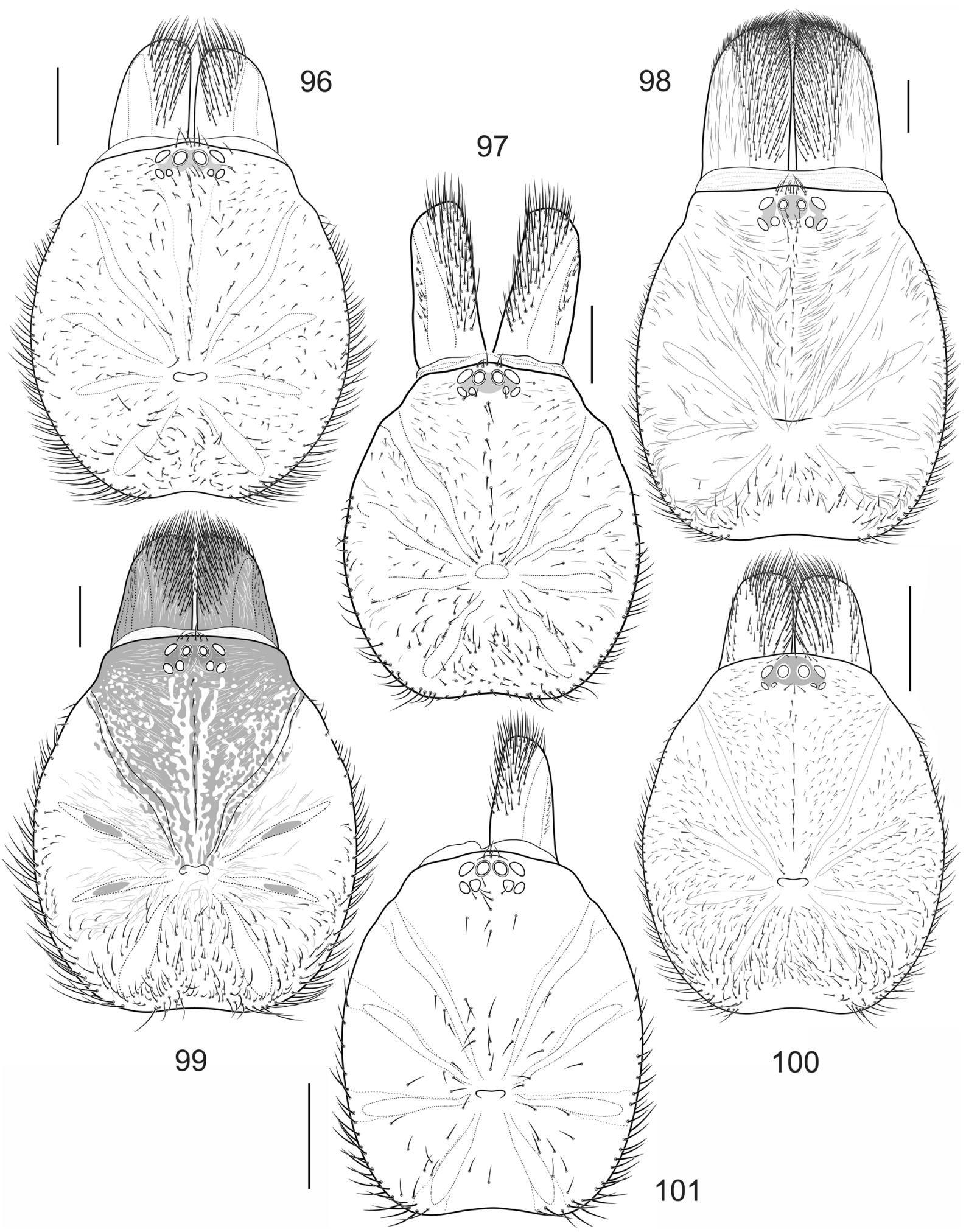

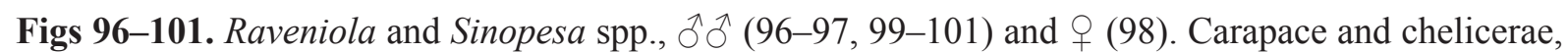
dorsal views. - 96. R. yunnanensis Zonstein \& Marusik, 2012 (holotype). 97. Undescribed Raveniola sp. E (Kyrghyzstan). 98-99. Undescribed Raveniola spp. J and M (Tadjikistan). 100. R. fedotovi (Charitonov, 1946) (Uzbekistan). 101. S. chinensis (Kulczyński, 1901) (China). Scale bars: $1.0 \mathrm{~mm}$. 

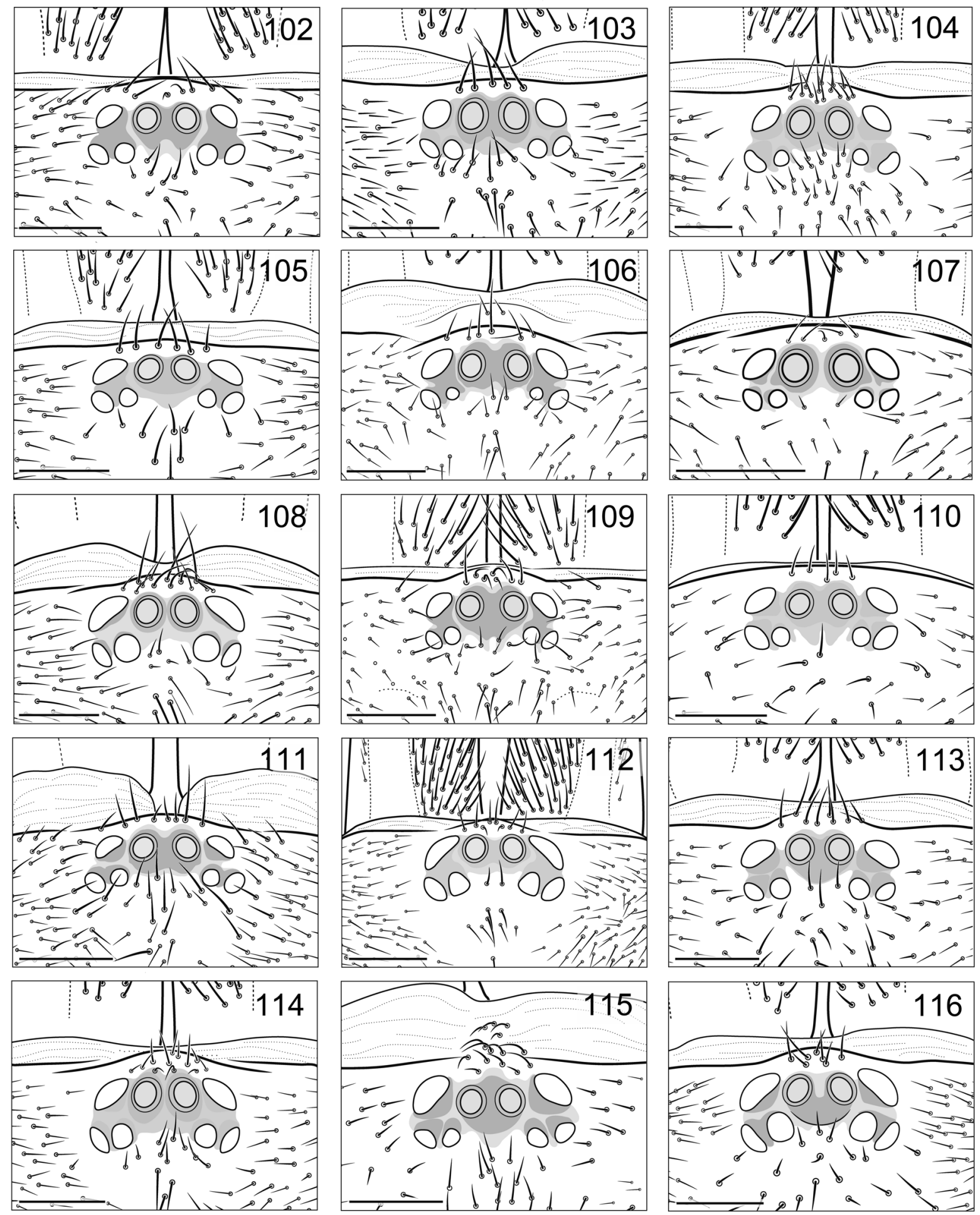

Figs 102-116. Raveniola spp., öó'. Eyes and clypeus, dorsal views. - 102. $R$. adjarica sp. nov. (holotype). 103. R. dunini sp. nov. (holotype). 104. R. hyrcanica Dunin, 1988 (holotype). 105. R. pontica (Spassky, 1937) (Lazarevskoe). 106. R. birecikensis sp. nov. (holotype). 107. Same species as preceding (dwarf conspecific male?). 108. R. anadolu sp. nov. (holotype). 109. R. arthuri Kunt \& Yağmur, 2010 (holotype). 110. $R$. turcica sp. nov. (holotype). 111. R. micropa (Ausserer, 1871) (Uludağ). 112. R. mazandaranica Marusik, Zamani \& Mirshamsi, 2014 (holotype). 113. R. zaitzevi (Charitonov, 1948) (Car). 114. R. marusiki sp. nov. (holotype). 115. R. vonwicki (Zonstein, 2000) (holotype). 116. $R$. niedermeyeri (Brignoli, 1972) (holotype). Scale bar: $0.5 \mathrm{~mm}$. 

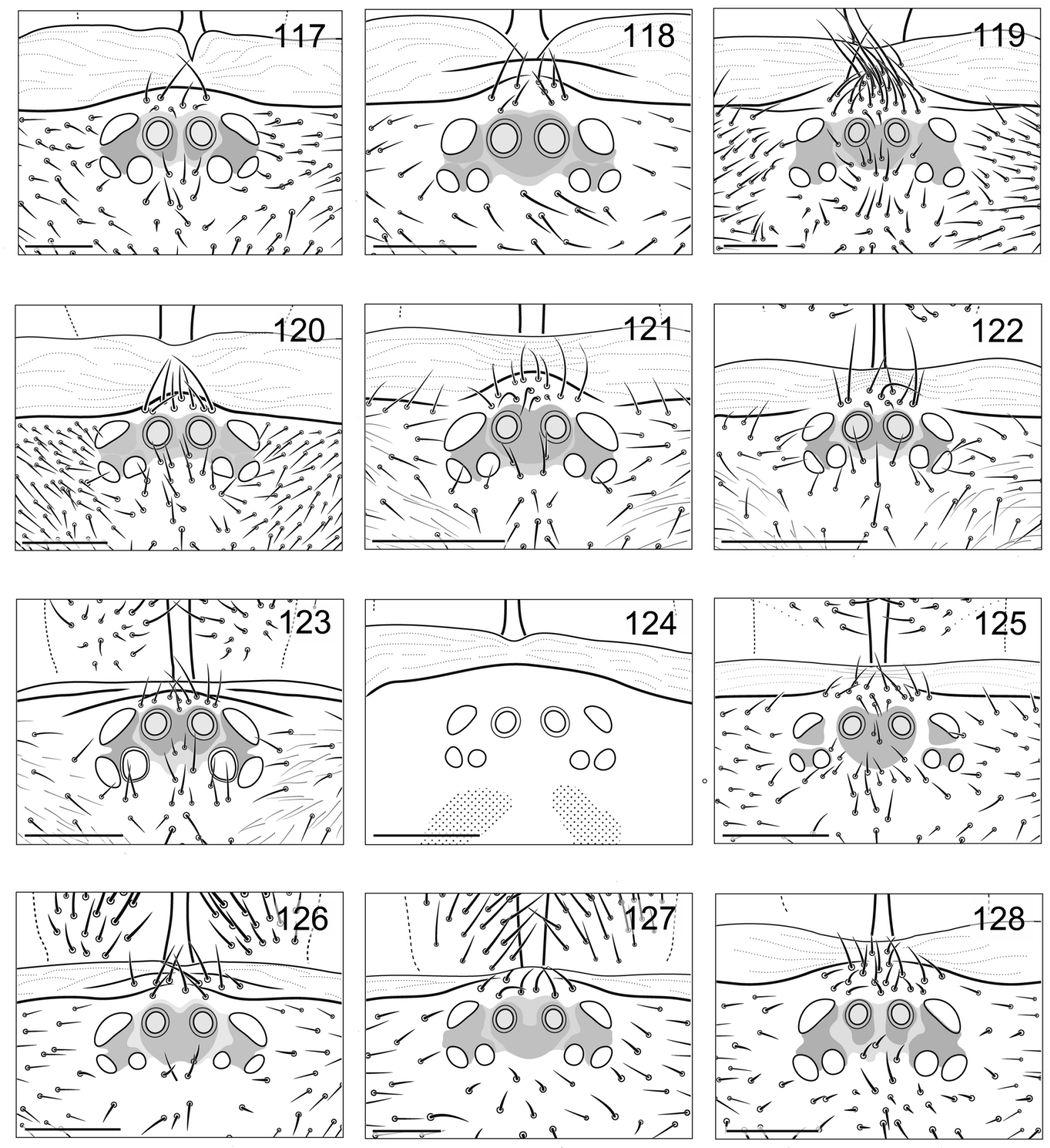

Figs 117-128. Raveniola spp., 우. Eyes and clypeus, dorsal views. - 117. $R$. adjarica sp. nov. (paratype). 118. . dunini sp. nov. (paratype). 119. R. hyrcanica Dunin, 1988 (paratype). 120. R. pontica (Spassky, 1937) (Lazarevskoe). 121. R. sinani sp. nov. (holotype). 122. R. nana sp. nov. (holotype). 123. . turcica sp. nov. (paratype). 124. R. micropa (Ausserer, 1871) (holotype). 125. Same species as preceding (Uludağ). 126. R. zaitzevi (Charitonov, 1948) (Lagodekhi). 127. R. vonwicki Zonstein, 2000 (paratype). 128. $R$. niedermeyeri (Brignoli, 1972) (paratype). Scale bar: $0.5 \mathrm{~mm}$. 


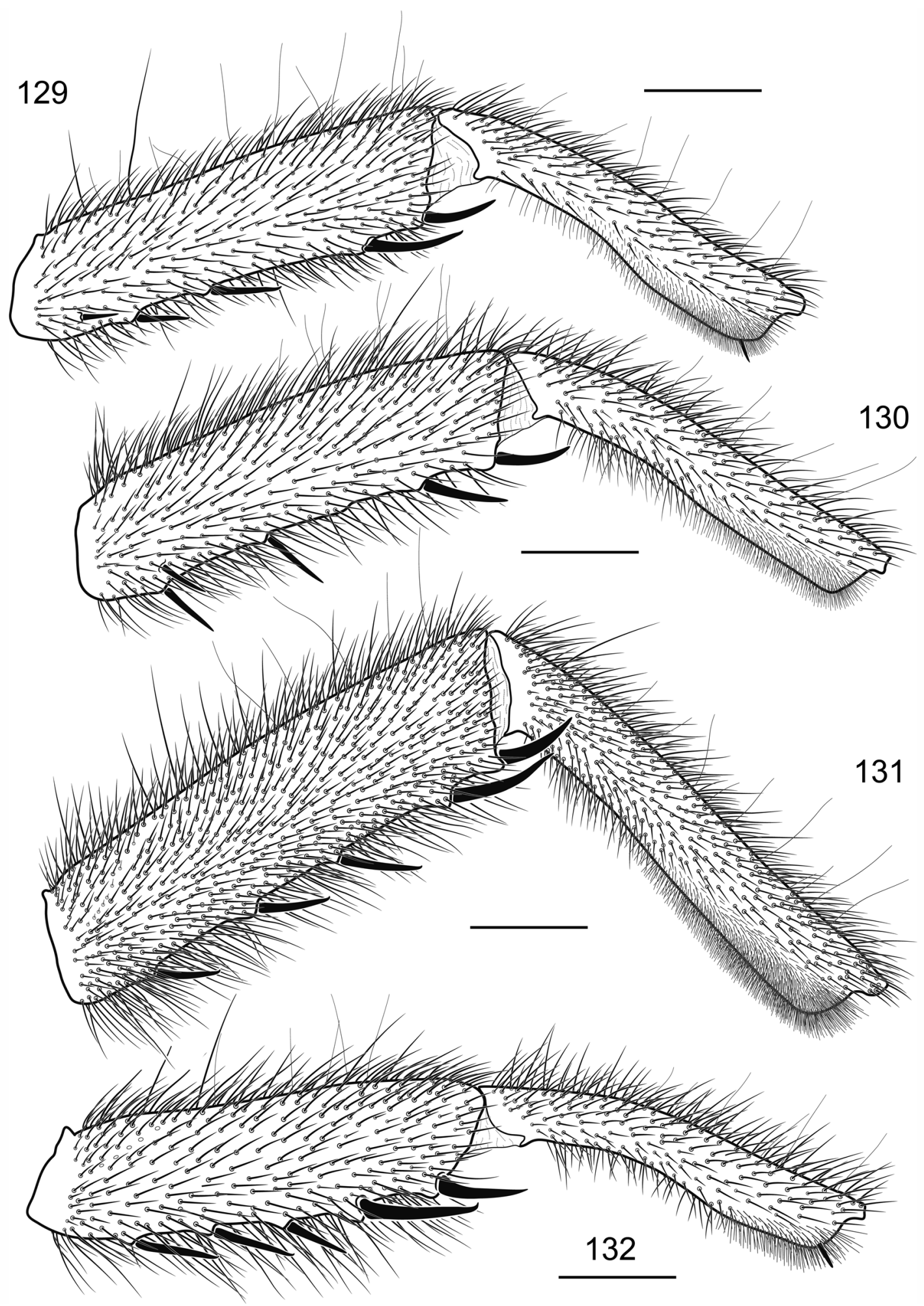

Figs 129-132. Raveniola spp., $\widehat{\partial}$. Tibia and metatarsus I, retrolateral views. - 129. R. adjarica sp. nov. (holotype). 130. R. dunini sp. nov. (holotype). 131. R. hyrcanica Dunin, 1988 (holotype). 132. R. pontica (Spassky, 1937) (Lazarevskoe). Scale bars: $1.0 \mathrm{~mm}$. 


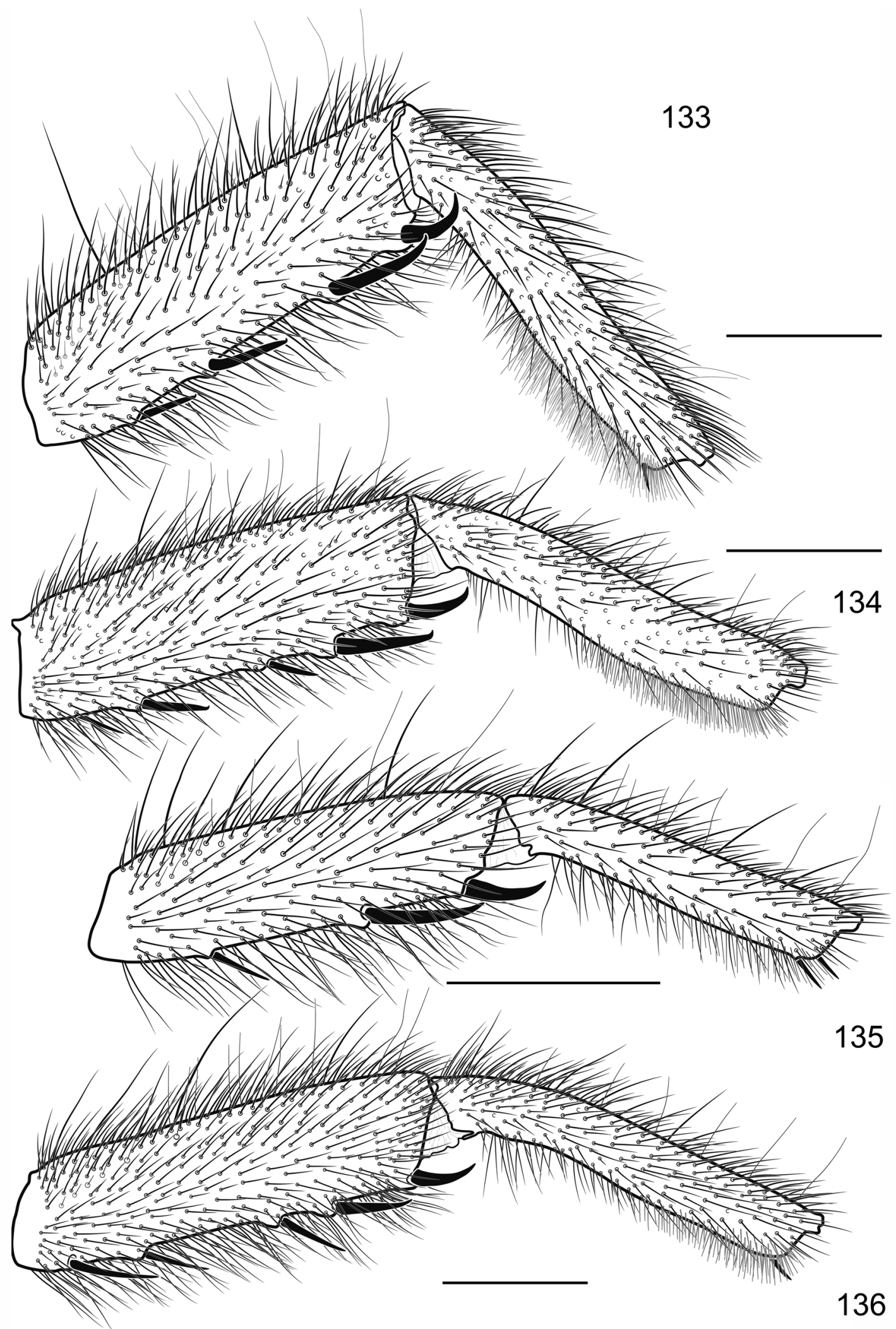

Figs 133-136. Raveniola spp., $\widehat{\partial} \hat{\jmath}$. Tibia and metatarsus I, retrolateral views. - 133. R. birecikensis sp. nov. (holotype). 134. Same species as preceding (paratype, Birecik). 135. Same species as preceding (dwarf conspecific male?). 136. R. anadolu sp. nov. (holotype). Scale bars: $1.0 \mathrm{~mm}$. 


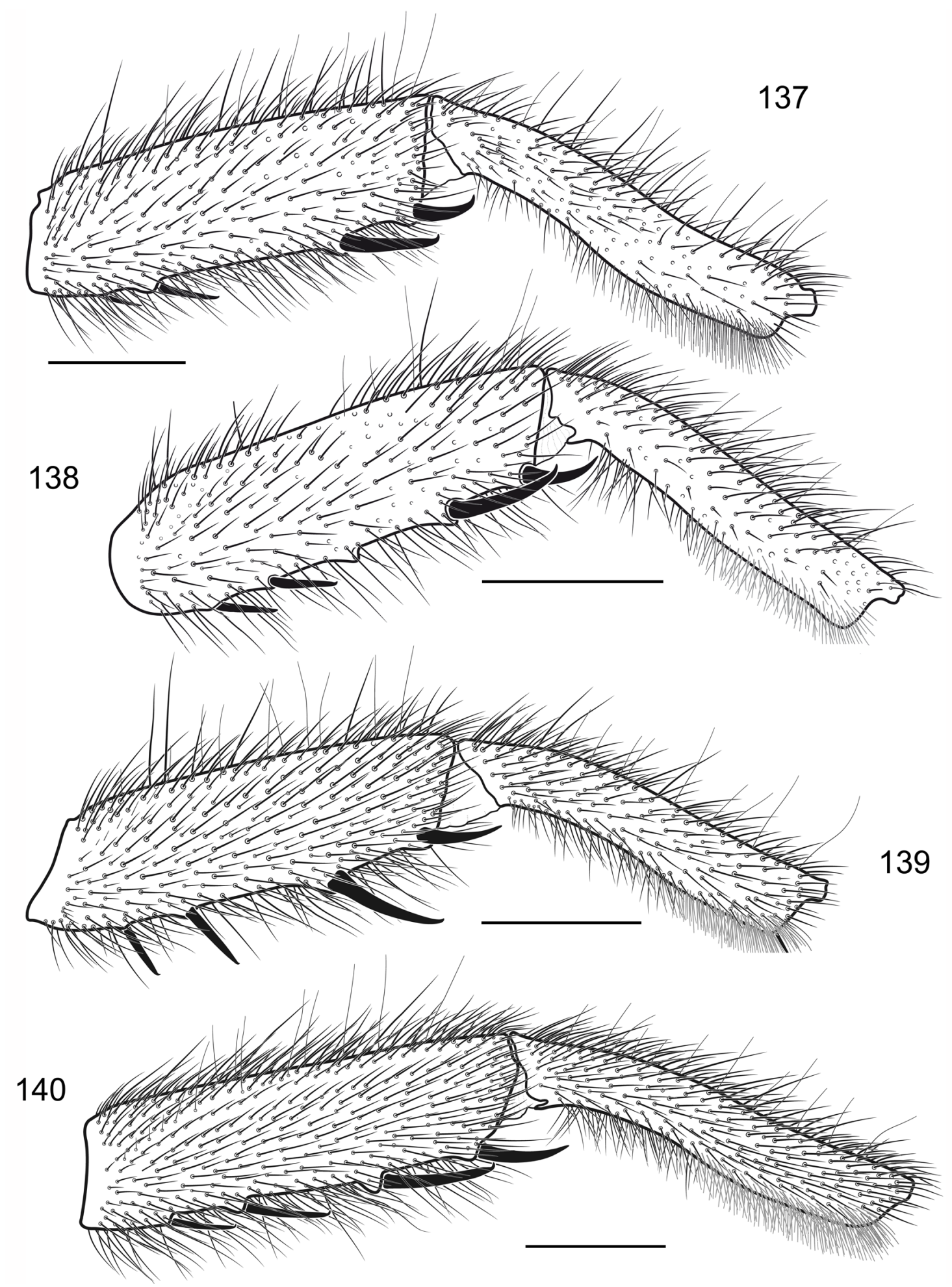

Figs 137-140. Raveniola spp., $\widehat{\partial} \widehat{\partial}$. Tibia and metatarsus I, retrolateral views. -137 . R. arthuri Kunt \& Yağmur, 2010 (holotype). 138. R. turcica sp. nov. (holotype). 139. R. micropa (Ausserer, 1871) (Uludağ). 140. R. mazandaranica Marusik, Zamani \& Mirshamsi, 2014 (holotype). Scale bars: $1.0 \mathrm{~mm}$. 


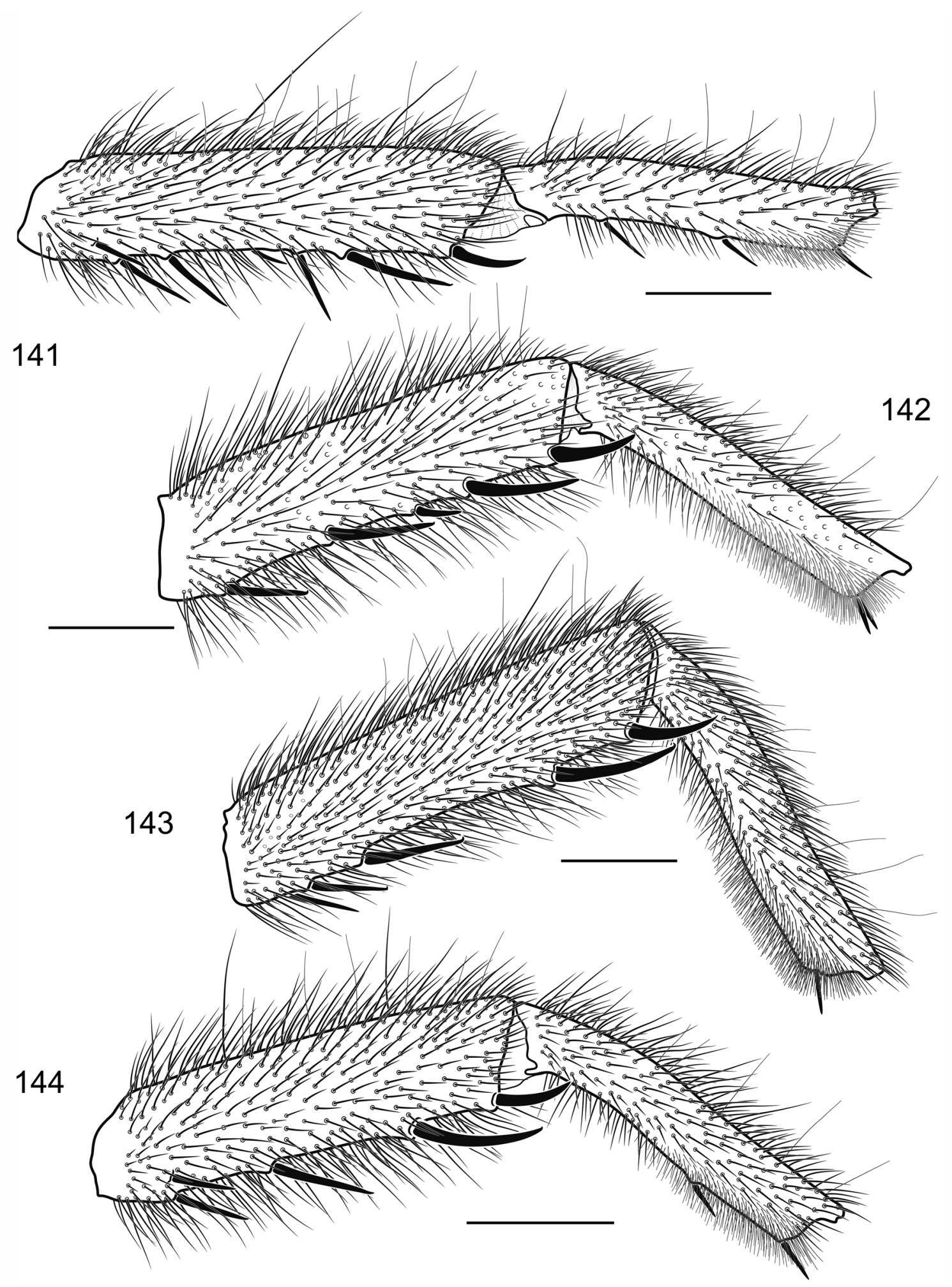

Figs 141-144. Raveniola spp., $\widehat{\partial}$. Tibia and metatarsus I, retrolateral views. - 141. R. zaitzevi (Charitonov, 1948) (Car). 142. R. marusiki sp. nov. (holotype). 143. R. vonwicki Zonstein, 2000 (holotype). 144. $R$. niedermeyeri (Brignoli, 1972) (holotype). Scale bars: $1.0 \mathrm{~mm}$. 


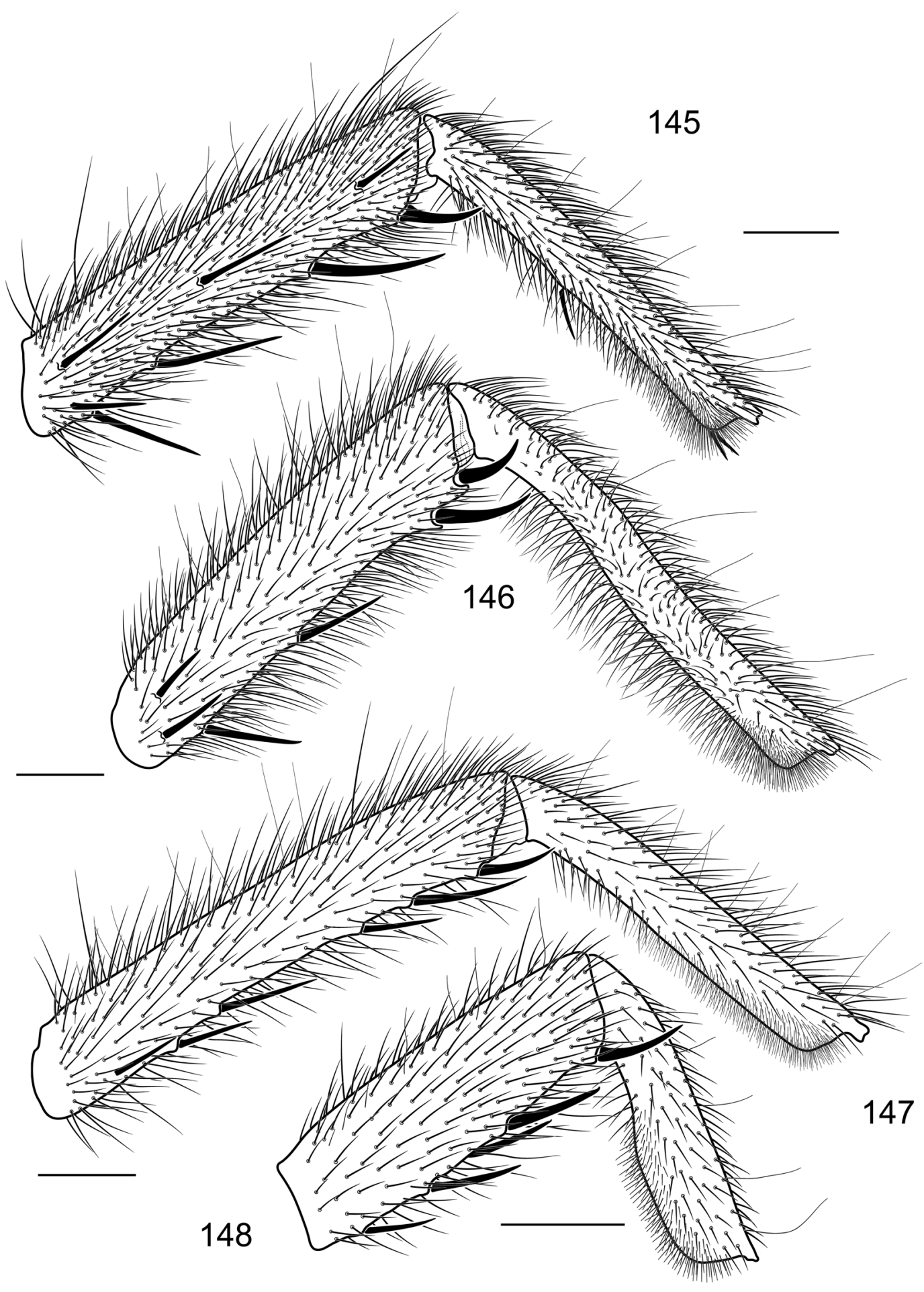

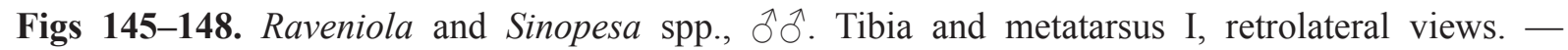
145. R. ferghanensis (Zonstein, 1984) (paratype). 146. R. concolor Zonstein, 2000 (holotype). 147. R. yunnaensis Zonstein \& Marusik, 2012 (holotype). 148. S. chinensis (Kulczyński, 1901) (China). Scale bars: $1.0 \mathrm{~mm}$. 


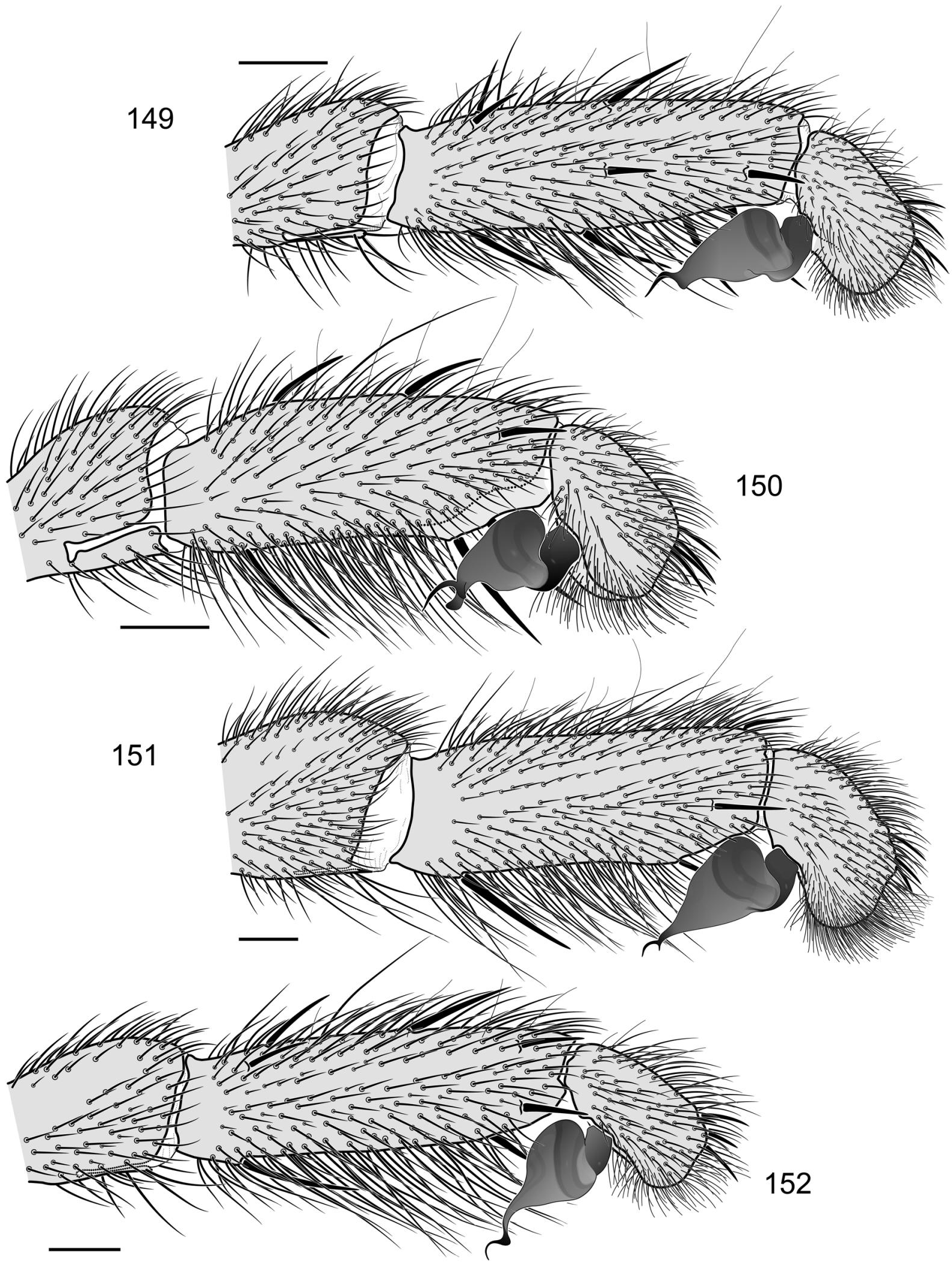

Figs 149-152. Raveniola spp., $\widehat{\jmath}$. Palpal tibia, cymbium and palpal organ, retrolateral views. 149. R. adjarica sp. nov. (holotype). 150. R. dunini sp. nov. (holotype). 151. R. hyrcanica Dunin, 1988 (holotype). 152. R. pontica (Spassky, 1937) (Lazarevskoe). Scale bars: $0.5 \mathrm{~mm}$. 


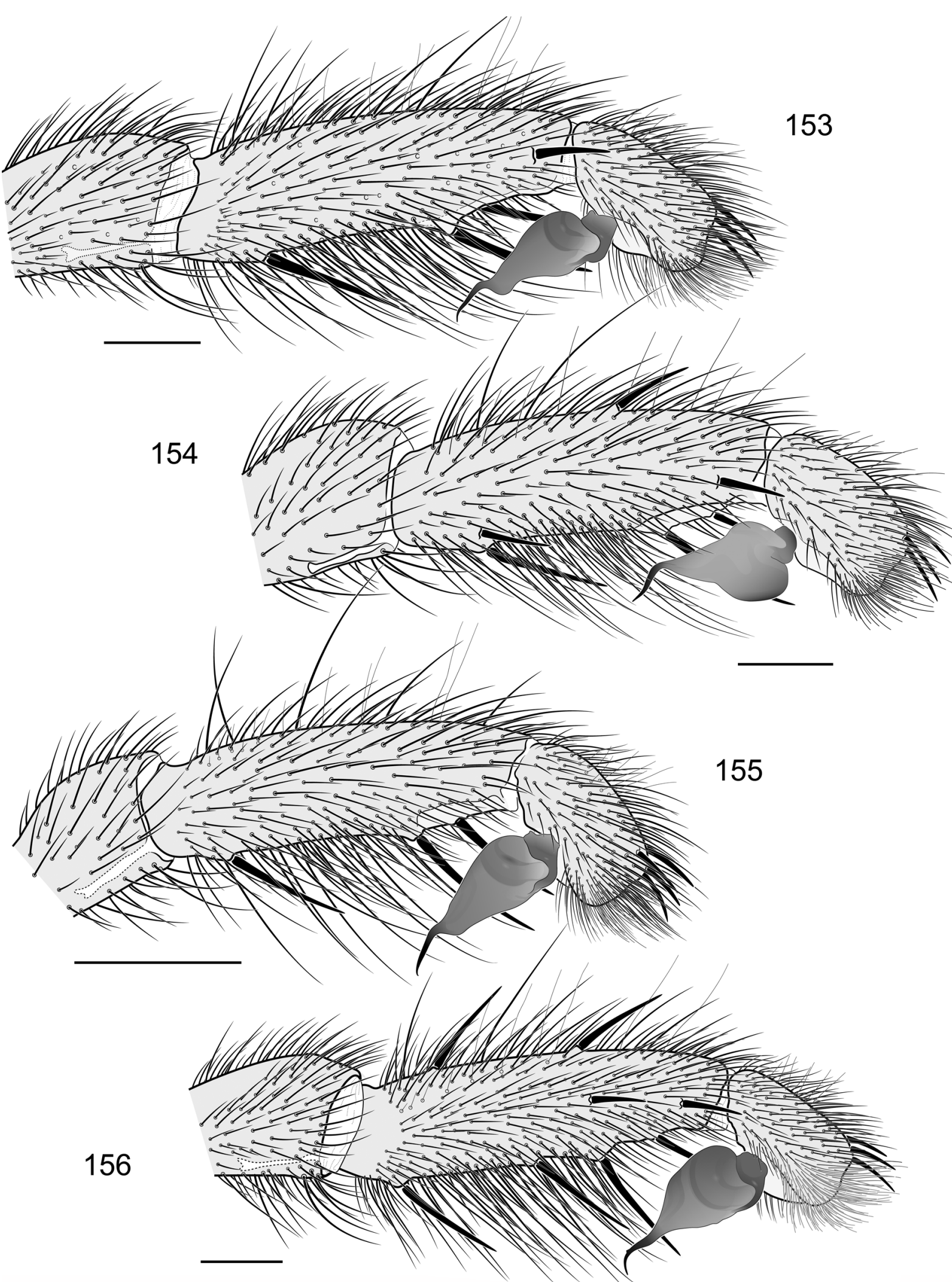

Figs 153-156. Raveniola spp., $\widehat{\partial} \hat{\jmath}$. Palpal tibia, cymbium and palpal organ, retrolateral views. 153. $R$. birecikensis sp. nov. (holotype). 154. Same species as preceding (paratype, Birecik, revolved bulb shown in ventral position). 155. Same species as preceding (dwarf conspecific $\precsim$ ? ?). 156. R. anadolu sp. nov. (holotype). Scale bars: $0.5 \mathrm{~mm}$. 


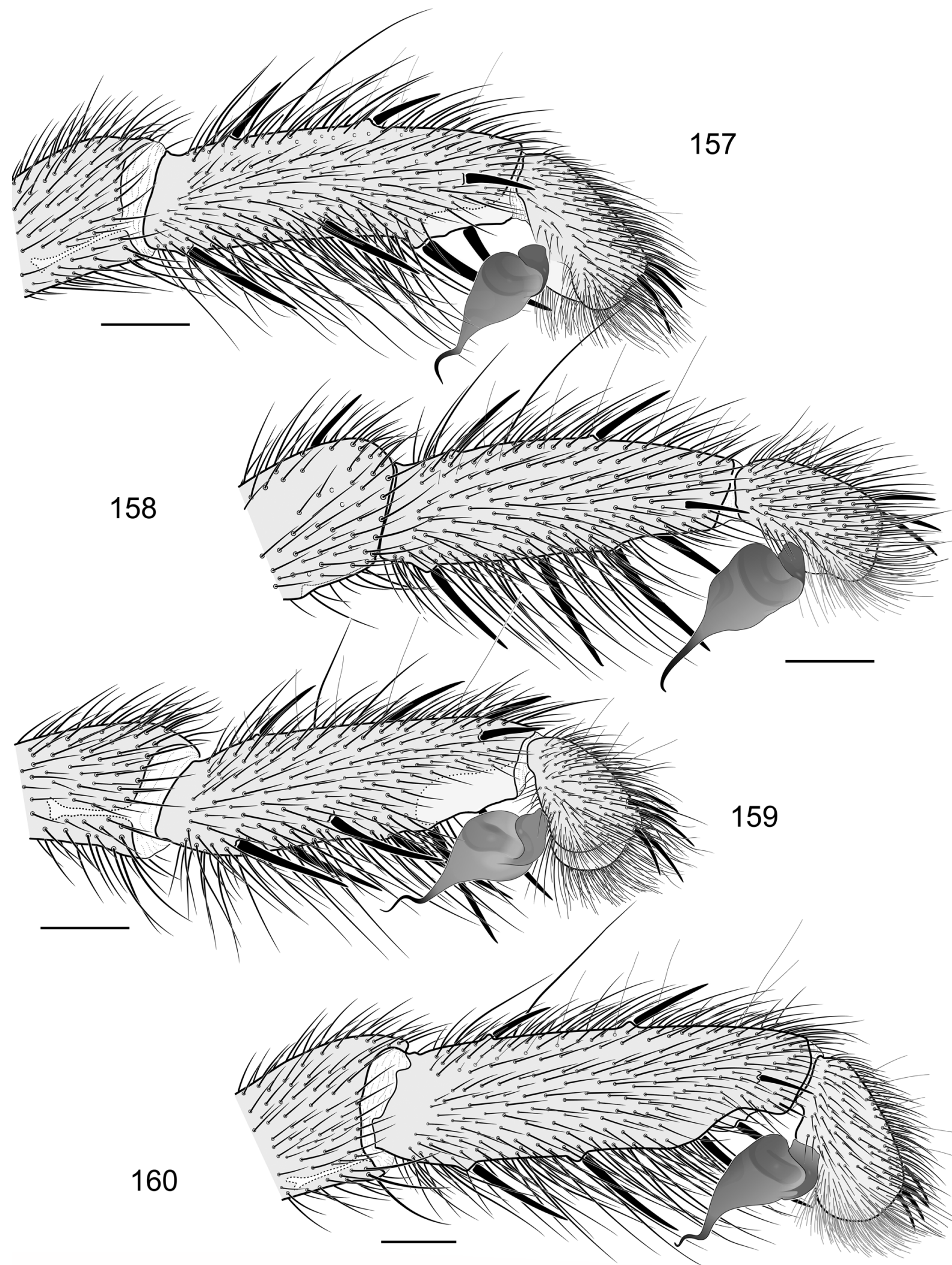

Figs 157-160. Raveniola spp., $\widehat{\partial} \hat{\partial}$. Palpal tibia, cymbium and palpal organ, retrolateral views. 157. R. arthuri Kunt \& Yağmur, 2010 (holotype). 158. R. turcica sp. nov. (holotype). 159. R. micropa (Ausserer, 1871) (Uludağ). 160. R. mazandaranica Marusik, Zamani \& Mirshamsi, 2014 (holotype). Scale bars: $0.5 \mathrm{~mm}$. 

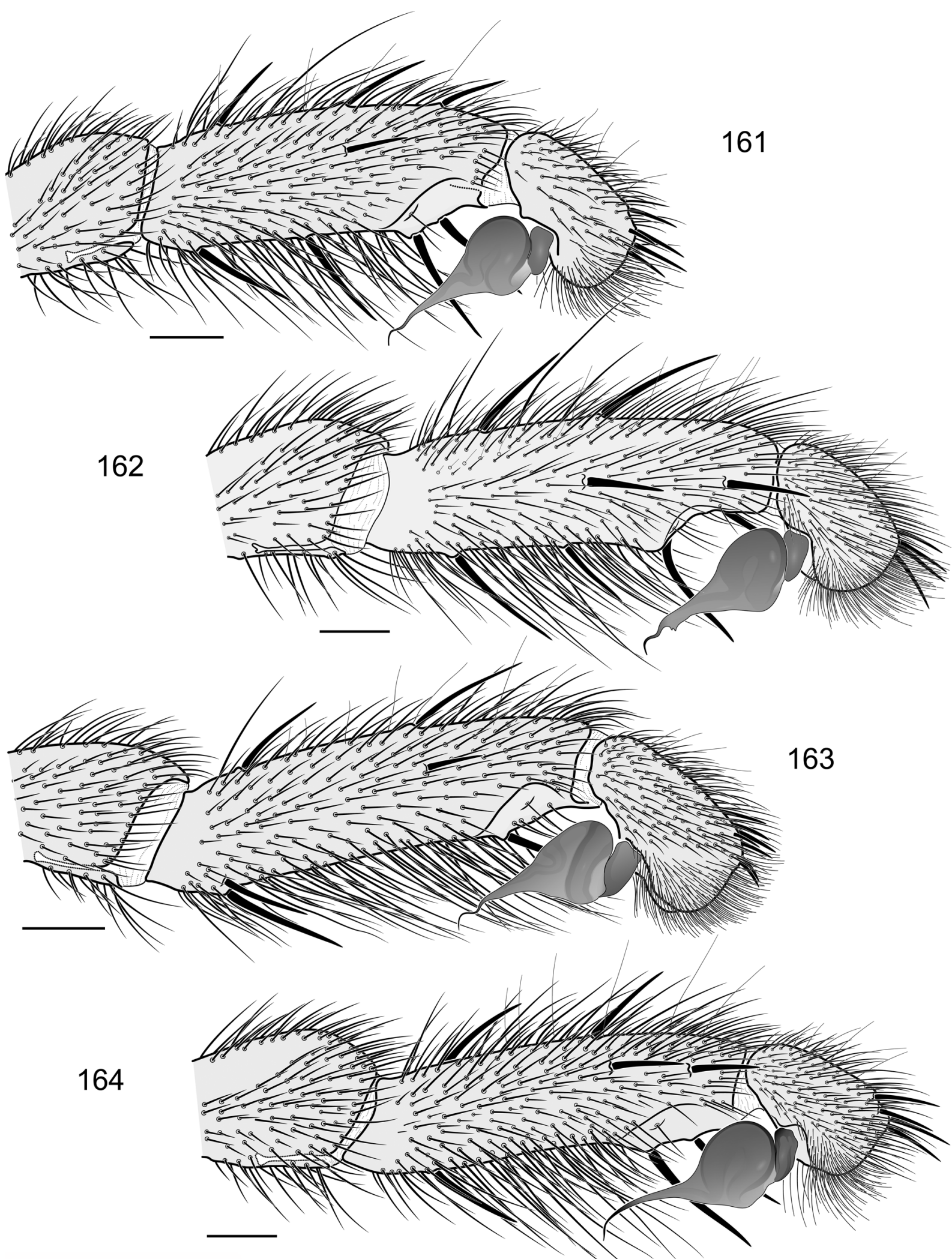

Figs 161-164. Raveniola spp., $\widehat{\partial} \widehat{\partial}$. Palpal tibia, cymbium and palpal organ, retrolateral views. 161. R. zaitzevi (Charitonov, 1948) (Car). 162. R. marusiki sp. nov. (holotype). 163. R. vonwicki Zonstein, 2000 (holotype). 164. R. niedermeyeri (Brignoli, 1972) (holotype). Scale bars: $1.0 \mathrm{~mm}$. 


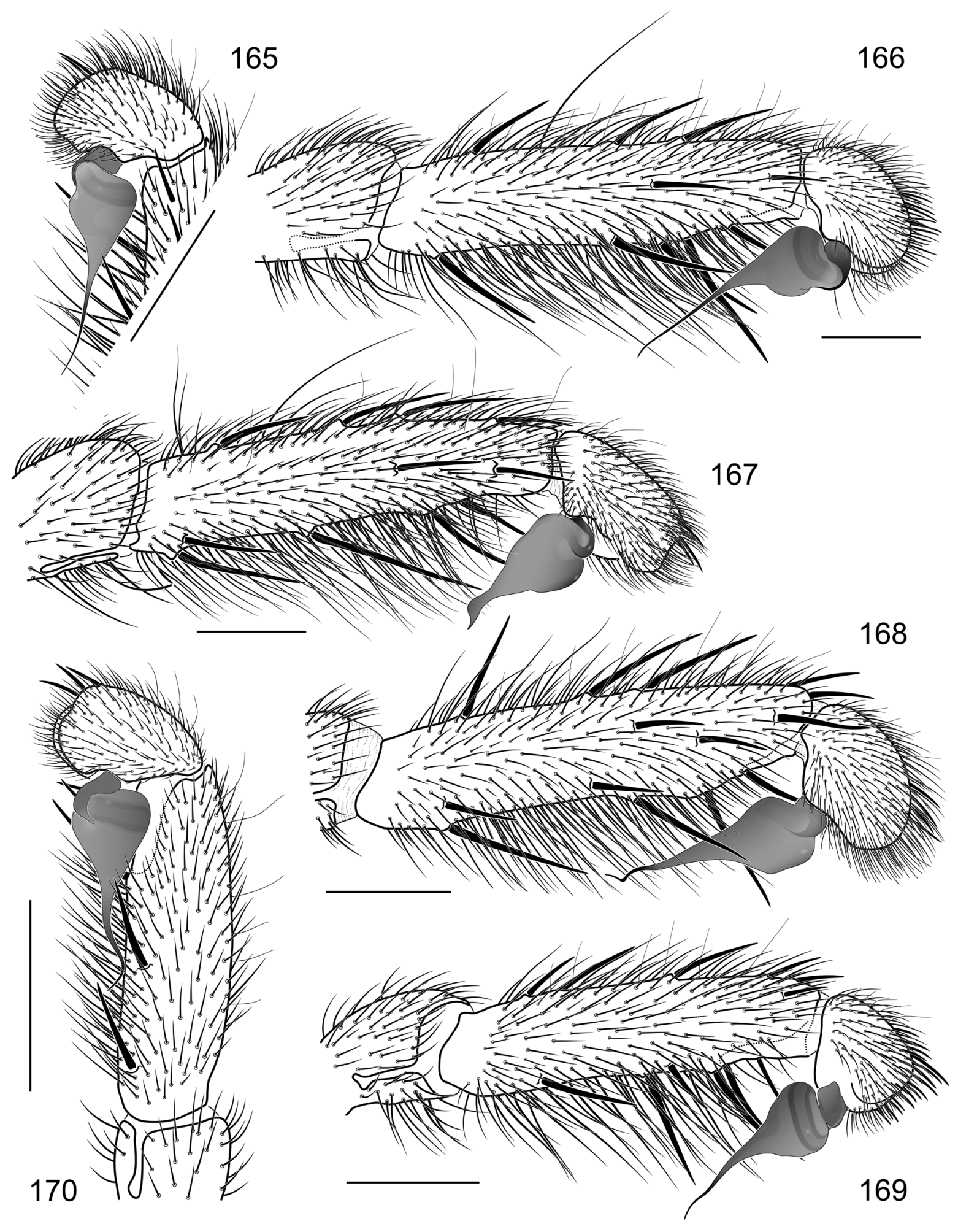

Figs 165-170. Raveniola and Sinopesa spp., $\widehat{\partial}$. Palpal tibia, cymbium and palpal organ, retrolateral views. - 165. R. virgata (Simon, 1891) (Kyrghyzstan). 166. R. ferghanensis (Zonstein, 1984) (paratype). 167. R. caudata Zonstein, 2009 (holotype). 168. R. concolor Zonstein, 2000 (holotype). 169. R. yunnaensis Zonstein \& Marusik, 2012 (holotype). 170. S. chinensis (Kulczyński, 1901) (China). Scale bars: $1.0 \mathrm{~mm}$. 

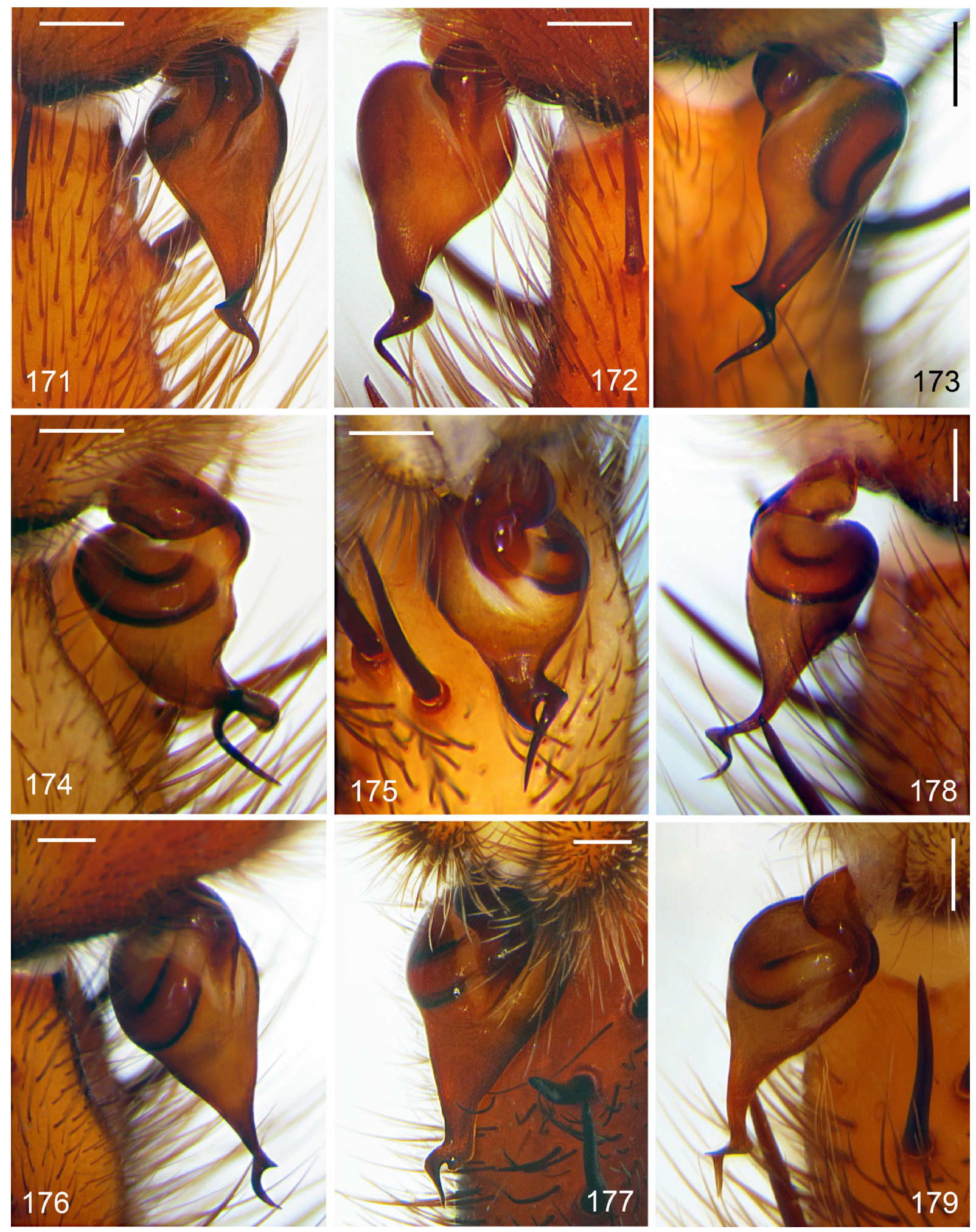

Figs 171-179. Raveniola hyrcanica species group, holotypic (171-177) and conspecific (178-179) $\partial \widehat{\partial}$. Details of palpal organ; retroventral (171), ventral $(172,175,177,179)$, proventral (173) and retrolateral $(174,176,178)$ views. - 171-173. $R$. adjarica sp. nov. 174-175. $R$. dunini sp. nov. 176177. R. hyrcanica Dunin, 1988. 178-179. R. pontica (Spassky, 1937). Scale bars: 0.25 mm. 

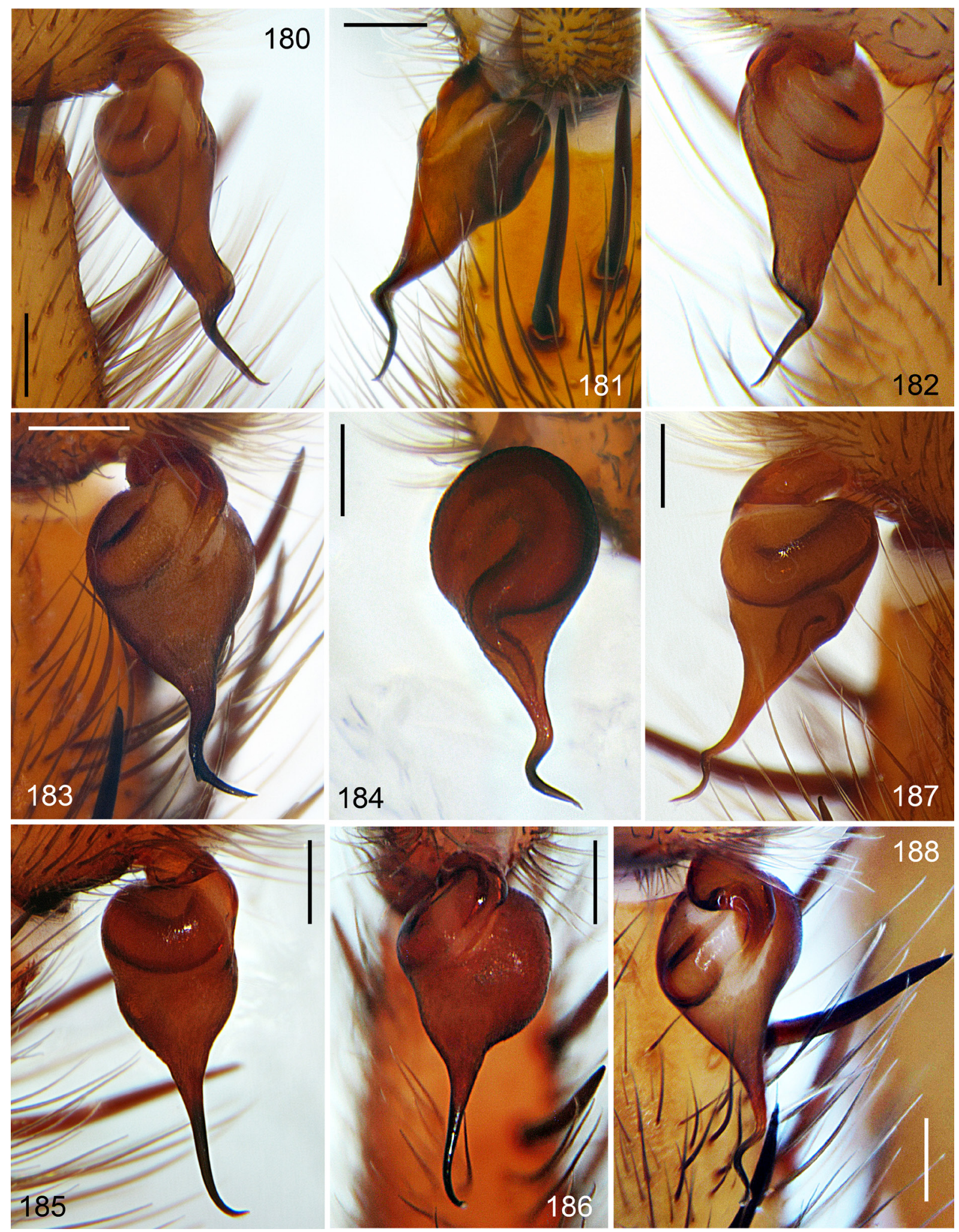

Figs 180-188. Raveniola micropa species group, holotypic (180-181, 183-186) and conspecific $(182,187-188) \hat{\jmath} \widehat{\partial}$. Details of palpal organ; retrolateral $(180,182,185,187)$, ventral $(181,186,188)$, retroventral (183) and prolateral (184) views. - 180-181. R. birecikensis sp. nov. 182. Same species as preceding (dwarf specimen?). 183. $R$. anadolu sp. nov. 184. $R$. arthuri Kunt \& Yağmur, 2010. 185186. . turcica sp. nov. 187-188. R. micropa (Ausserer, 1871). Scale bars: $0.25 \mathrm{~mm}$. 

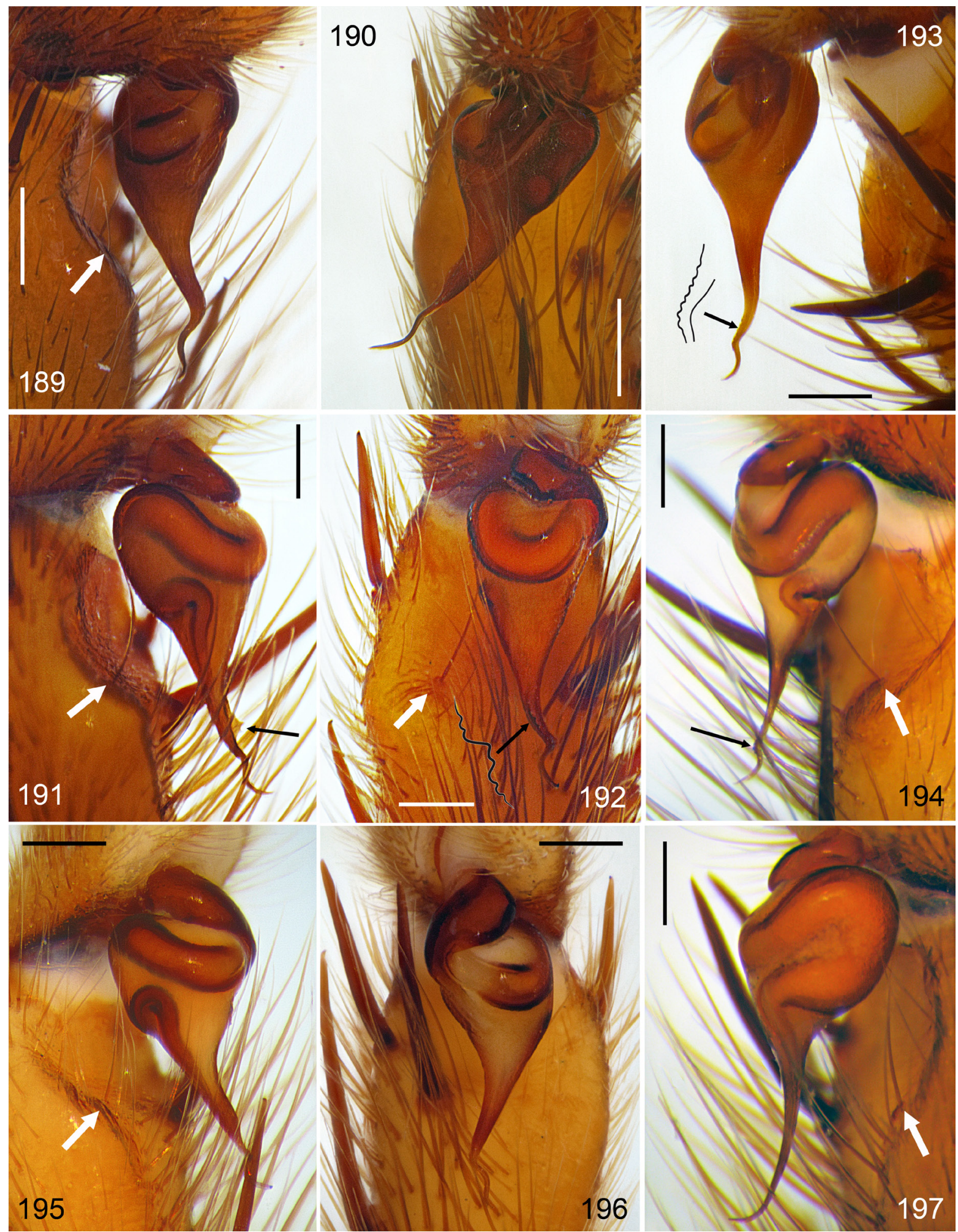

Figs 189-197. Raveniola niedermeyeri species group, holotypic (189-192, 195-197) and conspecific (193-194) $\widehat{\jmath}$. Details of palpal organ; retrolateral $(189,191,194-195,197)$ and ventral (190, 192-193, 196) views. - 189-190. R. mazandaranica Marusik, Zamani \& Mirshamsi, 2014. 191, 192. R. marusiki sp. nov. 193-194. R. zaitzevi (Charitonov, 1948). 195-196. R. vonwicki Zonstein, 2000. 197. R. niedermeyeri (Brignoli, 1972). White arrows indicate low tibial mound with sensilla. Black arrows and contour lines show a dentate vestige of the embolic keel. Scale bars: $0.25 \mathrm{~mm}$. 

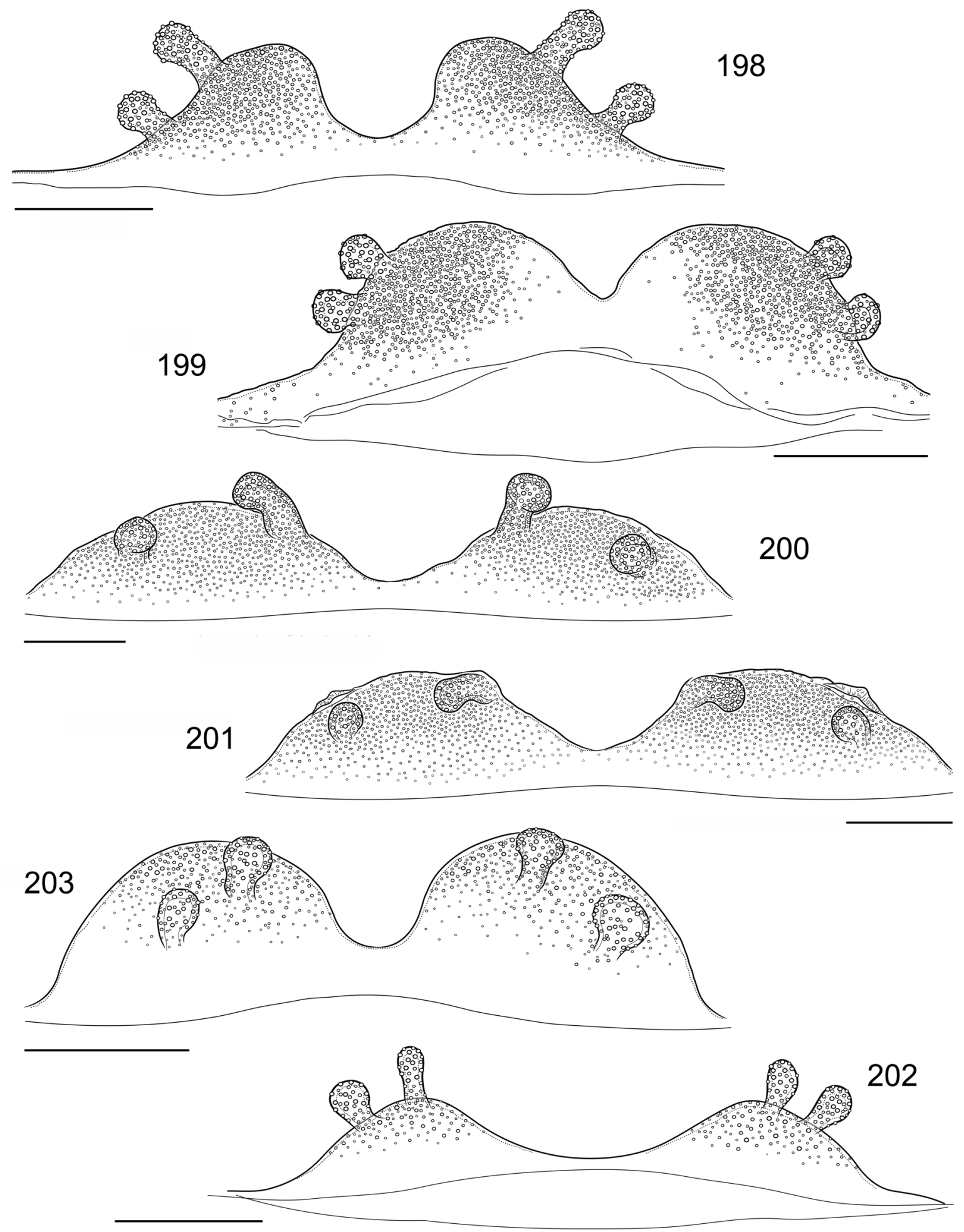

Figs 198-203. Raveniola spp., $\odot \uparrow$. Vulva, dorsal views. - 198. $R$. adjarica sp. nov. (paratype). 199. R. dunini sp. nov. (paratype). 200. R. hyrcanica Dunin, 1988 (paratype, Avas). 201. Same species as preceding (Gaftoni). 202. R. pontica (Spassky, 1937) (Lazarevskoe). 203. R. sinani sp. nov. (holotype). Scale bars: $0.25 \mathrm{~mm}$. 

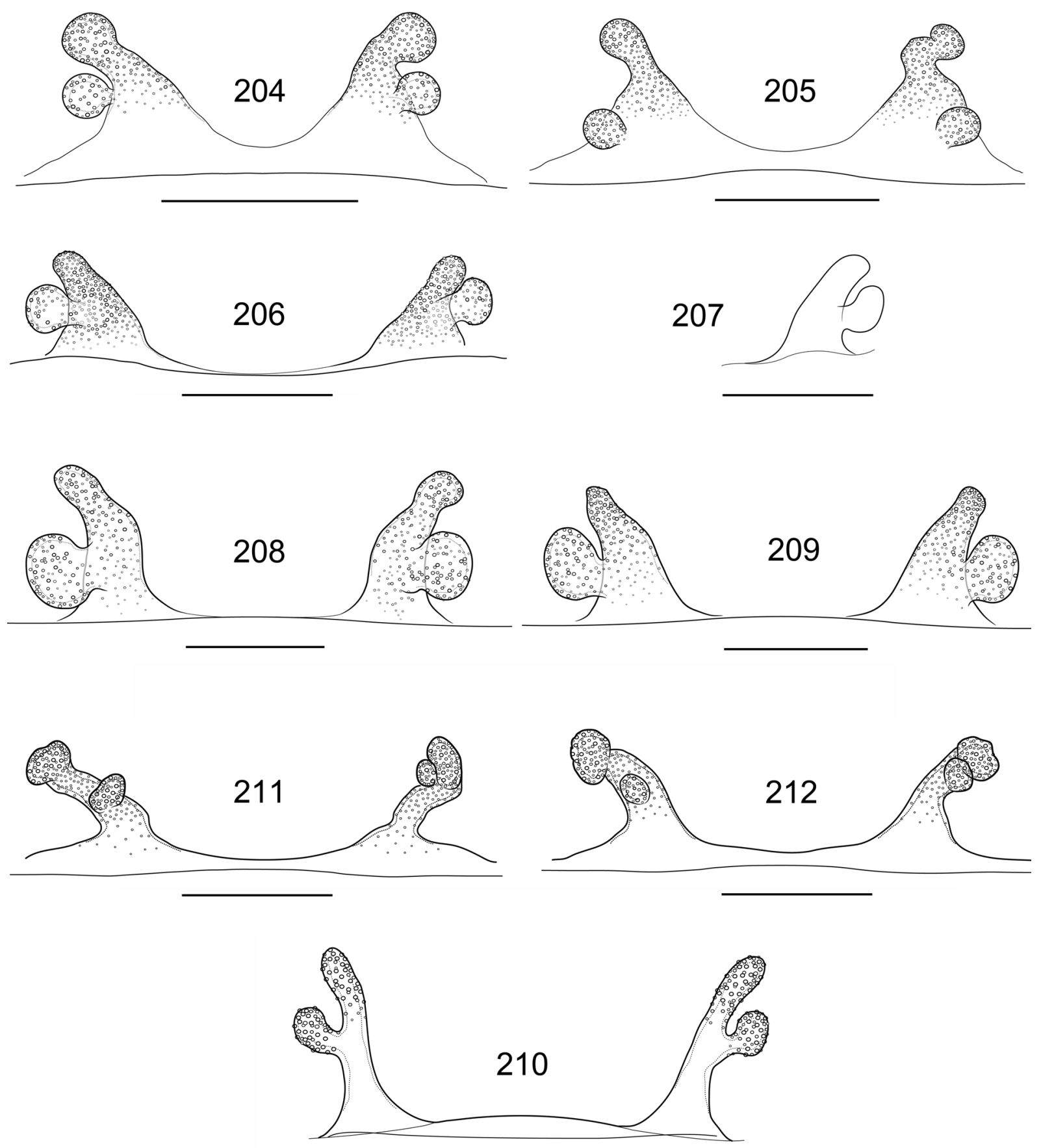

Figs 204-212. Raveniola spp., $q \uparrow$. Vulva, dorsal views. - 204. $R$. nana sp. nov. (holotype). 205. . turcica sp. nov. (paratype). 206. $R$. micropa (Ausserer, 1871) (Uludağ). 207. Same aspecies as preceding (holotype). 208. $R$. zaitzevi (Charitonov, 1948) (Lagodekhi). 209. Same species as preceding (Pirkuli). 210. R. vonwicki Zonstein, 2000 (paratype). 211. R. niedermeyeri (Brignoli, 1972) (paratype, Gorgan). 212. Same species as preceding (Mazandaran). Scale bars: $0.25 \mathrm{~mm}$. 

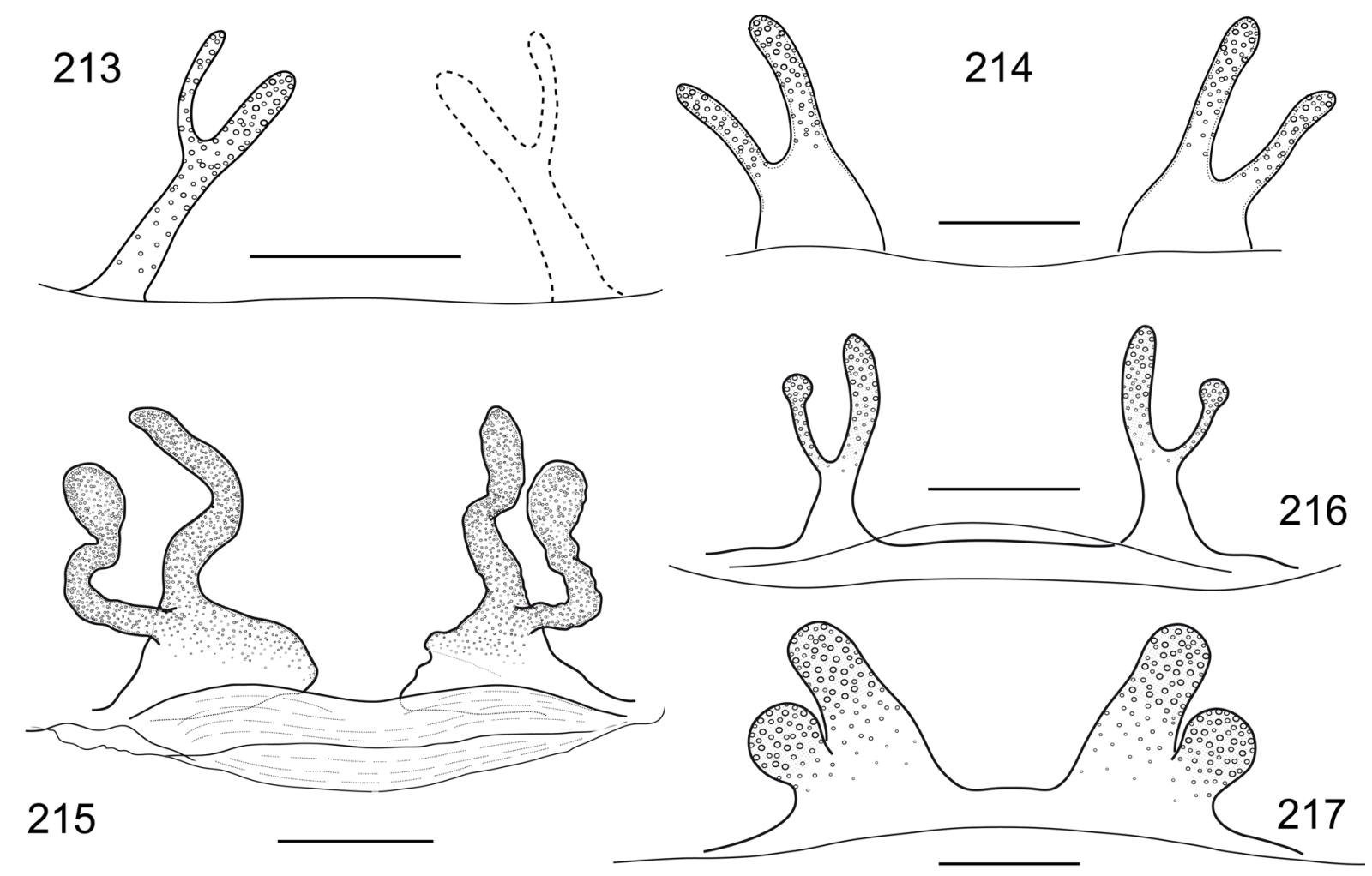

Figs 213-217. Raveniola spp., 웅. Vulva, dorsal views. - 213. R. virgata (Simon, 1891) (Kyrghyzstan). 214. R. concolor Zonstein, 2000 (paratype). 215. R. chayi Li \& Zonstein, 2015 (paratype). 216. R. hebeinica Zhu, Zhang \& Zhang, 1999 (Taihang Mts, China). 217. R. montana Zonstein \& Marusik, 2012 (paratype). Scale bars: $0.25 \mathrm{~mm}$. 


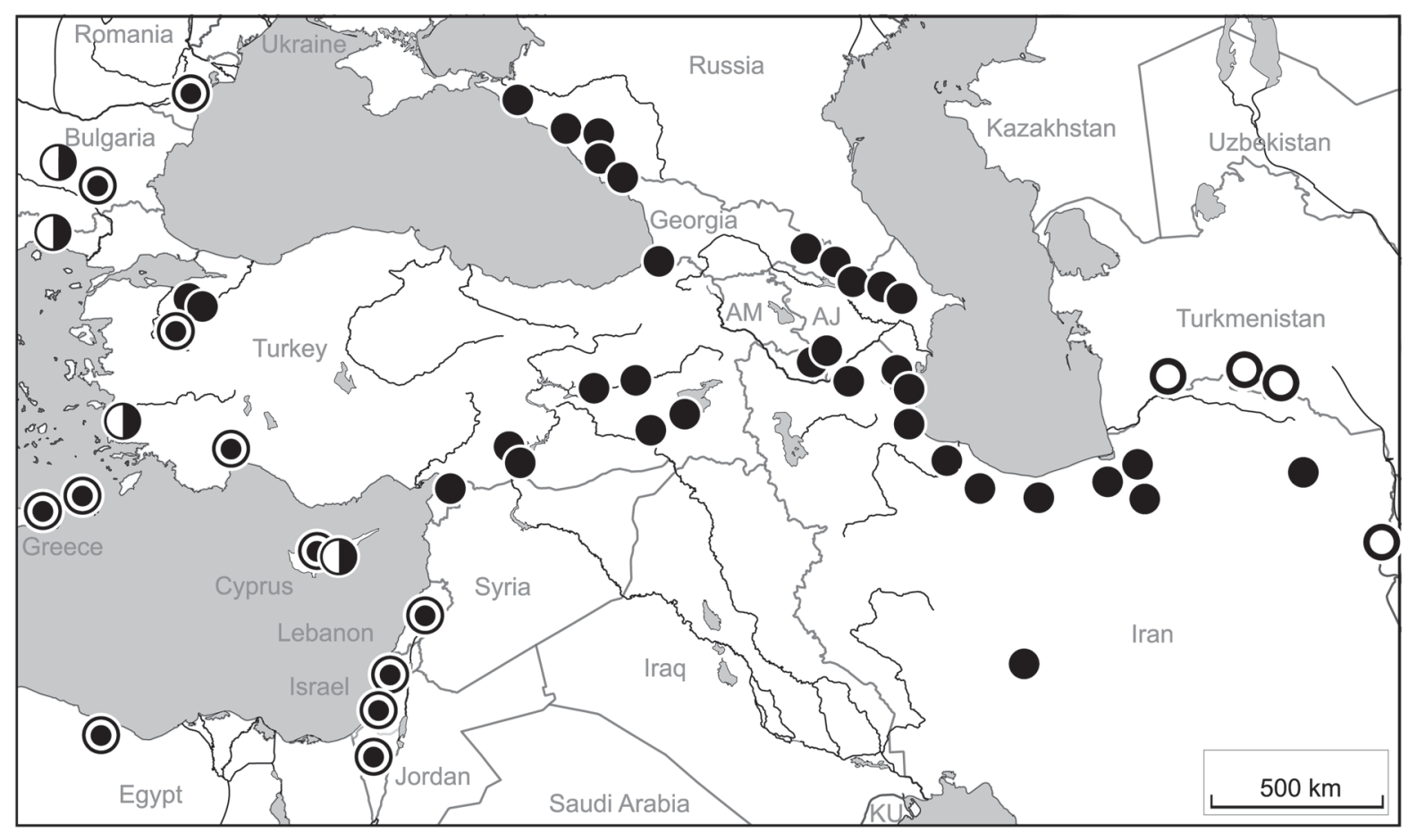

Figure 218. Localities of the Nemesiidae in the far Eastern Mediterranean and in the Middle East: Brachythele Ausserer, 1871 (O); Nemesia Audouin, 1826 (O); Central Asian species groups of Raveniola Zonstein, 1987 (O); Western Asian species groups of Raveniola (O). Abbreviations: AJ = Azerbaijan; $\mathrm{AM}=$ Armenia; KU = Kuwait. 


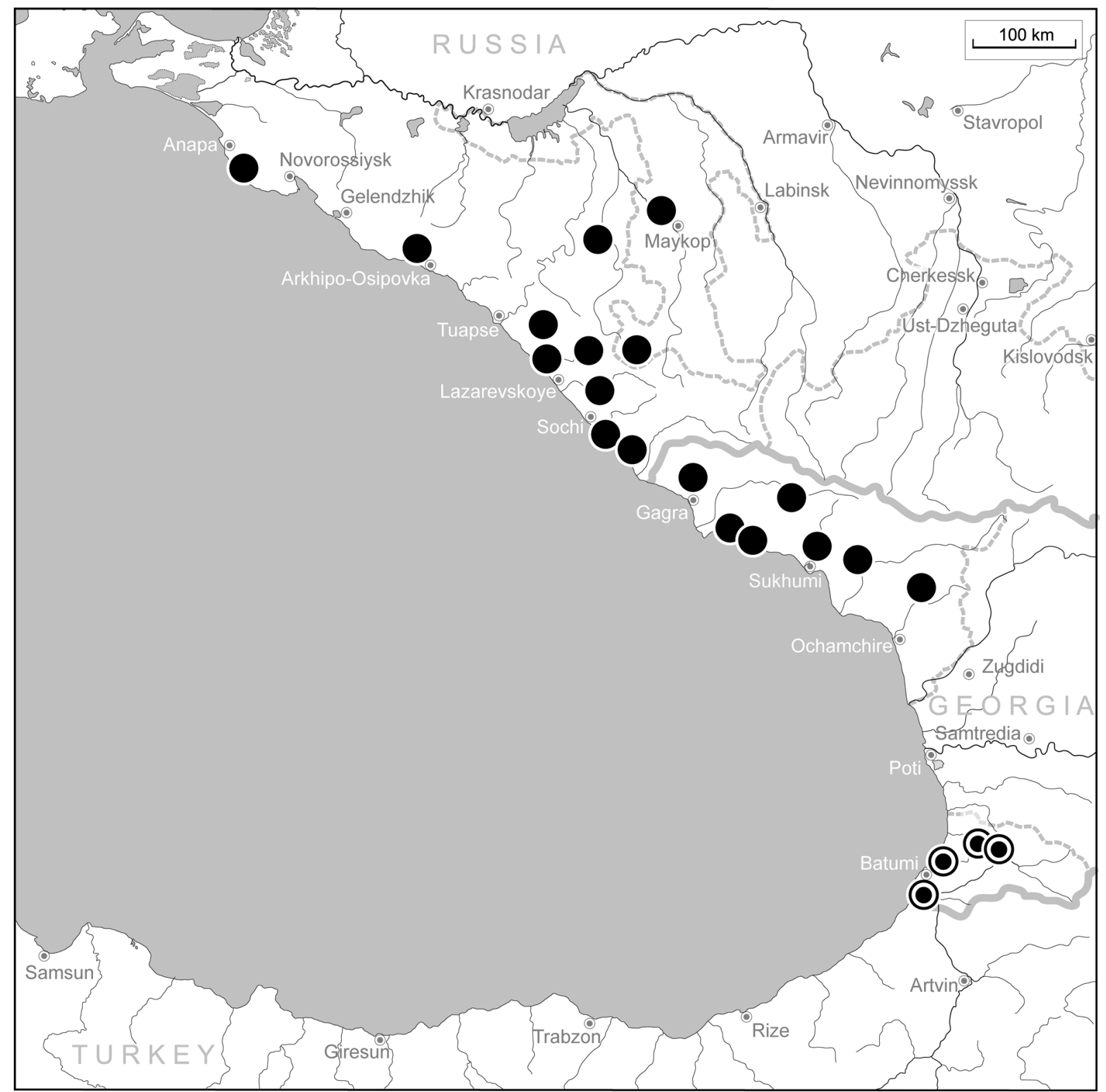

Figure 219. Localities of Raveniola spp. in the western part of the Caucasus: $R$. adjarica sp. nov. (O) and R. pontica (Spassky, 1937) 


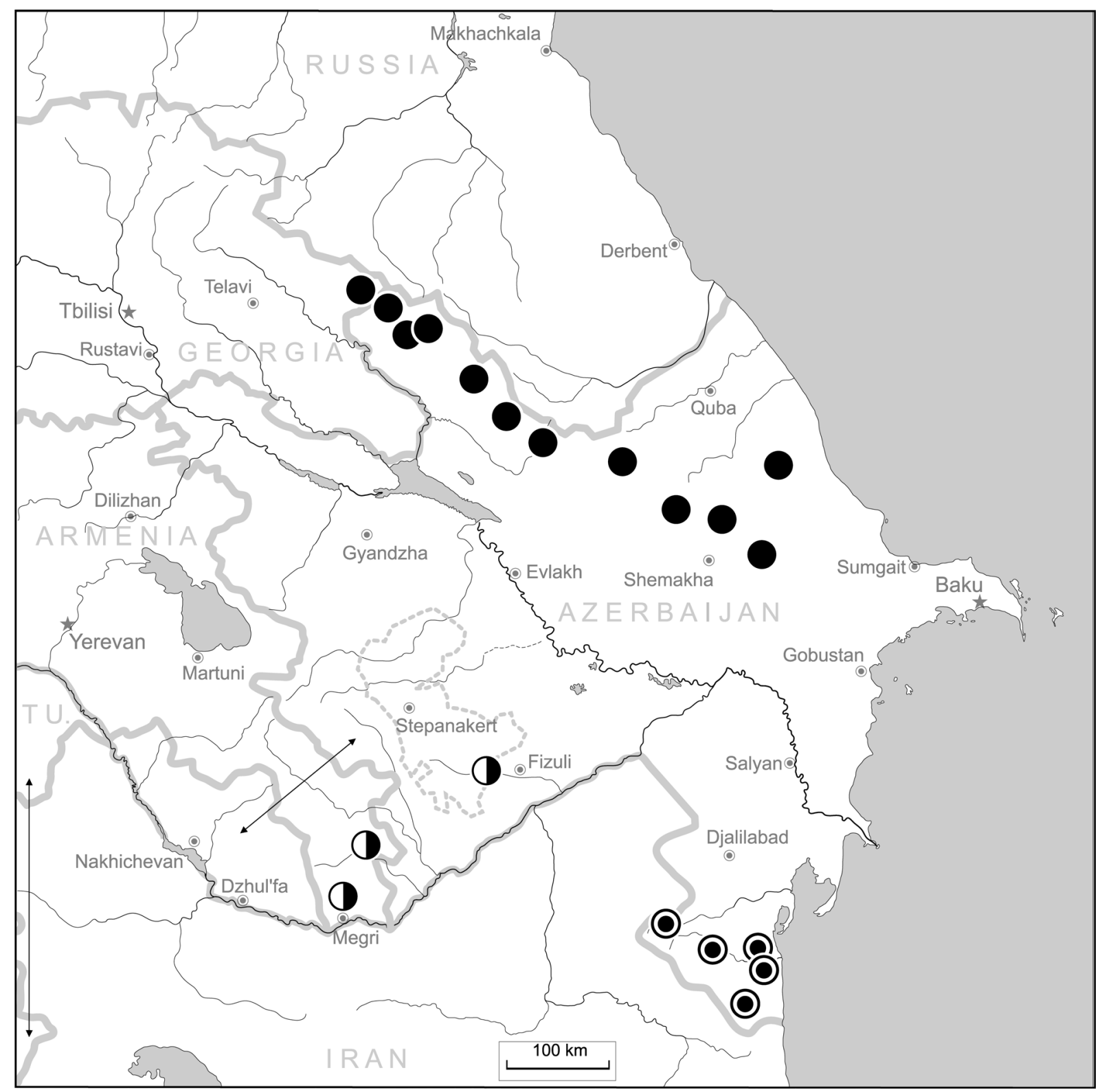

Figure 220. Localities of Raveniola spp. in the eastern part of the Caucasus: $R$. dunini sp. nov. (O), R. hyrcanica Dunin, 1988 (O) and $R$. zaitzevi (Charitonov, 1948) (O). Abbreviation: TU = Turkey. 


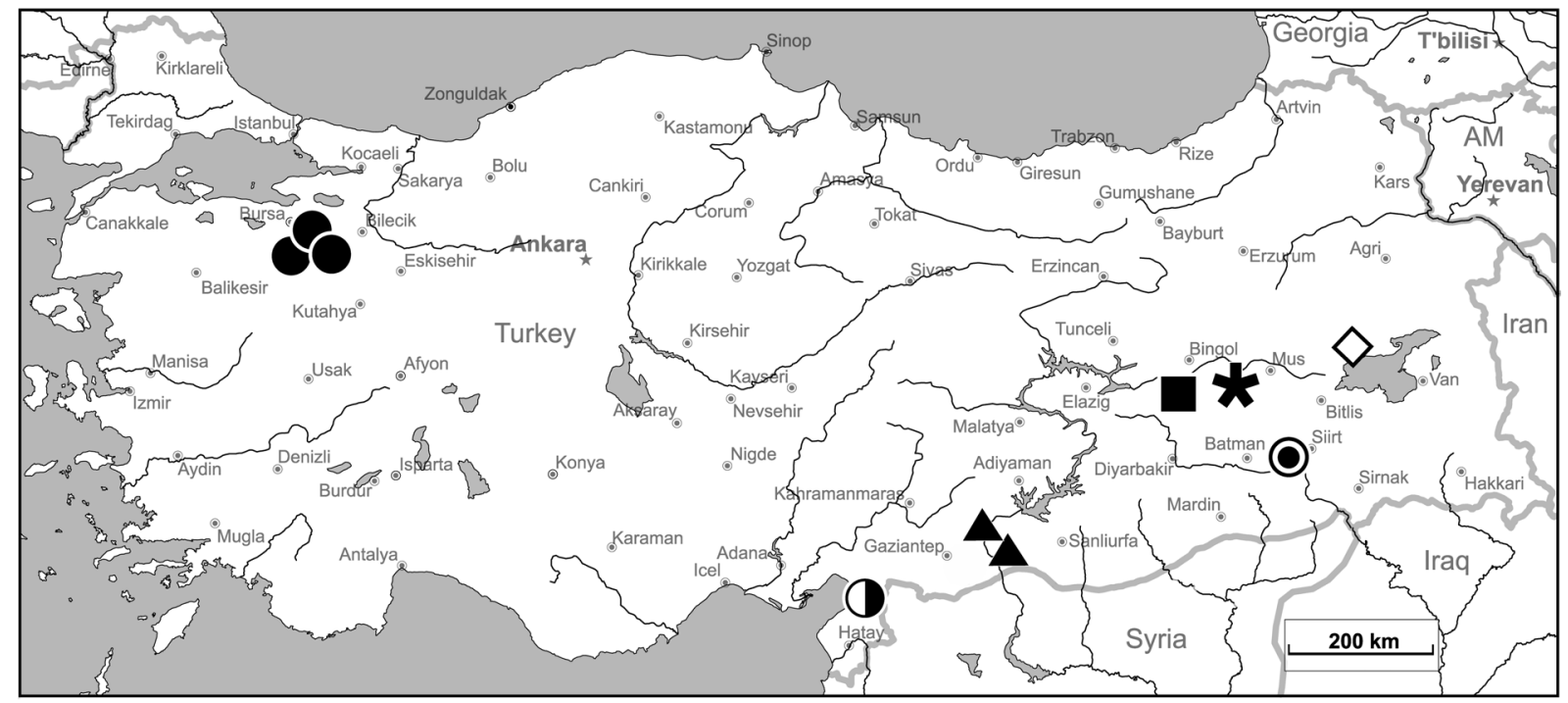

Figure 221. Localities of Raveniola spp. in Turkey: R. anadolu sp. nov. $(\diamond), R$. arthuri Kunt \& Yağmur, $2010(\square)$, R. birecikensis sp. nov. (\), R. micropa (Ausserer, 1871) (O), R. nana sp. nov. (O), R. sinani

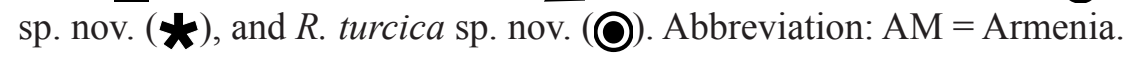

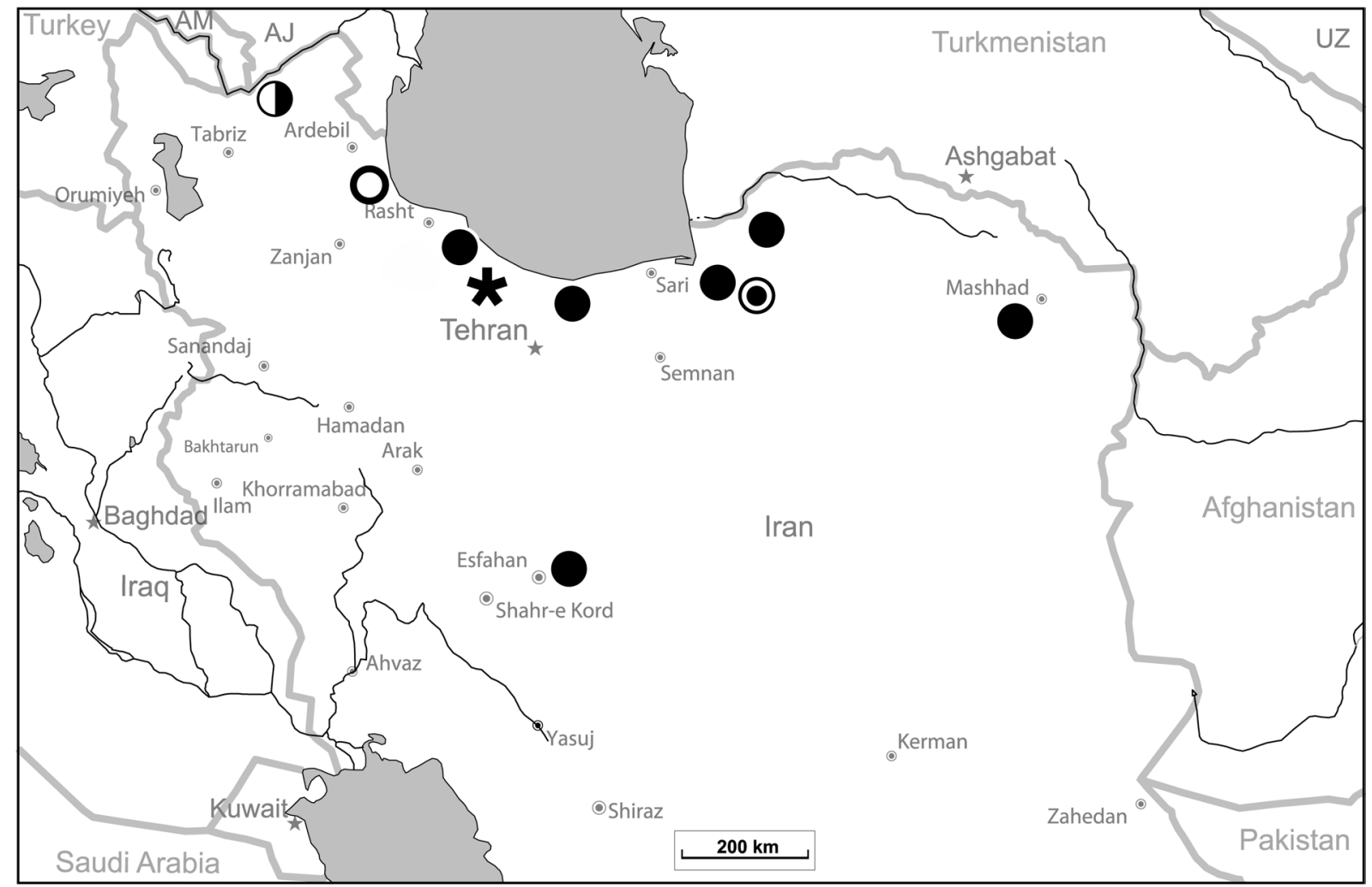

Figure 222. Localities of Raveniola spp. in Iran: $R$. dunini sp. nov. ((), R. marusiki sp. nov. (O). R. mazandaranica Marusik, Zamani \& Mirshamsi, 2014 ( $\star$ ), R. niedermeyeri (Brignoli, 1972) and $R$. vonwicki Zonstein, 2000 (O). Abbreviations: $\mathrm{AJ}=$ Azerbaijan; $\mathrm{AM}=\mathrm{Armenia} ; \mathrm{UZ}=\mathrm{Uzbekistan}$. 

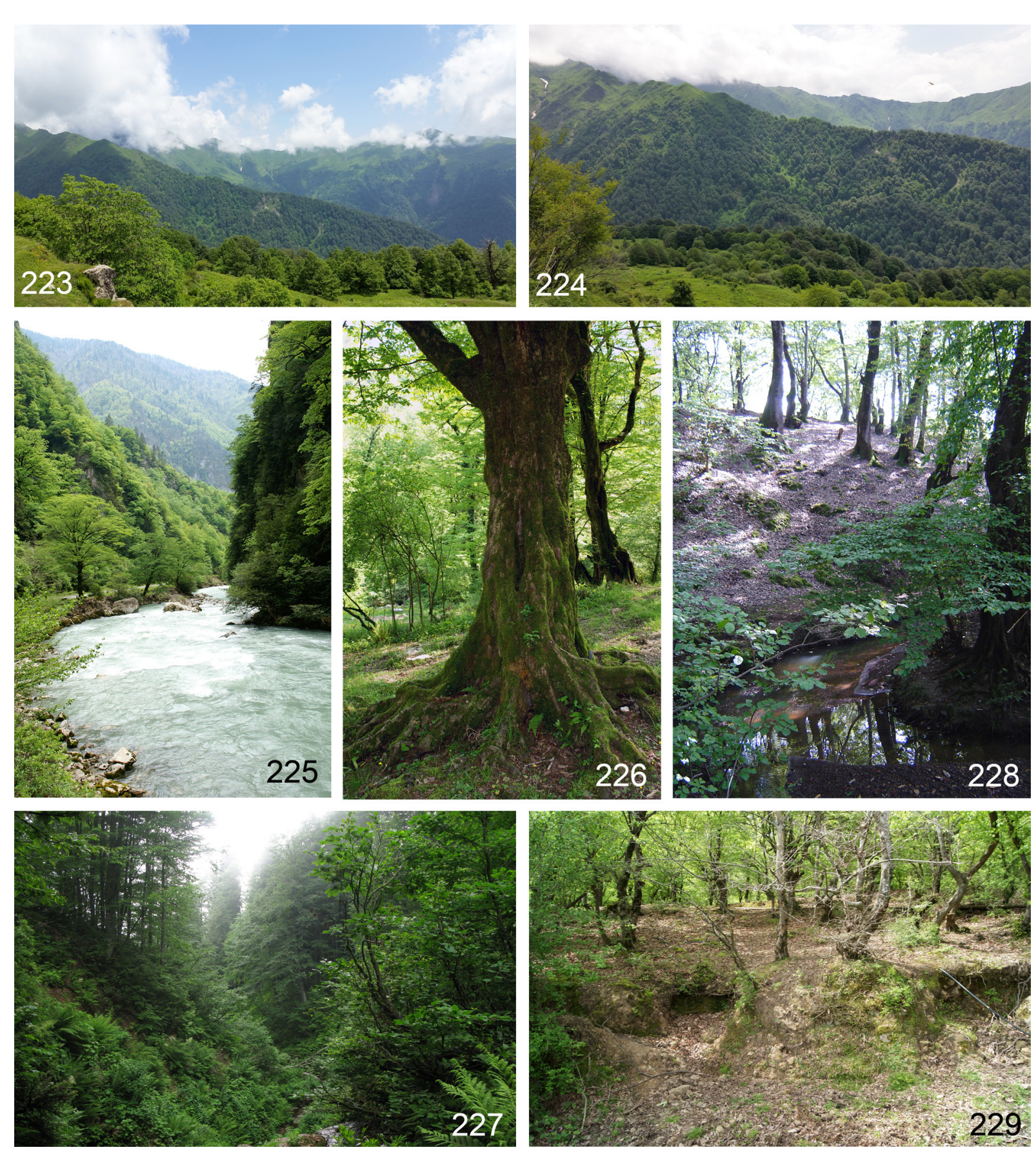

Figs 223-229. Habitats of Raveniola spp. - 223-224. Azerbaijan, southern macroslope of Caucasus Major, forested midlands in Belokany area, between Lagodekhi, Georgia [the type locality of $R$. zaitzevi (Charitonov, 1948)] and Zakataly, Azerbaijan. 225-227. Abkhazia, canyon of the Bzyb River, forested biotopes inhabited by R. pontica (Spassky, 1937). 228-229. Azerbaijan, foothills of Talysh Mts, Hyrcan Reserve, humid localities typical for $R$. hyrcanica Dunin, 1988. Images courtesy of Natasha Snegovaya (223-224, 228-229) and Mykola Kovblyuk (225-227). 

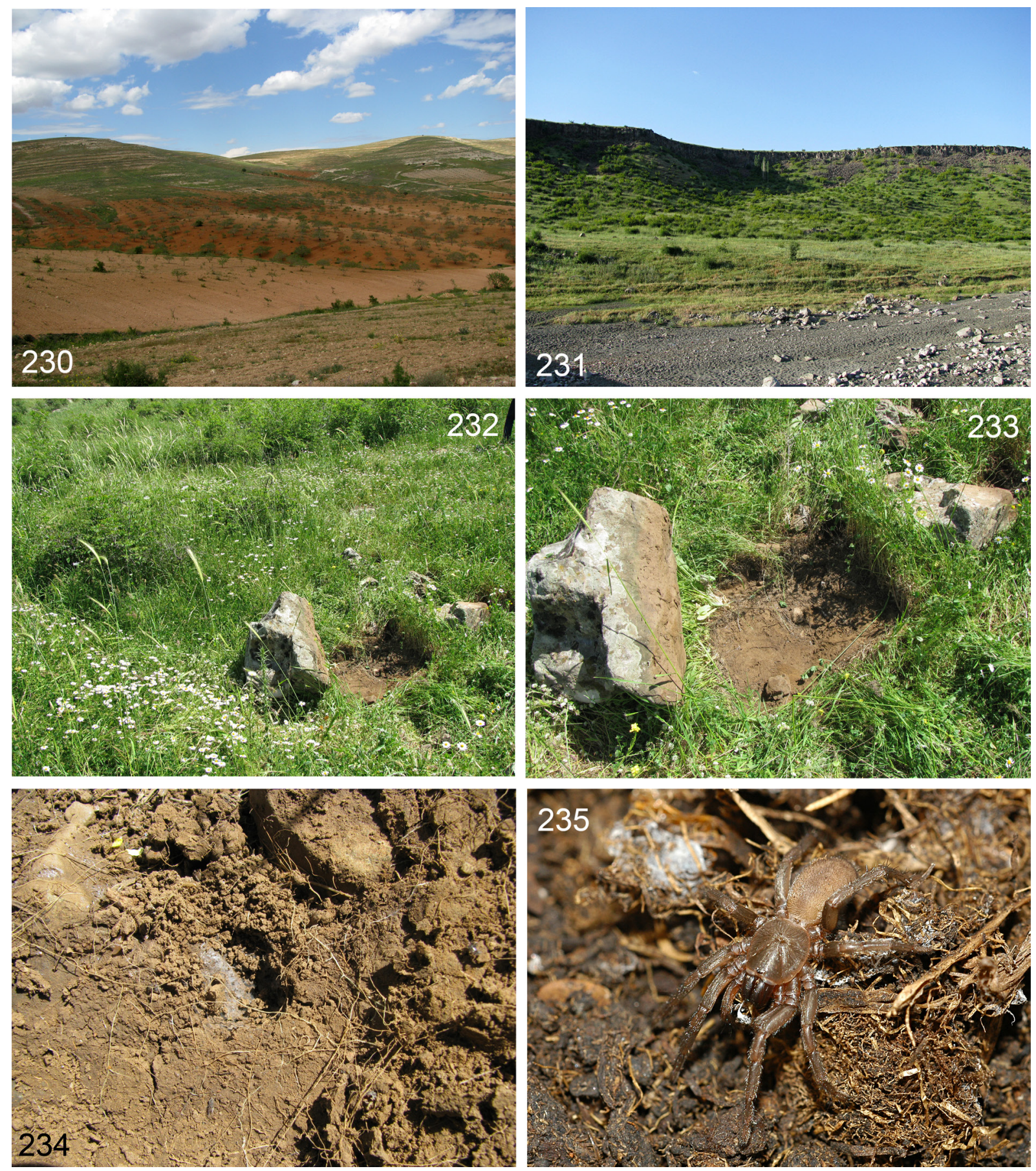

Figs 230-235. Habitats of Raveniola birecikensis sp. nov. (230) and R. sinani sp. nov. (231-235). 230. Turkey, Yukarı Habip, $2 \mathrm{~km}$ of N Birecik. 231-235. Turkey, foothills near Baykan, $4 \mathrm{~km} \mathrm{~N}$ of Siirt, showing collecting locality, inhabited cavity under a turned stone, and a live female. 


\section{ZONSTEIN S. et al., Revision of Raveniola (I): species from western Asia}
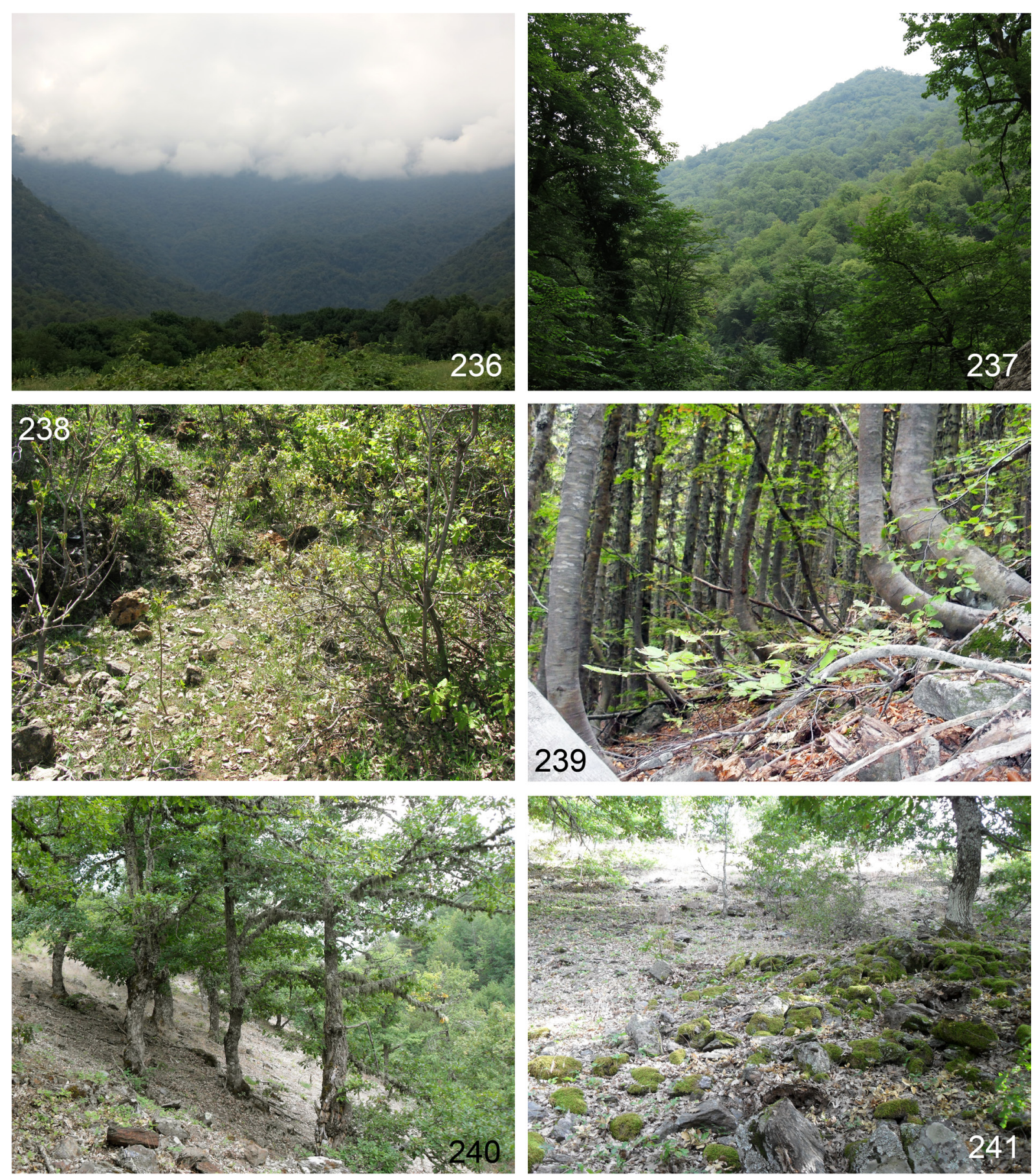

Figs 236-241. Habitats of Raveniola niedermeyeri (Brignoli, 1972) (236-237), R. turcica sp. nov. (238) and R. micropa (Ausserer, 1871) (239-241). - 236-237. Iran, montane forests of Alborz Mts near Shirābād (image courtesy of Alireza Zamani). 238. Turkey, vicinity of Boyunlu Village, collecting locality. 239. Turkey, Oylat area. 240-241. Turkey, Uludağ Mts. 

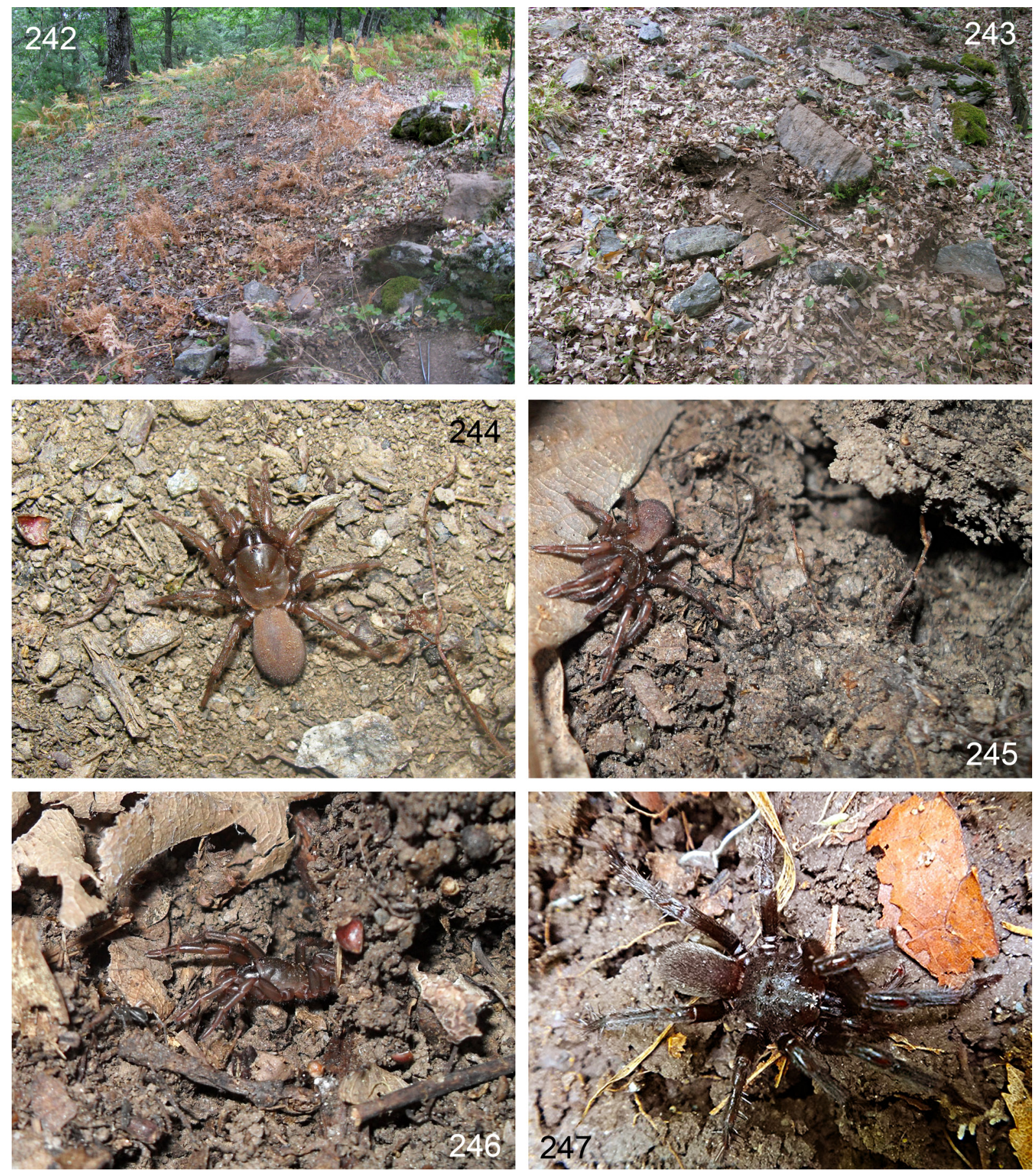

Figs 242-247. Raveniola spp., microhabitats of $R$. micropa (Ausserer, 1871) in Uludağ Mts (242243) and live spiders (244-247). - 244-246. 우우 of $R$. micropa (Ausserer, 1871) near their retreats. 247. Holotype, $\widehat{\partial}$ of $R$. mazanderanica Marusik, Zamani \& Mirshamsi, 2014 (image courtesy of Alireza Zamani). 

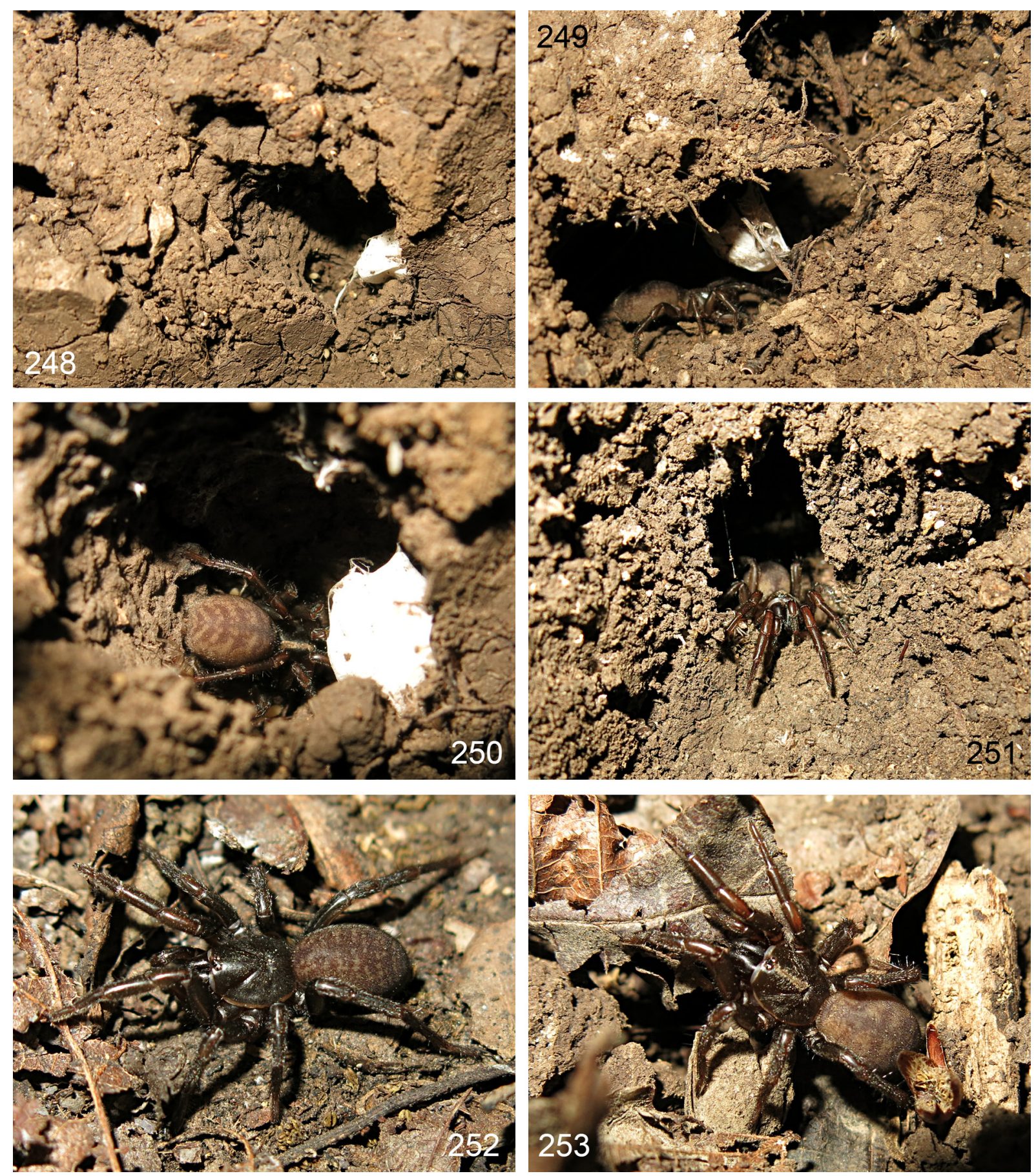

Figs 248-253. Live $q \propto$ of Raveniola niedermeyeri (Brignoli, 1972) from the surroundings of Gorgan, Iran, and their retreats (images courtesy of Alireza Zamani). - 248. A retreat entrance (with covering stone turned over). 249-250. $q$ with an egg sac. 251. $q$ near the entrance of a retreat. 252-253. Two $ᄋ$ 우 showing slightly different variants of the abdominal pattern. 